\title{
Thermogravimetric analysis and Kinetic study of marine plastic litter
}

\author{
Master's thesis \\ Leonora Bonell \\ Stud Kennz.: 427/Matr. Nr.: 0910745 \\ Institut für Verfahrens- und Energietechnik \\ Universität für Bodenkultur Wien
}

Wintersemester 2016/2017 


\section{ACKNOWLEDGEMENT}

I would first like to thank my thesis advisor Dipl.-Ing. Dr. Gregor Tondl of the Institute for Chemical and Energy Engineering at the University of Natural Resources and Life Sciences. The door to Prof. Tondl office was always open whenever I ran into a trouble spot or had a question about my research or writing. I would also like to thank Reinhold Ottner for his important help with the analysis and David Soukup, Denis Soldo and Andreas Frohner for their support. I would also like to acknowledge Univ. Prof. Dipl.-Ing. Dr. techn. Christoph Pfeifer of the Institute for Chemical and Energy Engineering as the second reader of this thesis, and I am gratefully indebted for his very valuable comments on this thesis. Finally, I must express my very profound gratitude to my parents and to my friends for providing me with unfailing support and continuous encouragement throughout my years of study and through the process of researching and writing this thesis. This accomplishment would not have been possible without them. Thank you. 
Table of contents

Abstract 7

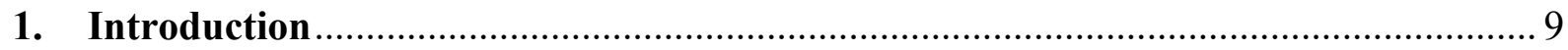

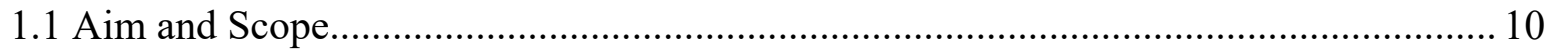

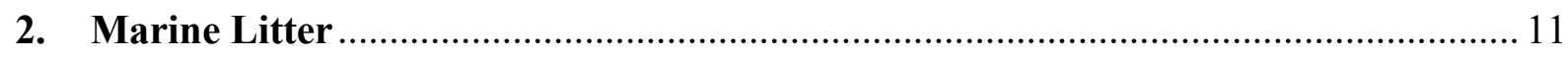

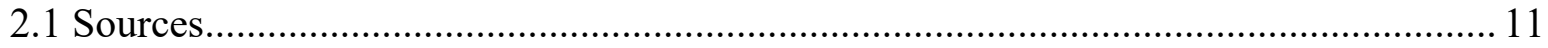

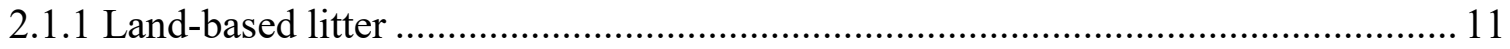

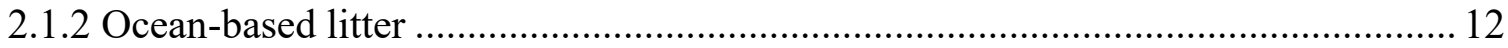

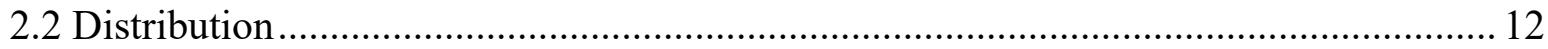

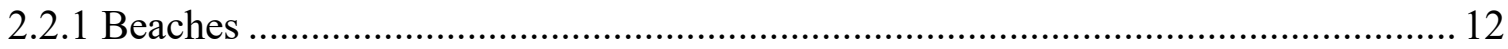

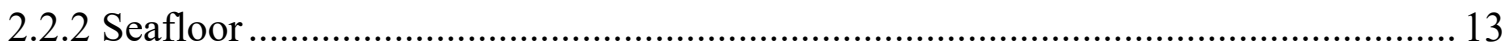

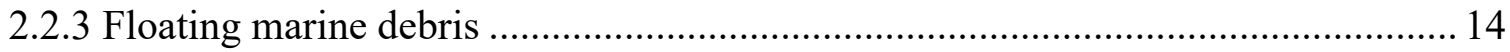

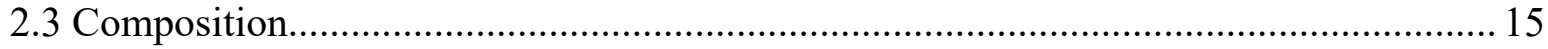

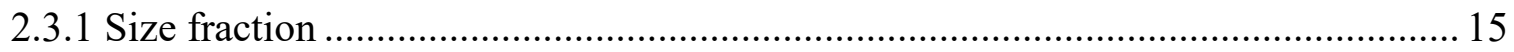

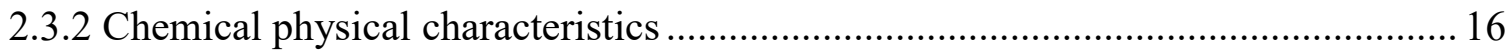

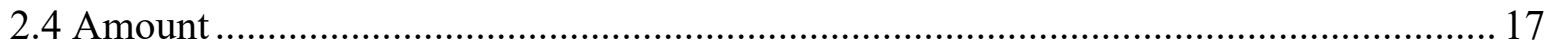

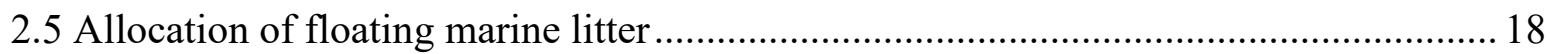

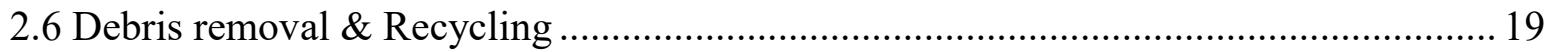

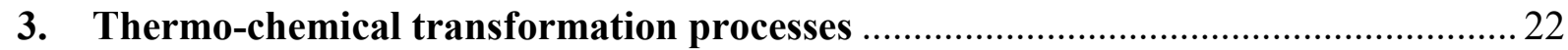

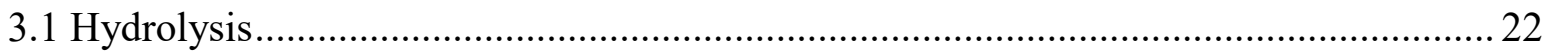

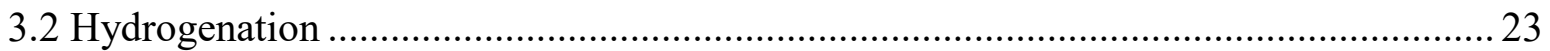

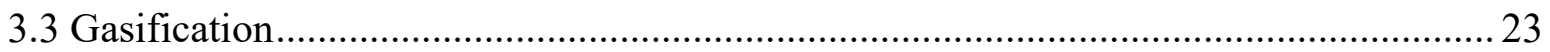

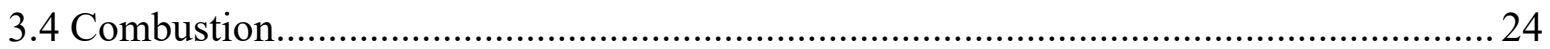

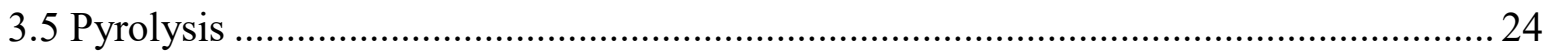

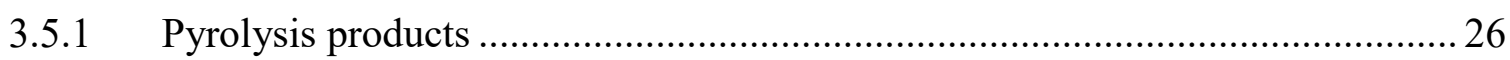

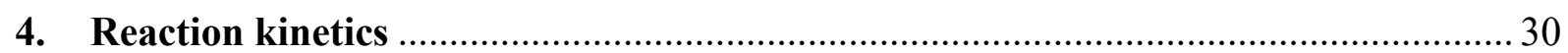

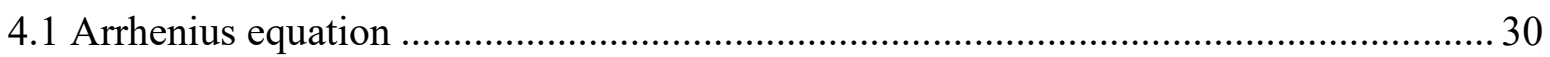

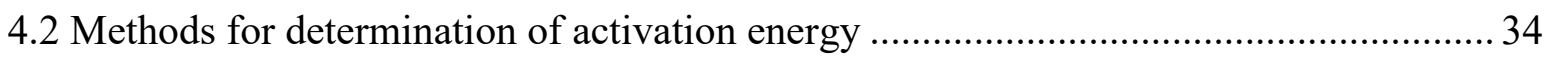

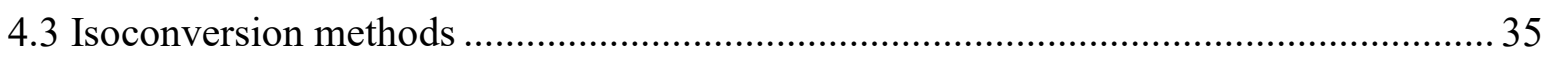

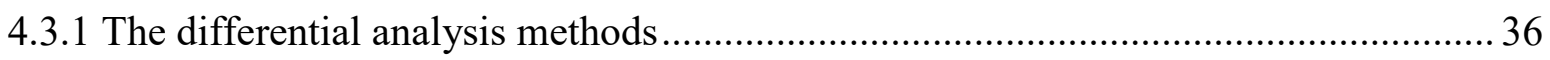

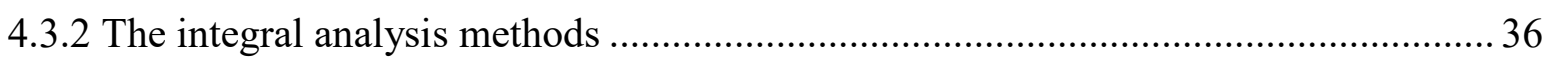

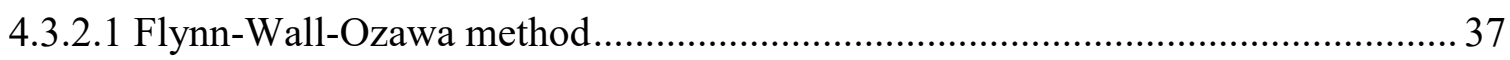

4.3.2.2 Kissinger Akahira and Sunose method ...................................................... 37

IVET-BOKU 


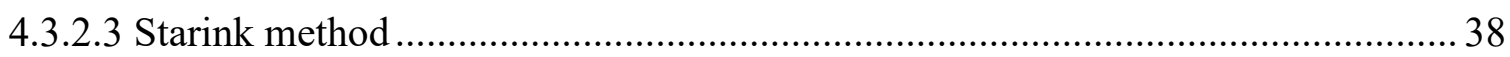

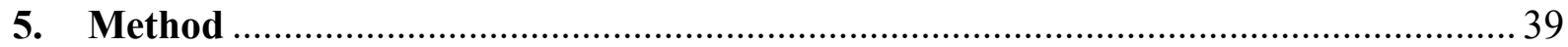

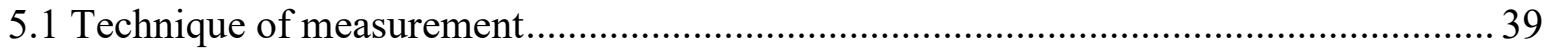

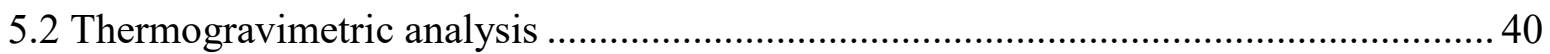

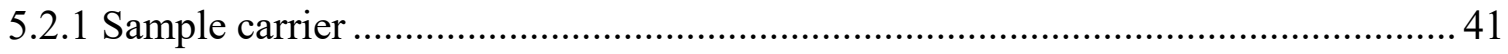

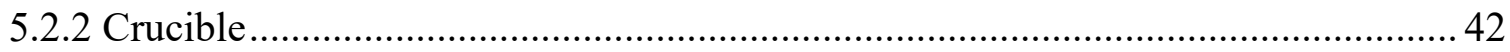

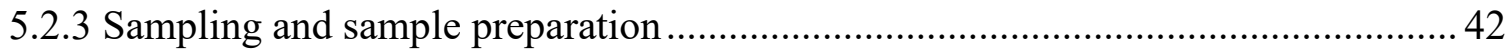

5.2.4 Measuring mode: temperature program, selection of atmosphere ......................... 44

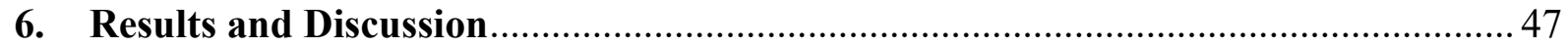

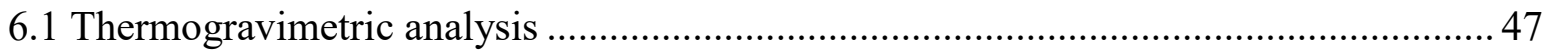

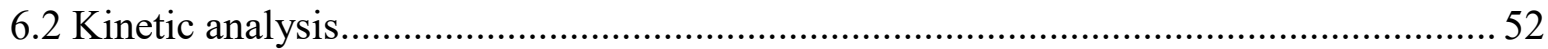

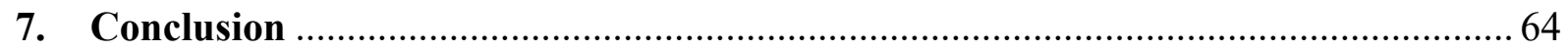

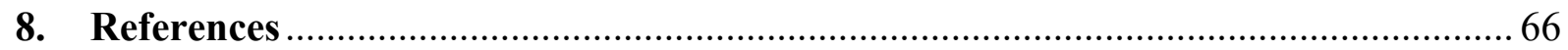

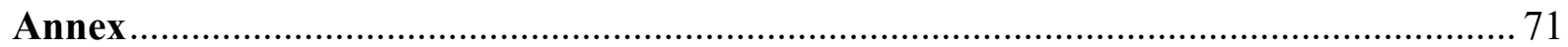




\section{Index of figures}

Figure 1: Pathway of plastic from production to ocean (OCEAN CONSERVANCY, 2016). 17

Figure 2: Model results for a global weight density $\left(\mathrm{g} \mathrm{km}^{-2}\right)$ in four size classes (ERIKSSEN et al, 2014)

Figure 3: Model results for global count density in four size classes (pieces $\mathrm{km}^{-2}$, see four size classes) ERIKSSEN et al, 2014)

Figure 4: Marine drone designed by students from the French International School of Design

(RAIN, 2012) 20

Figure 5: V-shaped nets of floating barriers (THE OCEAN CLEAN UP, 2016) ..................... 20

Figure 6: One Earth - One Ocean- Recycle-catamaran (DIE WELT, 2016) ........................... 20

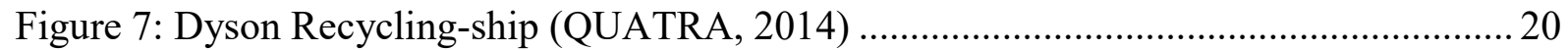

Figure 8: Curves for yield distribution of pyrolysis products from municipal plastic waste (wt $\%$ ) (Heating rate $10 \mathrm{~K} / \mathrm{min}$ ) (DEMIRBAS, 2004).

Figure 9: Various methods for kinetic analysis (VYAZOVKIN and WIGHT, 1999;

VYAZOVKIN, 2000).

Figure 10: Measurement curves of PET recorded from 30 to $1000^{\circ} \mathrm{C}$ at a heatingnrate of 20

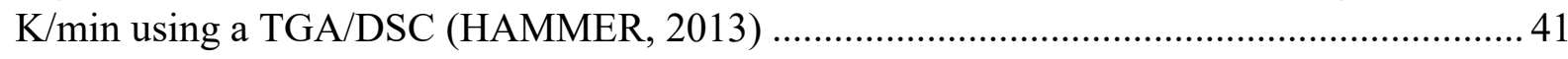

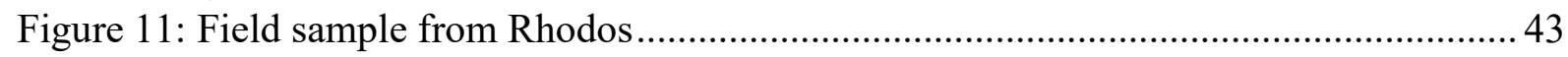

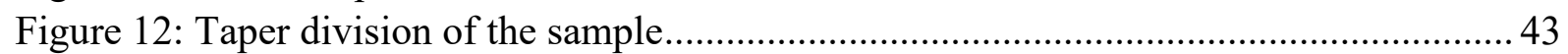

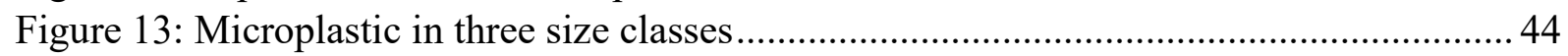

Figure 14: TG curves for small microplastic at four heating rates....................................... 47

Figure 15: TG curves for large microplastic at four heating rates ........................................ 48

Figure 16: TG curves for mesoplastic at four heating rates ................................................ 48

Figure 17: DTG curves of small microplastic at four heating rates ......................................50

Figure 18: DTG curves of large microplastic at four heating rates ......................................... 50

Figure 19: DTG curves of mesoplastic at four heating rates............................................... 51

Figure 20: Extent of conversion for the degradation process for mesoplastic at heating rate 5

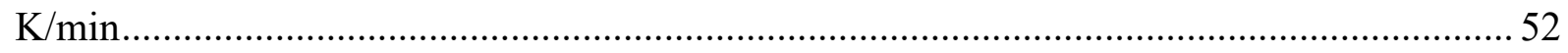

Figure 21: Regressionlines for KAS method for small microplastic .................................... 53

Figure 22: Regressionline for FWO method for small microplast ......................................... 54

Figure 23: Regressionline for Starink method for small microplastic ................................... 54

Figure 24: Regressionline for KAS method for large microplastic ........................................56

Figure 25: Regressionline for Starink method for large microplastic ....................................56

Figure 26: Regressionline for FWO method for large microplastic........................................5 57

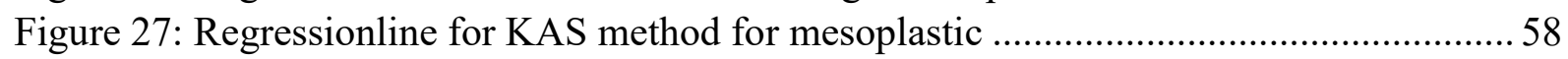

Figure 28: Regressionline for Starink method for mesoplastic............................................... 58

Figure 29: Regressionline for FWO method for mesoplastic ..............................................59

Figure 30: Activation energy of small microplastic according the KAS, Starink and FWO

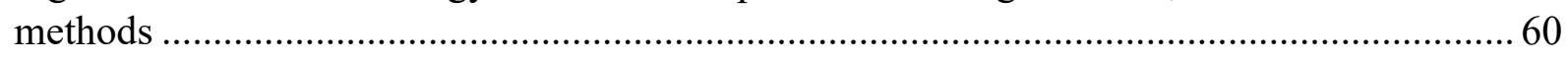

Figure 31: Activation energy of large microplastic according the KAS, Starink and FWO

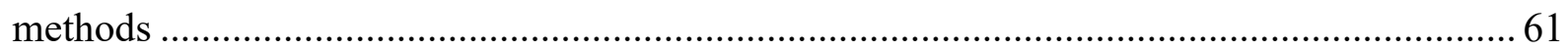

Figure 32: Activation energy of mesoplastic according the KAS, Starink and FWO methods61 


\section{Index of tables}

Table 1: Density (item $\mathrm{m}^{-2}$ ) and percentage of plastic litter in different regions (GALGANI et al., 2015).

Table 2: Depth (m), density (item $\mathrm{km}^{-2}$ ) and percentage of plastic debris on the sea floor in different regions (GALGANI et al., 2015).

Table 3: Density (item $\mathrm{km}-2$ ) and percentage of floating plastic debris in different regions

(GALGANI et al., 2015)

Table 4: Types of plastic, their density $\left(\mathrm{g} \mathrm{cm}^{-3}\right)$ and fraction (\%) of $\mathrm{C}$ and $\mathrm{H}$ (HIDALGO-

RUZ et al., 2012 and MORÉT-FERGUSON et al., 2010).

Table 5: Processes and their temperature, pressure, lambda and corresponding end products

(MARTENS and GOLDMANN, 2016; KALTSCHMITT et al., 2009).

Table 6: Product yield from pyrolysis of individual plastics (wt $\%)$ at different heating rates (ENCINAR and GONZALEZ, 2007)

Table 7: Product yield from pyrolysis of individual plastics (wt $\%$ ) (Heating rate $20 \mathrm{~K} / \mathrm{min}$ )

(ENCINAR and GONZALEZ, 2007)

Table 8: Overview of the possible applications of the different thermoanalytical measurement

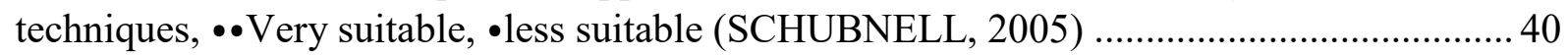

Table 9: Timeline of all pyrolysis test, oxidative processes and the blank curve runs ........... 46

Table 10: Result table for small microplastic for the analysis methods: KAS, Starink and

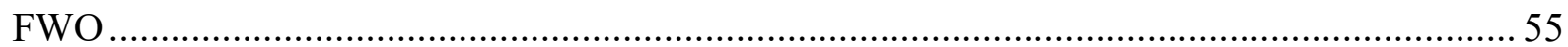

Table 11: Result table for large microplastic for the analysis methods: KAS, Starink and FWO

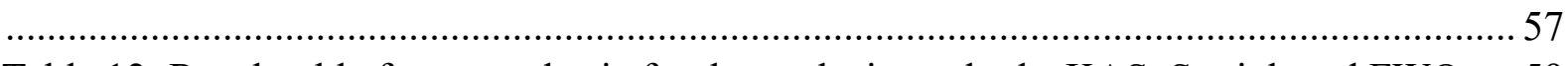

Table 12: Result table for mesoplastic for the analysis methods: KAS, Starink and FWO ..... 59 


\section{Abbreviations}

DMA Dynamic Mechanical Analysis

DSC Differential Scanning Calorimeter

DTG Differential thermogravimetric

FWO Flynn-Wall-Ozawa method

HDPE High Density Polyethylene

KAS Kissinger Akahira and Sunose

LDPE Low Density Polyethylene

MSW Municipal Solid Waste

PE Polyethylene

PET Polyethylene terephthalate

PP Polypropylene

PS Polystyrene

PVC Polyvinylchloride

TGA Thermogravimetric Analysis

TMA Thermomechanical Analysis 


\section{Abstract}

Marine litter is not merely an aesthetic problem but an ecological and economical one, causing damage around the world. To solve a complex problem like this there are many approaches necessary and one of them is to build a pyrolysis reactor, which would transform the collected litter into high-energy products in gaseous, liquid and solid state. A pyrolysis requires, compared to other thermal processes, less technical effort and the end products can be stored or directly used. In order to design such a pyrolysis reactor it is required to know more facts about the feedstock especially the thermochemical behaviour and kinetic parameters. Their does not exists a worldwide-standardized classification yet for the found plastic particles but in general the marine plastic litter is divided into two to four sizes-classes. In the course of this research the selected size-classes are "small microplastic" $(<1 \mathrm{~mm})$, "large microplastic" $(1-4 \mathrm{~mm})$ and "mesoplastic" (4-25mm). A thermogravimetric analysis (TGA) was carried out for the three different plastic sizes with a temperature program of $34-1000^{\circ} \mathrm{C}$ and heating rates of $5,10,15$ and $20 \mathrm{~K} / \mathrm{min}$. The results obtained from the thermogravimetric analysis showed for all samples the same shape for the curve: single stage degradation in the temperature region $700-$ $780 \mathrm{~K}$ with most of the total weight loss $(95 \%)$. The DTG curve revealed a single peak, which shifted with heating rate. The Arrhenius parameters, such as activation energy and preexponential factor, were obtained by model-free methods offered by KAS, Starink and FWO. The generated values for a size class differed slightly, respectively. All three selected sizeclasses of plastic showed in the average value a same trend: small microplastic had average activation energy between $320-325 \mathrm{~kJ} / \mathrm{mol}$, large microplastic between $329-334 \mathrm{~kJ} / \mathrm{mol}$ and mesoplastic $338-344 \mathrm{~kJ} / \mathrm{mol}$. Based on these results, thus high temperatures and short residence time, a flash pyrolysis reactor would be suitable. A flash pyrolysis process of mixed contaminated plastic produces a high amount of liquid oil, which can be directly used in several applications like furnaces, boilers and turbines. The gaseous and solid products can also be used, e.g. to compensate the overall energy requirement of the pyrolysis plant.

Meeresmüll ist nicht bloß ein ästhetisches Problem, sondern ein ökologisches und ökonomisches welches weltweit Schäden verursacht. Um ein solches komplexes Problem zu lösen, gibt es viele Ansätze und einer von ihnen ist es, einen Pyrolysereaktor zu bauen. Dieser würde den gesammelten Abfall in hochenergetische Produkte umwandelt, welche in gasförmigem, flüssigem und festem Zustand auftreten. Um einen solchen Pyrolysereaktor zu entwerfen ist es erforderlich, mehr Fakten über das Einsatzmaterial, insbesondere das thermochemische Verhalten und die kinetischen Parameter, zu kennen. Es existiert noch keine weltweit genormte Klassifizierung der gefundenen Kunststoffpartikel, doch meist wird der maritime Kunststoffmüll in zwei bis vier Größenklassen unterteilt. Im Zuge dieser Forschung sind die ausgewählten Größenklassen "small microplastic" (<1mm), "large microplastic" (1$4 \mathrm{~mm})$ und "mesoplastic" (4-25mm). Eine Thermogravimetrische Analyse (TGA) wurde für die drei verschieden Kunststoffgrößen mit einem Temperaturprogramm von $34-1000^{\circ} \mathrm{C}$ und Heizraten von 5, 10, 15 und $20 \mathrm{~K} /$ min durchgeführt. Die Ergebnisse der TGA zeigten für alle Proben denselben Kurvenverlauf auf: einen einstufigen Zerfall im Temperaturbereich 700-780 $K$ mit Großteils Gesamtgewichtsverlusts (95\%). Die DTG-Kurve ergab einen einzigen Peak, 
der sich mit der Heizrate änderte. Die Arrhenius-Parameter, wie Aktivierungsenergie und Präexponentialfaktor, wurden durch modell-free Methoden von KAS, Starink und FWO berechnet. Die ermittelten Werte der drei verschiedenen Methoden für jede Kategorie unterschieden sich nur geringfügig. Alle drei Größenklassen zeigten im Mittelwert einen gleichen Trend: „small microplastic“ hatte mittlere Aktivierungsenergiewerte zwischen 320 $325 \mathrm{~kJ} / \mathrm{mol}$, ,large microplastic“"zwischen 329 - $334 \mathrm{~kJ} / \mathrm{mol}$ und, ,mesoplastic “ hatte Werte zwischen 338 - $344 \mathrm{~kJ} / \mathrm{mol}$. Basierend auf diesen Ergebnissen, demnach hohen Temperaturen und kurzer Verweilzeit, wäre ein Flash-Pyrolysereaktor geeignet. Ein Flash-Pyrolyseverfahren von gemischten, verunreinigten Kunststoffen erzeugt eine hohe Menge an flüssigem Öl, das direkt in mehreren Anwendungen wie Öfen, Kesseln und Turbinen eingesetzt werden kann. Die gasförmigen und festen Produkte können auch verwendet werden, beispielsweise um den Gesamtenergiebedarf der Pyrolyseanlage auszugleichen. 


\section{Introduction}

In November 2015 The Guardian published an article with the alarming headline: "More plastic than fish in the sea by 2050"; a statement made by the record-breaking sailor Ellen MacArthur. Her foundation, the MacArthur Foundation, launched a report stating that every minute contents of one garbage truck, is dumped into the ocean and this will double by 2030 . The increasing demand, hence production, of plastic particles results in a growing volume of plastic in the everyday waste. This leads to the fact that a third of the plastic will end up in the fragile ecosystem like the oceans. If no action is taken then the ocean will contain one tonne of plastic for every three tonnes of fish by 2015, and by 2050 there will be more tonnes of plastic in the ocean than fish (WEARDEN, 2016).

The durability of plastic is one property which makes it so useful for the consumer, but also so harmful for the marine environment because it persist in the ocean for decades. Furthermore characteristic like buoyancy let the plastic float with currents in remote areas, so there is not a specific area affected but the entire globe, from the Artic to the Antarctic (UNEP, 2016).

This fact creates not merely an aesthetic problem but various negative effects for the economic, environment and the human health. The economic suffers in reduced tourist numbers, due to the presence of litter on the shore and sea surface, and reduction of fishing days (UNEP, 2016).

The harm to marine fauna is especially alarming because the numbers of species, which suffer from ingestion or entanglement of marine litter doubled from 267 (in 1997) to 557 (in 2015). The affected animals rank form zooplankton to whales so are, for example, $66 \%$ of marine mammals and $50 \%$ of seabirds are involved (KUEHN et al, 2015). Through weathering processes plastic breaks up into smaller fragments, which ends up in the size category for food and get easily mixed up and therefore ingested (ERIKSSEN et al., 2014). This results as accumulation in the human food chain (KUEHN et al., 2015). Additionally the sorption of toxicants while traveling through the ocean creates a hazard also for marine flora (ERIKSSEN et al., 2014).

This huge amount of plastic in the ocean is a result of a collective failure to behave in a considered and sustainable manner and thus based on a lack of ecological consciousness. To solve the problem of marine litter it will require a shared effort, ranking from sustainable production, consumption and disposal (UNEP, 2016). 


\subsection{Aim and Scope}

The aim of this thesis is to present a possible solution for the marine litter problem by undertaking the first steps in designing a reactor to convert the collected debris into high-energy products.

Essential to determine the dimension of such a reactor is the thermochemical behaviours of the feedstock. Already numerous studies exist which concentrate on individual plastic types but only a few examine mixed and contaminated plastic. The marine plastic is obviously a mixed and contaminated feedstock but furthermore affected by the marine environment. There exist no literature on such a feedstock and so it is important to study the decomposition behaviour of marine plastic waste material before designing a reactor (SAHA and GHOSHAL, 2006).

In the centre of this work stands the research of the thermal behaviour and kinetic analysis of plastic debris from the sea. To gain an overview of the potential feedstock, the first chapter gives a summary of the marine litter problem by defining the sources, distribution, composition, amount, as well as the latest ideas for removal. The following chapter lists a few of existing thermal treatment for plastic and underlines the pyrolysis as best choice. The third chapter introduces the kinetic as important tool to design a reactor. The following chapter explains the method and the thermogravimetric analysis in order to calculate the kinetic parameters. The last chapter shows the results of the study, compares it with other authors and gives an outlook for the following research. 


\section{Marine Litter}

A general definition of marine litter was made by GALGANI et al (2010): "Marine litter consists of items that have been made or used by people and [are] deliberately discarded or unintentionally lost into the sea or coastline including such materials transported into the marine environment from land by rivers, drainage or sewage systems or wind."

The composition of marine litter has changed in the last decades from organic materials to synthetic ones, due to the increasing demand and therefore production of plastic. The largescale production of plastic started in the 1950s (ALLSOPP et al., 2006) and already since the 1970s plastic particles have been detected in the marine environment (CARPENTER and SMITH, 1972). Today the marine debris contains mainly plastic thus reaching often over $90 \%$ within observed samples (GALGANI et al., 2015). Therefore is the marine plastic litter in the focus of this thesis and to illuminate this further it is distinguished into sources, distribution, composition, amount and ideas for the removal.

\subsection{Sources}

Plastics have become indispensable in our economic and social development and are used in nearly every sector from health and food preservation, over transportation and construction (UNEP, 2016). The way in to the marine environment is various but can be divided into two sources. Marine litter is either origin form land-based sources $(80 \mathrm{wt} \%)$ or ocean-based sources $(20 \mathrm{wt} \%)$ (ALLSOPP et al., 2006). To distinguish the litter exactly in one of those two categories very difficult, because only a few items can be related to a specific source (GALGANI et al., 2011).

2.1.1 Land-based litter is transported in various ways to the ocean than can be general be divided into

- Storm water discharges and combined sewer overflows (e.g. heavy rain events may cause litter to be transported into nearby streams, rivers or directly into the ocean (SHEAVLY and REGISTER, 2007)

- Littering (e.g. litter may find its way to the ocean from recreational areas, general public litter form beaches by being washed by wind or directly disposed into waterways (SHEAVLY and REGISTER, 2007)

- Solid waste disposal and landfills (e.g. run-off from uncovered dumpsites and landfills near the coast) (GALGANI et al., 2015; THOMPSON, 2015) 
- Industrial activities (e.g. industrial discharges or industrial products if they are not properly disposed or lost during transportation (GALGANI et al., 2015; THOMPSON, 2015)

2.1.2 Ocean-based litter are all types of ships and offshore industrial platforms that are accidentally lost into the sea or illegal disposal.

- Commercial fishing (main problem lost fishing gear)

- Recreational boaters,

- Merchant, military and research vessels (GALGANI et al., 2015)

- Offshore oil and gas platforms and exploration (GALGANI et al., 2015; THOMPSON, 2015).

\subsection{Distribution}

Plastic litter is globally distributed across all oceans due to its properties of buoyancy and durability and can travel long distances before being stranded on the beach or sink to the seafloor. Although there exist no certain number yet for the amount of debris in the ocean neither the exact distribution of it, to deal with this global problem the estimations are important (GALGANI et al 2015). The estimations on the distribution of marine litter differ because there exist not yet a standardized approach on which global assessment should be done (GALGANI et al., 2015). In general the scientists agree that the majority of the plastic debris is on the sea floor (some studies estimate $70 \%$ ) and the rest is divided nearly equally on the shore or floating on the sea surface (TIMROTT, 2015).

\subsubsection{Beaches}

Research studies in the last years focused mainly on coastal litter. Reasons therefore are that polluted beaches can be found along all coasts (GALGANI et al., 2015), create an aesthetic reason and are easy to access for an evaluation (MACGRANAHAN et al., 2007).

The variety of studies focusing on litter on beaches has no common approach therefore it is difficult to estimate a global quantitative situation of the litter distribution. The approaches differ in measurements of quantities, categories of litter and areas on the shore (GALGANI et al., 2015). For most studies the focus lies on cleaning hence a proper classification of the items is missed (GALGANI et al., 2015), and distinguish the litter general in material (e.g. plastic, glass, wood) or function (e.g. drinking vessel, sport item) based (GALGANI et al., 2013). 
Furthermore is the measurement of debris on beaches influenced by factors like weather events, which influence the density. The sensitivity of the measure cannot monitor changes in abundance but this could be solved with surveys that record the litter on beaches in a regular distance (RYAN et al., 2009). This infrequent sampling in the past may have led to an underestimation of the quantity of debris (SMITH and MARKIC, 2013).

Table 1 shows six different regions and the according density (item $\mathrm{m}^{-2}$ ) and percentage of the plastic share of marine litter on those beaches. It shows clearly that the majority of the found debris was plastic (at least 68\%).

\begin{tabular}{|l|l|l|}
\hline Region & Density $\left(\right.$ item $\left.\mathrm{m}^{-2}\right)$ & Plastic (\%) \\
\hline Black Sea & 0.88 & 91 \\
\hline Costa do Dende, Brazil & n.d. & 75 \\
\hline Monterey, USA & $1 \pm 2.1$ & 68 \\
\hline $\begin{array}{l}\text { Bootless Bay, Papua New } \\
\text { Guinea }\end{array}$ & 15.3 & 89 \\
\hline Kaosiung, Taiwan & 0.9 & 77 \\
\hline Midway, North Pacific & n.d. & 91 \\
\hline
\end{tabular}

Table 1: Density (item $\mathrm{m}^{-2}$ ) and percentage of plastic litter in different regions (GALGANI et al., 2015)

\subsubsection{Seafloor}

Approximately 50\% of the plastic litter sinks to the seafloor (ENGLER, 2012) and has therefore a high potential to impact benthic habitats and organism (GALGANI et al., 2015). Problematic is the fact that half of the planet's surface is inaccessible deep water floor and the few studies which look for seafloor debris focus on continental shelves which are easier, and therefore often cheaper, to access (GALGANI et al., 2015). Through fouling and other degradation processes also low-density polymers lose buoyancy and sink to the floor (ENGLER, 2012).

It is not only the difficulty to have access to the litter in the deep sea but the next problematic is to collect it. The approaches vary from acoustic approaches to pole trawling, which may lead to underestimation and/or destruction to seafloor habitats (GALGANI et al., 2015). Studies published in the past years used bottom trawl and more recent studies worked with remotely operated vehicles and towed camera systems to explore the deep sea (PHAM et al., 2014). The distribution is influenced by hydrodynamics, geomorphology and human factors (PHAM et al., 2014) as well as by temporal or seasonal variations (GALGANI et al., 2015). Debris on the sea floor was found in all oceans but is still uncommon in remote areas (BARNES et al., 2009). 
Table 2 shows four regions and the according depth (in meters), density (in item $\mathrm{km}^{-2}$ ) and percentage of the plastic share of the marine litter on the sea floor.

\begin{tabular}{|l|l|l|l|}
\hline Region & Depth $(\mathrm{m})$ & Density $\left(\right.$ item $\left.\mathrm{km}^{-2}\right)$ & Plastic (\%) \\
\hline Southern China & $0-10$ & 693 & 47 \\
\hline Malta & $50-700$ & 102 & 47 \\
\hline Turkey & $200-800$ & 290 & 81.1 \\
\hline California & $25-3.971$ & 632 & 33
\end{tabular}

Table 2: Depth $(\mathrm{m})$, density (item $\mathrm{km}^{-2}$ ) and percentage of plastic debris on the sea floor in different regions (GALGANI et al., 2015)

\subsubsection{Floating marine debris}

The existence of litter floating in the sea was reported already decades ago (VENRICK et al., 1972) but the accumulation zones in oceanic greys, closed bays, gulfs and seas surrounded by densely populates coastlines are a recent discovery (GALGANI et al., 2015).

The majority of this floating litter are synthetic polymers due to their physic-chemical assets combined with the environmental conditions their densities are lower than seawater. They float, strand on shores or sink to the sea floor if their density changes on account of and leaching of additives. Subsequently the debris can undergo a physical and/or chemical degradation, which ends in smaller fragments called microplastic (GALGANI et al., 2015).

The macro litter can be observed visually from ships or by analysing net trawls. But also here exists the same problem, as with the costal litter, there is no standardized approach to quantify the debris floating in the sea. The observation depends on many factors such as methodology but also weather condition, speed of the ship or height of the observation position (GALGANI et al., 2015).

Table 3 shows eight regions and the according density (item $\mathrm{km}^{-2}$ ) and percentage of the plastic share of the floating marine litter.

\begin{tabular}{l|l|l|}
\hline Region & Density $\left(\right.$ item $\left.\mathrm{km}^{-2}\right)$ & Plastic (\%) \\
\hline North Sea & $25-38$ & 70 \\
\hline Mediterranean Sea & 10.9 & 95.6 \\
\hline Belgian coast & 0.7 & 95 \\
\hline British Columbia & 1.48 & 92 \\
\hline South China Sea & 4.9 & 68 \\
\hline
\end{tabular}




\begin{tabular}{l|l|l|}
\hline North Pacific & 459 & 95 \\
\hline Strait of Malacca & 579 & 98.8 \\
\hline Bay of Bengal & 8.8 & 95.5 \\
\hline Table 3: Density (item km-2) and percentage of floating plastic debris in different regions (GALGANI et al., 2015)
\end{tabular}

The focus lies on the floating litter because it is the source for the litter on the seafloor as well as the debris on the shore, since there occurs an exchange.

\subsection{Composition}

The paragraphs above show clearly that the majority of marine debris today contains of plastic reaching often over $90 \%$ of the observed samples. Obviously there exists variation in different regions of the world (GALGANI et al., 2015) but other common found materials, next to the plastic, have been metal, rubber, wood and glass (SHEAVLY and REGISTER, 2007).

To elucidate the composition of floating plastic litter it is important to explain the size classes as well as the chemical physical characteristics of the observed plastic.

\subsubsection{Size fraction}

The term "microplastics" bases on size, but there is no general consensus about a specific nomenclature. Since 2004, when this term was firstly used, the majority of studies agreed that microplastics should be defined as particles smaller than $5 \mathrm{~mm}$ in length. The minimum size collected from the sea depends on the mesh size of the net. The majority of mesh size varies from 53 micrometre to $3 \mathrm{~mm}$ (HIDALGO-RUZ et al., 2012).

There is not yet a coherent methodology therefore the size classes vary between the different authors. To have a better possibility for monitoring and assessment of marine litter, the European Working Group on Marine Litter has proposed a classification system for the size (DUEMICHEN et al, 2015). This classification should be applied uniformly in Europe and looks as follow:

$$
\begin{aligned}
& >25 \mathrm{~mm} \text { macroplastic } \\
& 5-25 \mathrm{~mm} \text { mesoplastic } \\
& 1-5 \mathrm{~mm} \text { large microplastic } \\
& <1 \mathrm{~mm} \text { small microplastic }
\end{aligned}
$$

Microplastic can be distinguished between primary and secondary sources. Primary microplastics are manufactured plastics of microscopic size (HIDALGO-RUZ et al., 2012) this 
include "microbeads" used in cosmetic industry (UNEP, 2016). Secondary microplastics are fragments derived from breakdown of larger plastic products due to biological breakdown, photo degradation, chemical weathering or physical forces like wave action and wind (HIDALGO-RUZ et al., 2012). Degradation and erosion processes are enhanced by exposure to sunlight and proceed slowly (UNEP, 2016).

\subsubsection{Chemical physical characteristics}

The term "plastic" is used to describe synthetic polymers, or in other words high-molecular organic compounds that were added with additives (MARTENS, 2011).

Polymers are made from monomers, low-molecular organic compounds, through chemical reactions and consist of the elements Carbon, Hydrogen and Oxygen as well as other non-metal elements. Between the atoms exists a covalent bond complemented with intermolecular forces (MARTENS, 2011). The raw material for plastic are commonly fossil fuels but also biomass (e.g. plant oils) can be used. But once the polymer is synthesised the material properties are the same, independent of the input material (UNEP, 2016).

The additive chemicals have the potential to improve the material properties like softening, colouring, UV-resistance and flame-retardation. Some of these chemicals have harmful assets when released into the environment (UNEP, 2016).

The types of plastic frequently found in the marine environment are also the most produced ones, which dominate the market: Polyethylene (PE, high and low density), Polyethylene terephthalate (PET), Polypropylene (PP), Polyvinylchloride (PVC) and Polystyrene (PS) (HIDALGO-RUZ et al., 2012). Table 4 shows the corresponding density $\left(\mathrm{g} \mathrm{cm}^{-3}\right)$ and the fraction (\%) of Carbon and Hydrogen for each plastic type.

\begin{tabular}{|l|l|l|l|}
\hline Types & Density $\left(\mathrm{g} \mathrm{cm}^{-3}\right)$ & \multicolumn{2}{|l|}{ Fraction of C and $\mathrm{H}(\%)$} \\
\hline Polyethylene (PE) & $0.917-0.965$ & 85.7 & 14.28 \\
\hline Polypropylene (PP) & $0.9-0.91$ & 85.7 & 14.28 \\
\hline Polystyrene (PS) & $1.04-1.1$ & 92.3 & 7.7 \\
\hline Polyvinylchloride (PVC) & $1.16-1.58$ & 38.46 & 4.81 \\
\hline Polyethylene terephthalate (PET) & $1.37-1.45$ & 62.5 & 4.17 \\
\hline
\end{tabular}

Table 4: Types of plastic, their density $\left(\mathrm{g} \mathrm{cm}^{-3}\right)$ and fraction (\%) of C and H (HIDALGO-RUZ et al., 2012 and MORÉTFERGUSON et al., 2010) 
The density and therefore also the buoyancy of plastics can change during prolonged exposure to the marine environment due to weathering and biofouling. Consequently the density of marine polymers may not correspondent with the density of primary plastics. This illuminates that plastics with high specific density, and therefore negative buoyancy, sink faster to the seafloor and are therefore to a lesser extent found in net samples (HIDALGO-RUZ et al., 2012).

\subsection{Amount}

Plastic commercial development started in the 1930s and 1940s, since then it became increasingly dominant. Between 1975 and 2012 the plastic production increased up to $620 \mathrm{wt} \%$. In 1960 plastic made up less than $1 \mathrm{wt} \%$ of total municipal solid waste (MSW) around the world (JAMBECK et al., 2015) and today it is already 8-12 wt\% which can easily increase in the near future up to 9-13 wt\% (HOORNWEG, 2012).

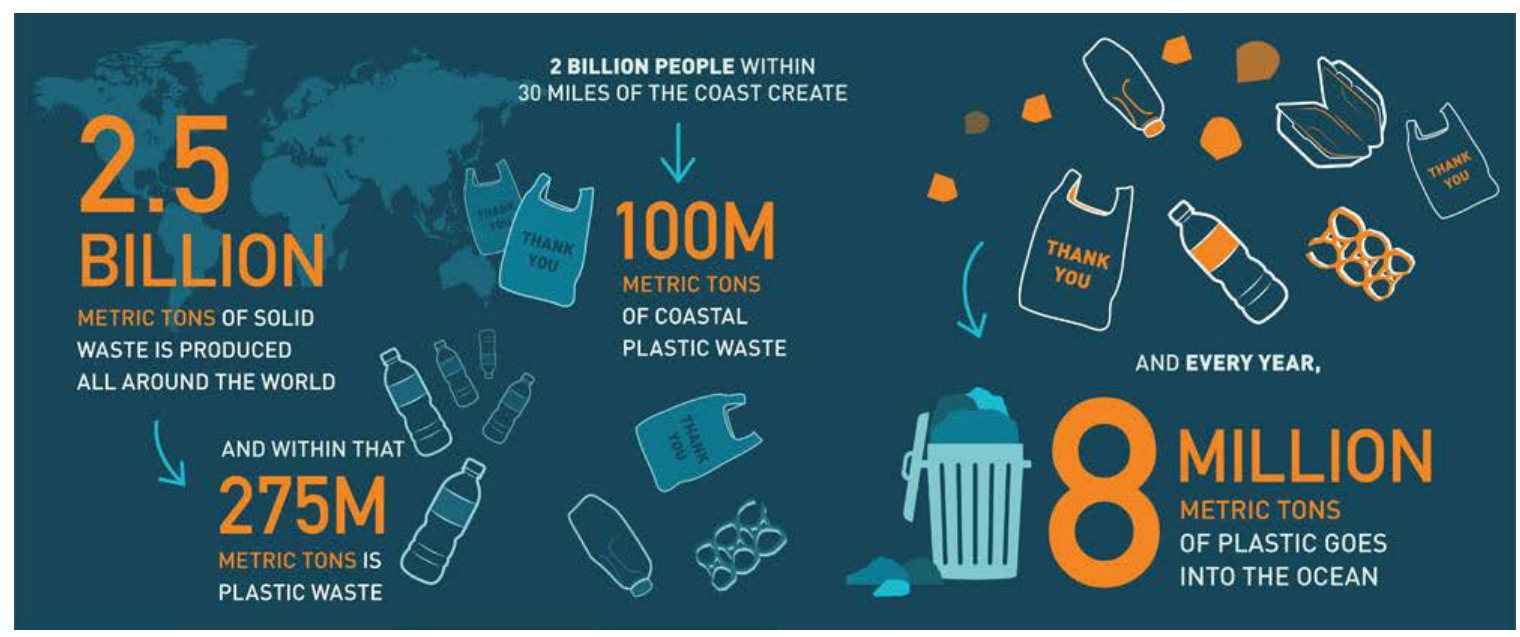

Figure 1: Pathway of plastic from production to ocean (OCEAN CONSERVANCY, 2016)

The majority of the debris in the marine environment comes from waste, generated on land. The exact amount is unknown, but a study published by JAMBECK et al. (2015) estimates that eight million tonnes of plastic entered the ocean in the year 2010. This estimation based on the calculation that 275 million tonnes of plastic waste generated in 192 coastal countries $(93 \%$ of the global population) in 2010 and 1.7 to $4.6 \%$ of it entered the ocean (JAMBECK et al., 2015). Figure 1 demonstrates the pathway from the waste produced all around the world to the share of plastic, which ends up in the ocean. JAMBECK et al. (2015) made even prediction up to the year 2025 and prophesied an increase to 100 million, 150 million or even 250 million tonnes of plastic debris that will enter in the ocean. 


\subsection{Allocation of floating marine litter}

Inconsistent reporting schemes, like different size range, concentration units and item categories, make it difficult to compare data from different scientific publications. The variation of the size-range category from study to study make it difficult to compare the abundance because the number of pieces increase significantly with decreasing size of the litter items. In addition the regions covered by the observation are limited and monitoring occurs not systematically but more sporadically (GALGANI et al., 2015).

A research made by ERIKSSEN et al. (2014) tries to create an overview of the actual situation of floating marine litter and to draw a map of its spatial distribution and gradients in concentration. Based on 24 expeditions between 2007 and 2013 across all five sub-tropical greys (North and South Pacific, North and South Atlantic, Indian Ocean) and coastal regions and enclosed seas (Bay of Bengal, Australian coasts and the Mediterranean Sea) they estimated a total number of plastic particles and their weight. The estimation is a minimum of 5.25 trillion particles with a weight of 268.940 tons.

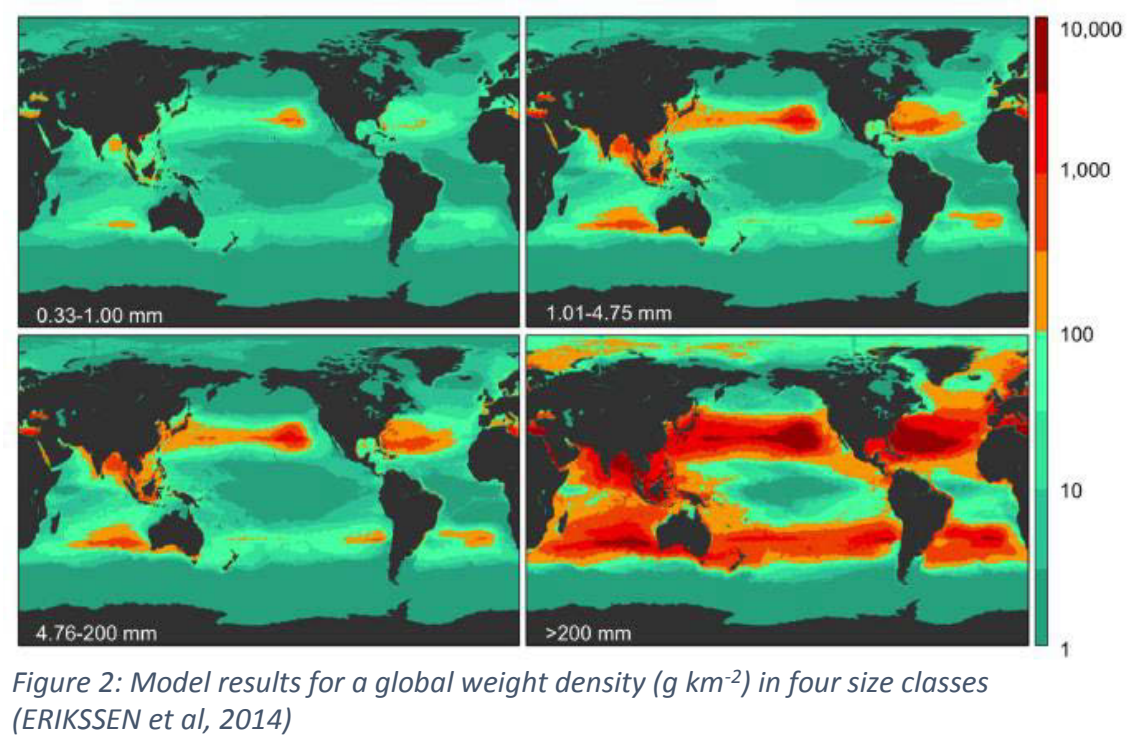

ERIKSSEN et al (2014) divided the litter into four size classes: small micorplastic (0.33 $1.00 \mathrm{~mm})$, large microplastic $(1.01-4.75 \mathrm{~mm})$, mesoplastic $(4.76-200 \mathrm{~mm})$ and macroplastic $(>200 \mathrm{~mm})$. Figure 2 shows the result for global weight density $\left(\mathrm{g} \mathrm{km}^{-2}\right)$ in four size classes and obviously the macroplastic fraction (right lower square) has the majority of the global weight.

Figure 3 illustrates the amount of particle counted divided again in four size classes. If combining the two classes of microplastic they reach $92.4 \%$ of the global particle count; 


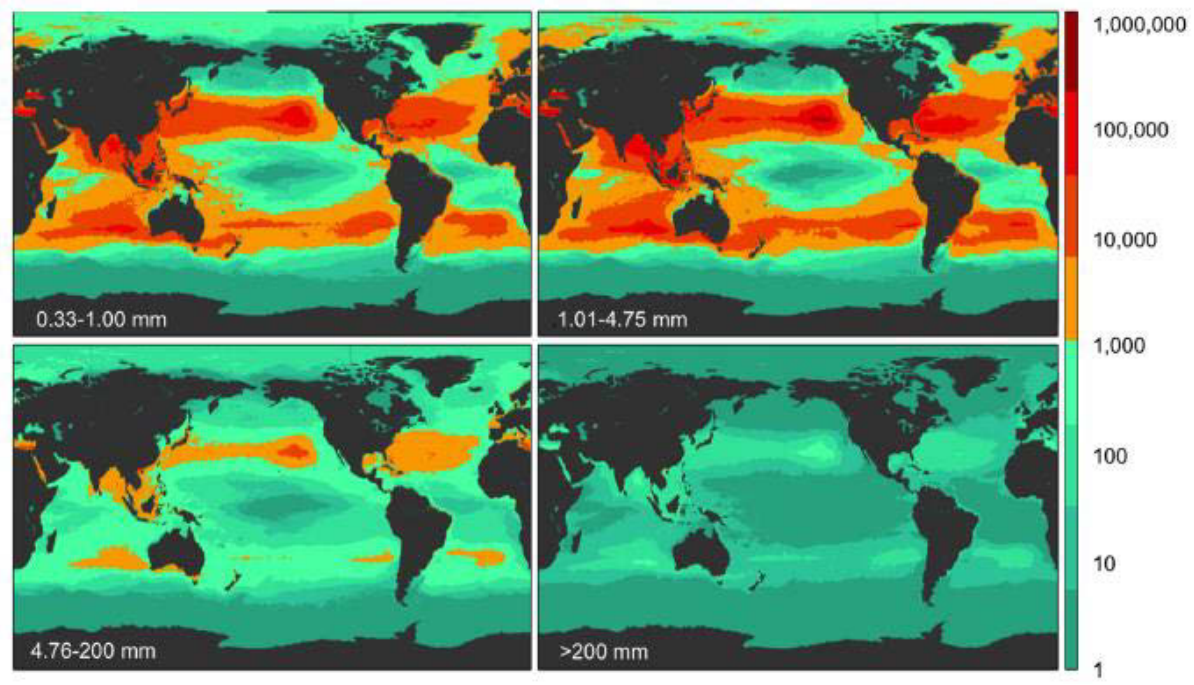

Figure 3: Model results for global count density in four size classes (pieces $\mathrm{km}^{-2}$, see four size classes) ERIKSSEN et al, 2014)

whereby the larger fraction of microplastic had approximately $40 \%$ more than the small fraction. According to this research the Northern Hemisphere contain over 55\% of amount and mass of plastic litter compared to the Southern Hemisphere. And the Indian Ocean has the greater number and weight than the South Atlantic and South Pacific combined. This could be related to the coastal population density, which is in the northern hemisphere much higher than in the southern (ERIKSSEN et al., 2014).

A new research by KOOI et al. (2016) illuminates the fact that numerical and mass concentration decreases exponentially with depth. Over $60 \%$ of microplastics are floating on or near the surface (water column) and within $5 \mathrm{~m}$ depth nearly none plastic particles could be found. These undervalue of the vertical distribution of buoyant microplastic leads to underestimation, which ranks between $3.4 \%$ up to $97 \%$ (KOOI et al., 2016).

\subsection{Debris removal \& Recycling}

In the last years more and more experts, researches and even companies published ideas how to collect the marine debris. The most prominent one to remove this plastic was invented by the young Dutch engineer Boyan Slut in 2013. He created the "The Ocean Cleanup foundation" which proposes a larger-scale, passive method of removing marine debris by means of 100 kilometre long V-shaped nets of floating barriers (figure 5). The plastic can be extracted through a platform where it is stored for transportation and recycling (THE OCEAN CLEAN UP, 2016). 


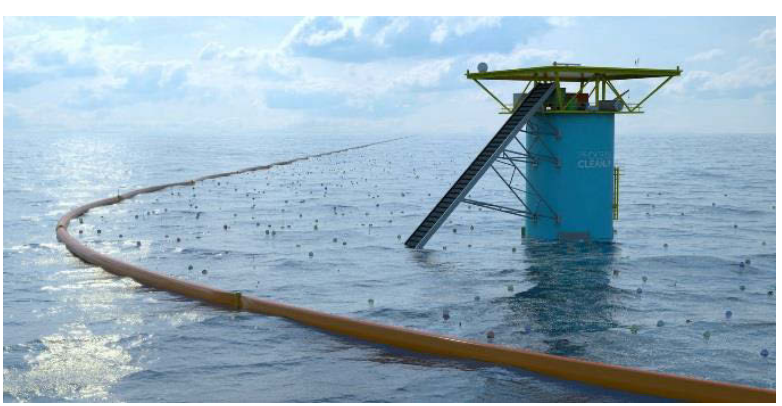

Figure 5: V-shaped nets of floating barriers (THE OCEAN CLEAN UP, 2016)

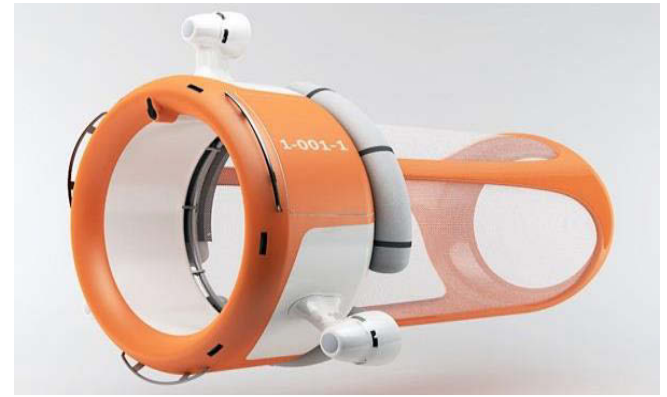

Figure 4: Marine drone designed by students from the French International School of Design (RAIN, 2012)

Another approach is the concept of a marine drone, which would patrol the oceans autonomously (figure 4). Students from the French International School of Design created this not yet realized idea. The drone would collet plastic waste with special sensors and avoid to pull in aquatic animals thanks to a sonic emitter which would send out an irritating signal. Equipped with high-powered batteries, those drones can stay for over two weeks in the ocean and dock to a nearby mothership where a crew would clean the net (RAIN, 2012).

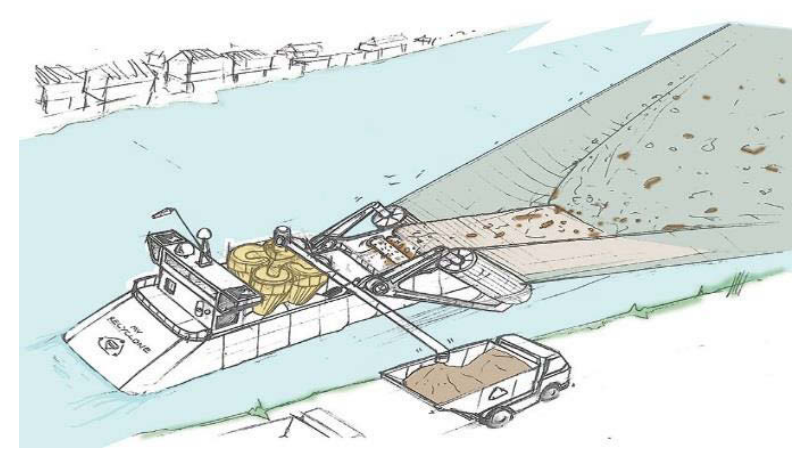

Figure 7: Dyson Recycling-ship (QUATRA, 2014)

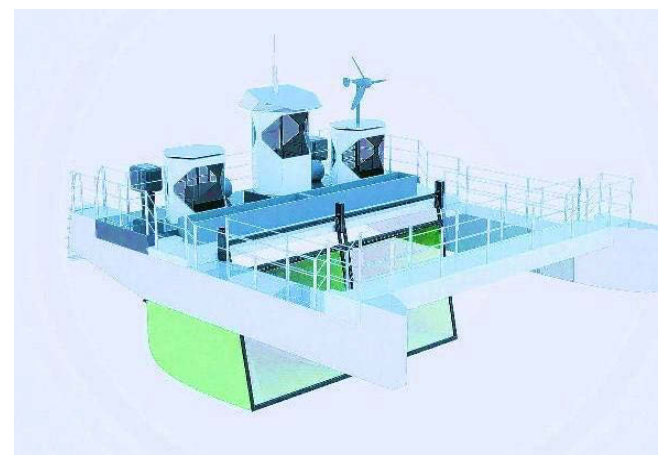

Figure 6: One Earth - One Ocean- Recyclecatamaran (DIE WELT, 2016)

Even the British technology company Dyson wants to build boats to collect waste in rivers and the ocean. The concept would be to pull trawls behind them and the collected garbage is then transported on the deck of the ship (figure 7). On the deck the waste is separated into plastic and non-plastic materials through aspirator with different power levels. The plastic is proceeded directly on board into granulate but the currently low value of recycled plastic makes the project uneconomical and therefore not yet realizable (QUATRA, 2014).

The One Earth - One Ocean team commissioned a shipyard in Lübeck to build a catamaran by summer 2016. The catamaran will consist of two twelve-meter-long hulls between which a four-meter-deep, movable net construction is attached (figure 6). With a speed of four kilometres per hour, purely powered by solar energy, the catamaran can collect two tons of 
garbage per trip which are then to be recycled on mainland. The operational area is intended to be inland waterways and coastal waters around the world; therefore the ship needs to be dismountable and packable in containers (DIE WELT, 2016).

The four mentioned ideas have in common that they would only collect the marine litter and for recycling transport it on the mainland. The possibilities to recycle plastic can be divided into primary, secondary, tertiary and quaternary recycling.

The primary recycling, also called closed loop process, is only applied on uncontaminated, single type of plastic. The characteristics should be near the original, virgin material, and are therefore also produced into products similar to the original one. Secondary recycling is similar to primary recycling also linked to mechanical means, but it is in contrast to primary recycling a transformation of material for less demanding products (SINGH et al., 2016). Marine plastic litter is hence not suitable for either of the mentioned recycling methods due to its heterogeneous composition and contamination.

Tertiary and quaternary recycling do not involve the difficult step of identification and sorting of material hence easier to apply. It contributes, in contrast to primary and secondary recycling, to the principle of energy sustainability. Polymers are petroleum-based products and a tertiary recycling leads to generate the originally raw material (SINGH et al., 2016). All tertiary methods recover the monomers through a depolymerisation process and include processes like pyrolysis, gasification and hydrolysis, depending on the atmosphere and additives. The quaternary recycling recovers energy through incineration of the waste. This method is the last step before discard the waste into landfills, which lead to possible contamination of the surface (SINGH et al., 2016).

To recycle the marine plastic litter the tertiary and quaternary recycling method are definitely a better fit. In contrast to the above-mentioned project, our idea is to build a reactor system which would process directly on board of a ship the plastic feedstock in secondary energy carrier and not postpone that step to the mainland. This energy, which could appear in solid, liquid or gaseous state, can be used directly or stored on board. There exists various thermochemical processes and in general they can be distinguished between hydrolyse, hydrogenation, pyrolysis, gassing and combustion. In the next chapter these methods are explained in more detail always with the perspective to find out, which one makes the optimal fit for the realization of our idea. 


\section{Thermo-chemical transformation processes}

Thermochemical processes transform carbonaceous feedstock in secondary energy carrier, which appear in solid, liquid or gaseous state. In general exist the distinction between hydrolysis, hydrogenation, pyrolysis, gasification and combustion. Those processes differ not only in scale of temperature and pressure but also in the combustion-air ratio, which is described as lambda number $(\lambda)$. This number determines the ratio between the total supplied air and the minimal amount of air necessary for an oxidation process. For a complete oxidation the combustion-air ratio needs to be at least one (KALTSCHMITT et al., 2009).

Table 5 gives an overview of the five different recycling treatments of plastic waste and a short description of them are in the following pages.

\begin{tabular}{|l|l|l|c|l|}
\hline Processes & Temperature & Pressure & Oxygen supply & End products \\
\hline Hydrolysis & $100-300{ }^{\circ} \mathrm{C}$ & $5-100 \mathrm{bar}$ & $\lambda=0$ & $\begin{array}{l}\text { Monomers in liquid } \\
\text { or gaseous state, } \\
\text { residue }\end{array}$ \\
\hline Hydrogenation & $300-500{ }^{\circ} \mathrm{C}$ & $200-250 \mathrm{bar}$ & $\lambda=0$ & $\begin{array}{l}\text { Inflammable gas, oil, } \\
\text { residue }\end{array}$ \\
\hline Pyrolysis & $400-600{ }^{\circ} \mathrm{C}$ & $1 \mathrm{bar}$ & $\lambda=0$ & $\begin{array}{l}\text { Inflammable gas, } \\
\text { pyrolysis oil and } \\
\text { pyrolysis coke }\end{array}$ \\
\hline Gasification & $700-900{ }^{\circ} \mathrm{C}$ & Up to $150 \mathrm{bar}$ & $0<\lambda<1$ & $\begin{array}{l}\text { Inflammable gas, } \\
\text { residue }\end{array}$ \\
\hline Combustion & $800-1300{ }^{\circ} \mathrm{C}$ & 1 bar & $\lambda \geq 1$ & Hot exhaust, ash \\
\hline
\end{tabular}

Table 5: Processes and their temperature, pressure, lambda and corresponding end products (MARTENS and GOLDMANN, 2016; KALTSCHMITT et al., 2009)

\subsection{Hydrolysis}

During the hydrolysis, polymer chains are mixed with water, so that they split up and form the original monomers. Conditions for this process are high pressure (5-100 bar), temperatures between $100^{\circ} \mathrm{C}$ and $300^{\circ} \mathrm{C}$ as well as the use of catalysts. The water molecules attach to the polymer chains and, together with the catalysts, cause the separation of the chains. The water molecules are also cracked and cause a reversal of the polymerization. The water molecule divides into a hydrogen ion and a hydroxion and deposits themself at the breaking points of the chains. This process is also called polycondensation. At the end of the process, there are monomer molecules, which have an $\mathrm{H}$-ion on one end and an $\mathrm{OH}$-ion on the other, as well as a solid residue of fillers, additives and impurities. Subsequently, the monomers are purified by 
filtration and distillation and can then either be polymerized again to plastics or are added to other substances (MARTENS and GOLDMANN, 2016).

The hydrolysis is suitable only for certain groups of plastics, which contain not only carbon groups, but also structures from esters, amides, urethanes or carbonates. This process can also be carried out with alcohol instead of water (alcoholysis) (MARTENS and GOLDMANN, 2016).

\subsection{Hydrogenation}

During hydrogenation, plastics are broken under hydrogen gas at high pressure (200-250 bar) and temperature $\left(300^{\circ} \mathrm{C}-500^{\circ} \mathrm{C}\right)$ so that the polymer chains separate. Hydrogen atoms are added to the opened carbon compounds. A catalyst is used which weakens the bond between the hydrogen molecules. This is necessary because the hydrogen must first split up in order to come in contact with other molecules. At the end, a mixture of long hydrocarbons is formed, the length of which depends on the chosen parameters. The final product is largely liquid and can be further processed as an artificial crude oil in refineries (MARTENS and GOLDMANN, 2016).

\subsection{Gasification}

The gasification is an incomplete oxidation because the oxygen supply is less than one. The gasification agent, the most important ones are oxygen, steam, air and carbon dioxide (or a mixture of them) (KALTSCHMITT et al., 2009), is introduced into the reactor and splits the hydrocarbon compounds. This results in $98 \%$ of a gas consisting of carbon monoxide, carbon dioxide and hydrogen. The remaining $2 \%$ are ash or ungasified residues (MARTENS and GOLDMANN, 2016).

Reactor types for gasification are fixed bed gasifier, fluidized bed gasifier and entrained-flow gasifier, depending on the contact between gasification agent and feedstock (KALTSCHMITT et al., 2009). A widely used type of reactor is the fixed bed gasifier where feed material travels through the reactor from the top to down through a plurality of tempering shafts (MARTENS and GOLDMANN, 2016). According to the flow direction of the gasification agent relatively to the feed material it can be further divided in co-current or counter current gasifier. A relatively new technique would be the twin-fire gasifier, which combines the two mentioned methods. Analogue to the co-current and counter-current principles the feedstock travels due to gravity through the reactor and the gasification agent is fed in two steps to the gasifier (KALTSCHMITT et al., 2009).

It is important in this process that the plastic is in a high degree of uniformity and therefore and a crushing process should be pre-positioned. Before the product gas can be used, it must be 
cleaned. For cooling, the gas flows through a quencher and the de novo synthesis is used to avoid the formation of dioxins and furans (MARTENS and GOLDMANN, 2016).

\subsection{Combustion}

Combustion is an energetic recycling which is targeted at the utilization of the heat content of the plastics. The polymer chains are completely dissolved by the addition of oxygen and heat. This complete oxidation makes it possible to use the energy chemically bound in the plastics as heat energy. This, in turn, can be used as steam for generating electricity or providing the necessary process heat. The remaining is ash, water, carbon dioxide and other emissions (MARTENS and GOLDMANN, 2016).

\subsection{Pyrolysis}

Pyrolysis is thermal decomposition process in an oxygen-free atmosphere with ambient pressure and a temperature that ranges from 400 to $900^{\circ} \mathrm{C}$. In contrast to the hydrolysis and hydrogenation there is no addition of water (MARTENS et al, 2016). The depolymerisation, the breakup of the links, enables to convert plastics into high energy content of liquid, gaseous and solid state (GOYAL et al.; 2008). In general the decomposition starts at $250{ }^{\circ} \mathrm{C}$ with the separation of composition water. From the temperature level of $350^{\circ} \mathrm{C}$ the aliphatic bonds start to collapse and between 400 and $600^{\circ} \mathrm{C}$ occurs the complete decomposition in coke, oil and gaseous substances (MARTENS and GOLDMANN, 2016).

Pyrolysis can be distinguished in two types: slow/conventional pyrolysis or fast/flash pyrolysis. The slow pyrolysis is characterized by: slow heating rate, low temperatures and long residence times. Yield is mainly containing of solid residue ergo coal (DI BLASI, 1996). Essential features of a fast pyrolysis are: very high heating rates, higher temperatures (temperature 450$500^{\circ} \mathrm{C}$ ) and short residence time (typically less than 2s) (BRIDGWATER et al., 1999). The outcome contains less solid residual (DI BLASI, 1996) and a rapid cooling of the pyrolysis vapour assures effective oil production (KALTSCHMITT et al., 2009). 
The proportion of those pyrolysis products is adjustable depending on the feedstock used and on the selected temperature program (MARTENS, 2011). Typical for a flash pyrolysis is the formation of $30-55 \%$ gas and $40-50 \%$ oil (MARTENS and GOLDMANN, 2016). Figure 8 shows the yields of pyrolysis products from municipal plastic waste with a heating rate of 10 $\mathrm{K} / \mathrm{sec}$. Low temperatures provide high solid products and the higher the temperature raises, the higher the proportion of the liquid and gaseous fractions (DEMIRBAS, 2004).

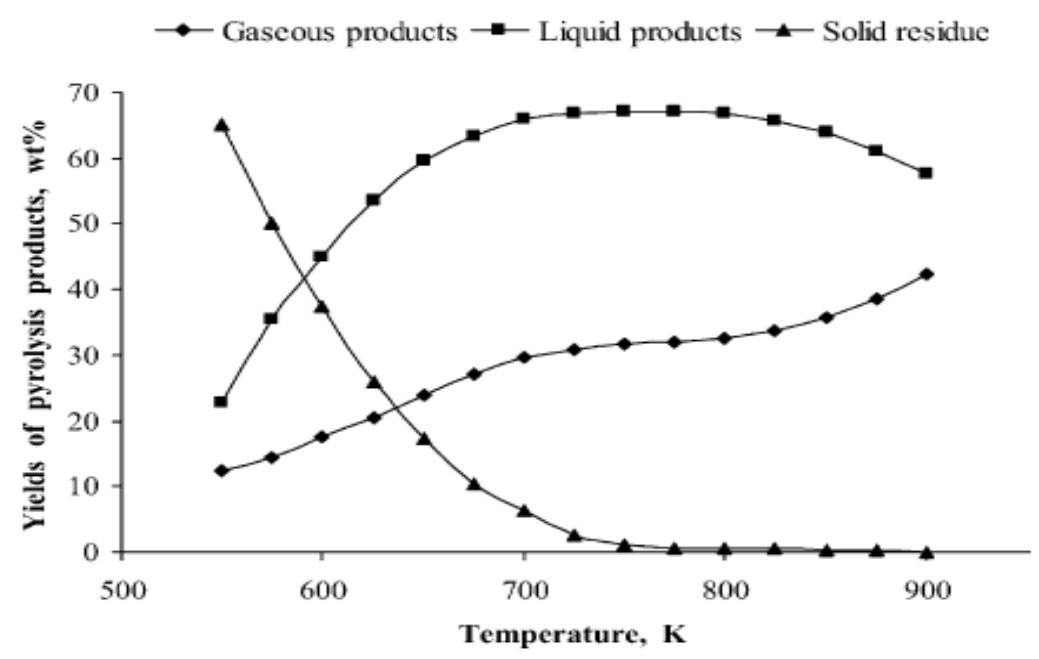

Figure 8: Curves for yield distribution of pyrolysis products from municipal plastic waste (wt\%) (Heating rate $10 \mathrm{~K} / \mathrm{min}$ ) (DEMIRBAS, 2004).

By listing the various chemical and technical processes it becomes clear that the pyrolysis process is the best method to recycle plastic debris decentralized on board of a ship. Hydrolysis is no good fit, because it is suitable for those types of plastics, which have a higher density than seawater $\left(1025 \mathrm{~kg} \mathrm{~m}^{-3}\right)$, e.g. polyamide or polyurethane, (HELLERICH et al., 2010) and can therefore found only to a small extent on the ocean surface. Hydrogenation can process mixed and contaminated plastic types, but the technical measures for the implementation are technical and economical very complex (HELLERICH et al., 2010), so that an application on open sea could become very costly. For some application the gasification process could be a good fit, but in general it is also a very complex method. Furthermore, the pre-treatment is complicated and the storage takes more space than comparatively liquids (MARTENS and GOLDMANN, 2016). Finally the combustion would also form a suitable solution, since it would be technically easy to implement and can process contaminated waste. The heat would have to be used directly, since storage is difficult to implement. 
Reasons for a pyrolysis are, compared to other thermal processes, less technical effort (moderate temperature, around $500^{\circ} \mathrm{C}$ ) and less labour intensity because it does not need an intense sorting process. Furthermore are the parameters adjustable to optimize the outcome. The pyrolysis process produces a high amount of liquid oil, for single plastic pyrolysis around $80 \mathrm{wt} \%$ and for mixed plastic a lower liquid yield around $50 \mathrm{wt} \%$. The quality of mixed contaminated plastic, in terms of oil composition, is still comparable and can be directly used without upgrading or treatment in several applications like furnaces, boilers, turbines and diesel engines. The gaseous and solid products can also be used, e.g. to compensate the overall energy requirement of the pyrolysis plant (SHARUDDIN et al., 2016). The end products can also be stored, that proves to be easy to implement and less space consuming (MARTENS and GOLDMANN, 2016). The possible yield of a pyrolysis of the most found plastic types floating in the ocean are described in next section (3.5.1).

\subsubsection{Pyrolysis products}

Plastics are distinguished into three categories, depending on the structural composition and consequential thermal and mechanical characteristics: thermoplast, elastomer, and duroplast (MARTENS, 2011).

Thermoplast are not cross-linked plastics. They are linear or branched molecular chains which can be displaced with exposure to heat or stress. The resulting softening and melting can be repeated discretionarily. In organic solvent they are swellable or soluble and the melting point lies between 130 and $260^{\circ} \mathrm{C}$ (MARTENS, 2011).

Elastomere are wide-meshed cross-linked plastics. They distinguish them through a rubberyelastic behaviour in a wide temperature scale whereby with closed meshes occur ebonite (hard rubber). The shaping through vulcanisation exclude a further forming of the material, hence are not meltable and not soluble, but in organic solvent swellable (MARTENS, 2011).

Duroplaste are close-meshed cross-linked plastics. They differ towards the others over not meltable, not soluble and not swellable. Hence heat-proofed (up to $180^{\circ}$ ) and high stiffness and tenacity (MARTENS, 2011).

The types of plastic which were mainly found in the conducted studies on floating marine debris, hence HDPE, LDPE, PET, PP, PVC and PS (HIDALGO-RUZ et al., 2012), are all thermoplastic. The yields of pyrolysis products of those types depend also on the lengths of the fragments (MEWES and TOKARZ, 2000). The long fragments form rings, such as aromatics (e.g. benzene, toluene and xylene), represent the liquid fraction. The shorter fragments form the 
gaseous part (methane, ethane and ethene) (MEWES and TOKARZ, 2000), and the individual hydrocarbon atoms deposit in the solid residue, the coke (MARTENS and GOLDMANN, 2016). Table 6 illuminates the percentage of char, oil/wax and gases of induvial plastics at different heating rate.

\begin{tabular}{|c|c|c|c|c|}
\hline Plastic & $\begin{array}{l}\text { Heating rate } \\
(\mathrm{K} / \mathrm{min})\end{array}$ & Char $(\%)$ & Oil/wax (\%) & Gases (\%) \\
\hline \multirow[t]{4}{*}{ Polystyrene (PS) } & 5 & 1,95 & 95.77 & 2.28 \\
\hline & 10 & 1.81 & 95.79 & 3.40 \\
\hline & 15 & 1.60 & 92.75 & 5.65 \\
\hline & 20 & 1.04 & 92.65 & 6.31 \\
\hline \multirow{4}{*}{$\begin{array}{l}\text { Polyethylene of } \\
\text { low density (PE) }\end{array}$} & 5 & 0.18 & 81.65 & 18.17 \\
\hline & 10 & 0.10 & 81.33 & 18.57 \\
\hline & 15 & 0.01 & 72.63 & 27.36 \\
\hline & 20 & 0.00 & 61.24 & 38.76 \\
\hline \multirow{4}{*}{$\begin{array}{l}\text { Polyethylene } \\
\text { terephthalate } \\
\text { (PET) }\end{array}$} & 5 & 9.37 & 39.02 & 51.61 \\
\hline & 10 & 8.28 & 35.40 & 56.32 \\
\hline & 15 & 5.75 & 29.71 & 64.54 \\
\hline & 20 & 5.63 & 29.16 & 65.21 \\
\hline \multirow{4}{*}{$\begin{array}{l}\text { Polypropylene } \\
\text { (PP) }\end{array}$} & 5 & 0.11 & 83.34 & 16.55 \\
\hline & 10 & 0.13 & 82.67 & 17.20 \\
\hline & 15 & 0.10 & 82.02 & 17.88 \\
\hline & 20 & 0.10 & 68.06 & 31.84 \\
\hline
\end{tabular}

Table 6: Product yield from pyrolysis of individual plastics (wt\%) at different heating rates (ENCINAR and GONZALEZ, 2007)

As the heating rate increases the yield of gases increases and the yield of oil/wax decreases; the solid fraction seems to be independent, except for the PET (ENCINAR and GONZALEZ, 2007). The product yield from pyrolysis of individual plastics at heating rate $20 \mathrm{~K} / \mathrm{min}$ is shown in Table 7. 


\begin{tabular}{|l|l|l|l|l|}
\hline GAS & $\begin{array}{l}\text { Polystyrene } \\
(\mathrm{PS})\end{array}$ & $\begin{array}{l}\text { Polyethylene } \\
(\mathrm{PE})\end{array}$ & $\begin{array}{l}\text { Polyethylene } \\
\text { terephthalate (PET) }\end{array}$ & $\begin{array}{l}\text { Polypropylene } \\
(\mathrm{PP})\end{array}$ \\
\hline Hydrogen $\mathrm{H}_{2}$ & 0.24 & 0.13 & 0.52 & 0.13 \\
\hline Methane $\mathrm{CH}_{4}$ & 3.21 & 3.04 & 1.20 & 2.56 \\
\hline Ethane $\mathrm{C}_{2} \mathrm{H}_{6}$ & 0.49 & 5.46 & 0.11 & 4.27 \\
\hline Ethene $\mathrm{C}_{2} \mathrm{H}_{4}$ & 1.58 & 12.68 & 2.31 & 9.60 \\
\hline Propane $\mathrm{C}_{3} \mathrm{H}_{8}$ & 0.12 & 4.55 & 0.36 & 3.95 \\
\hline Propene $\mathrm{C}_{3} \mathrm{H}_{6}$ & 0.30 & 12.71 & 0.22 & 10.35 \\
\hline $\begin{array}{l}\text { Carbon dioxide } \\
\text { CO }\end{array}$ & & & 37.18 & \\
\hline $\begin{array}{l}\text { Carbon } \\
\text { monoxide } \mathrm{CO}\end{array}$ & & & 23.26 & \\
\hline
\end{tabular}

Table 7: Product yield from pyrolysis of individual plastics (wt\%) (Heating rate 20K/min) (ENCINAR and GONZALEZ, 2007)

The composition of principal gases formed of PE and PP are very similar. The gases ethene and propene were the most produced ones (ENCINAR and GONZALEZ, 2007). Conveniently the pyrolysis gas, which contains, after separation of water vapour and pyrolysis oil, mostly $\mathrm{H}_{2}$, $\mathrm{CH}_{4}, \mathrm{C}_{2} \mathrm{H}_{4}, \mathrm{C}_{2} \mathrm{H}_{6}, \mathrm{C}_{3} \mathrm{H}_{6}, \mathrm{C}_{3} \mathrm{H}_{8}, \mathrm{CO}$ and $\mathrm{CO}_{2}$ can be used for heating the reactor (MARTENS, 2011).

Important requirement for the input material is the possibility to measure the unite size and the prevention of ultrafine grain. The pyrolysis process is suitable for contaminated and mixed plastic types, but the starting material has to be homogenized in order to achieve complete pyrolysis and to achieve a high end product quality (MARTENS and GOLDMANN, 2016). There will be a difference in the heat transfer if the plastic particles are not homogenized and come directly out of the sea. Consideration should be given to the treatment of the exhaust gases, the movement of the ash and the contamination by poisoned pyrolysis oils (MARTENS, 2011).

The most common reactors types for a flash pyrolysis are stationary fluidised bed reactor and circulating fluidised bed reactor, but also other techniques like reactor with ablative effect can be applied. In a fluidized bed reactor the feedstock is fed in a fluidized bed (usually sand) where it is thermally decomposes with absence of oxygen. The volatile components are led into a cyclone system that separates the coke particles and sand from the gas flow. This gas flow is further led into a quencher, which enables the cooling of the gas flow. The resulting condensed 
oils are collected in containers and the remaining cold gas flow is led into an electrostatic precipitator to remove the remaining oils components. In an electrostatic precipitator the separation occurs through the influence of a strong electric field, which transports the negative charge particles within the gas flow to the positive charged collecting electrode (KALTSCHMITT et al., 2009).

Due to the chlorine content within the plastic particles as well as the chlorine from the sea water contaminations in the off gas are to be expected. After the thermal process chlorine can be present in form of salts (sodium chloride or potassium chloride) or it can emit as hydrogen chloride or polychlorinated dioxins and furans. To reduce the development of such substances steps can be made in the planning of a reactor as well as in the off gas cleaning. As example furans and dioxins could occur in the temperature window between $150-500^{\circ} \mathrm{C}$ and to reduce the occurrence this temperature region should be passed quickly (de-novo synthesis). Other forms of chlorine contamination can be cleaned with filter and scrubbers (KALTSCHMITT et al., 2009).

In order to design a pyrolysis reactor it is necessary to gain knowledge of kinetics reaction of the marine plastic (SAHA and GHOSHAL, 2005). There exist many papers on pyrolysis kinetics on diverse plastic types, but they values vary a lot. It depends on the choice of kinetic model, values of Arrhenius parameters and also the different samples used, the experimental conditions employed and the methodology followed for analysis (ENCINAR and GONZALEZ, 2007). But as there are no papers published yet which study the decomposition behaviour of marine litter or rather it is necessary to make an own study and not rely on the information available for single or mixed plastic types (SAHA and GHOSHAL, 2005). 


\section{Reaction kinetics}

The focus of reaction kinetics is the study of speed of chemical reactions and how they are influenced by reactant concentration and physical parameters such as pressure and temperature. How the reaction is governed by these conditions depends on the mechanism of the reaction, which describes in more detail how a reaction sequence consists of individual steps. To gain understanding of the mechanism, therefore the factors, and its rate expression creates the possibility to influence the steps during a conversion process. This allows us to engineer the reaction and to control the transformation from reactant to end product (WOJCIECHOWSKI and RICE, 2003).

\subsection{Arrhenius equation}

An important role of explaining the mechanisms of chemical kinetic is the temperature factor, as is has a major effect on the rate of change (LIDLER, 1970).

In the $19^{\text {th }}$ century scientists created, based on empirical method, an equation that connected the rate constant $(k)$ with the temperature $(\mathrm{T})$, whereby the letters A and B represent constants:

$$
k=A e^{\frac{-B}{T}}
$$

Arrhenius and Van't Hoff then further preceded this equation. Based on the work of Van't Hoff, Arrhenius brought a new development in the chemical kinetic study thanks to his understanding that the precursor molecule needs to run through an activated state in order to convert in a reaction product (LIDLER, 1970). His argumentation started with the law of mass action, which applies for reversible chemical reaction in a chemical equilibrium. The condition of equilibrium for a reaction can be described as

$$
A+B \rightleftharpoons C+D
$$

and with the equalization of the two opposite on-going rates of reaction, $\left(k_{1}, k_{-1}\right)$ the equation looks as followed (LIDLER, 1970).

$$
k_{1}[A][B]=k_{-1}[C][D]
$$


The equilibrium constant $K_{c}$, shown in the formula below, is the quotient of the products of reactant and the product of the reaction (LIDLER, 1970).

$$
\frac{[C][D]}{[A][B]}=\frac{k_{1}}{k_{-1}}=K_{C}
$$

The free enthalpy ( $\Delta G$, Gibbs free energy) is for the rate of change an important formula and is defined for a system at a chemical equilibrium as followed

$$
\Delta G=-R T \ln K
$$

$\mathrm{R}$ is the gas constant $(\mathrm{JK} / \mathrm{mol})$ and $\mathrm{T}$ the absolute temperature (in Kelvin). The equilibrium constant can therefore also be described as

$$
K_{c}=e^{\frac{-\Delta G}{R T}}
$$

To combine the two equation (4) and (6) the logarithm is an useful tool and creates the result

$$
\ln k_{1}-\ln k_{-1}=-\frac{\Delta G}{R T}
$$

Arrhenius made the assumption that the rate constant is only depended of the reaction in one direction and the according changes of the enthalpy. Therefore is it possible to split the equation (7) up into

$$
\begin{aligned}
& \ln k_{1}=-\frac{\Delta G_{1}}{R T}+\text { const } \\
& \ln k_{-1}=-\frac{\Delta G_{-1}}{R T}+\text { const }
\end{aligned}
$$


Observing the reaction from the initial state towards the activated state, the rate constant is only depended of the increase of $\Delta G_{1}$, and from the activated state towards the end state only of the change of $\Delta G_{-1}\left(\left(\Delta G=\Delta G_{1}-\Delta G_{-1}\right)(\right.$ LIDLER, 1970).

$$
\begin{aligned}
& \text { Initial state } \leftarrow \Delta G_{1} \rightarrow \text { activated state } \leftarrow \Delta G_{-1} \rightarrow \text { end stat } \\
& \text { Initial molecules A + B } \quad \leftrightarrows \quad \text { product molecules } \mathrm{C}+\mathrm{D}
\end{aligned}
$$

The schematically illustration of the described process can be also explained with molecules. If there is a reaction between $\mathrm{A}$ and $\mathrm{B}$ than there exists at one site an equilibrium and another side a push, in order to move from the initial state to the activated state. This free activation enthalpy can also be called activation energy (LIDLER, 1970).

The equation (1) can be therefore changed into

$$
k=\text { constant } e^{-\frac{\Delta G}{R T}}
$$

or, expressed as the Arrhenius equation which describes the temperature dependence of the rate constant $k$ as followed (VYAZOVKIN et al., 2011)

$$
k=A e^{-\frac{E_{\propto}}{R T}}
$$

$k=$ rate constant

$A=$ pre-exponential factor $\left(\right.$ in $\left.\min ^{-1}\right)$

$E_{\propto}=$ activation energy (in $\mathrm{kJ} / \mathrm{mol}$ )

$R=$ universal gas constant $(8,314 \mathrm{~J} / \mathrm{mol} \mathrm{K})$

$T=$ absolute temperature (in Kelvin) 
The activation energy can be described as the minimum amount of energy needed in order for molecules to break existing bonds during a chemical reaction. It can also be defined as the energy difference between the reactants and the transition state. In a chemical reaction, the transition state is defined as the highest-energy state of the system. If molecules in the reactant state collide they need to overcome this energy barrier with enough kinetic energy thus the reaction occurs and end products are formed. In other words, the higher the activation energy, the harder it is for a reaction to occur and vice versa product (WOJCIECHOWSKI and RICE, 2003).

The pre-exponential factor is also called the frequency factor because it represents the frequency of collisions between molecules. The frequency is proportional to the product of the concentrations product (WOJCIECHOWSKI and RICE, 2003).

The value alpha $(\propto)$ describes the overall transformation that a reactant progresses. This transformation involves numerous reaction each with it specific extent of conversion. Therefore alpha is described as the conversion, which is calculates through the total weight loss (VYAZOVKIN et al., 2011).

$$
\propto=\frac{m_{i}-m_{a}}{m_{i}-m_{f}}
$$

$m_{i}=$ Initial mass, $m_{a}=$ actual mass, $m_{f}=$ end mass

The transformation rate $(\mathrm{d} \alpha / \mathrm{dt})$ during the reaction can be defined as the product of the function depending exclusively on the temperature and the function depending only on the conversion (STARINK, 2003) and also called the solid state reaction:

$$
k(T) f(\alpha)=\frac{d \alpha}{d t}
$$

The combination of the function (11) and (13) creates the fundamental expression for the study of kinematics of heterogeneous solid-state thermal decomposition (VYAZOVKIN et al., 2011). 


$$
\frac{d \propto}{d t}=A f(\propto) e^{-\frac{E_{\propto}}{R T}}
$$

To calculate dynamic analysis it is important to involve the heating rate $\beta$ (in $\mathrm{K} / \mathrm{min}$ ) in the above equation (14). The linear heating rate $\beta$ is constant and defined as

$$
\beta=\frac{d T}{d t}
$$

The final equation for dynamic analysis of non-isothermal data looks as follow

$$
\frac{d \propto}{d t}=\frac{A}{\beta} f(\propto) e^{-\frac{E_{\propto}}{R T}}
$$

\subsection{Methods for determination of activation energy}

There exist various methods for kinetic analysis of decomposition processes generally classified in "model fitting kinetics" and "model free kinetics" methods (KHAWAM, 2007). The graphic no. 9 gives an overview of different methods for kinetic analysis and displays the methods used in this study.

The model-fitting method follows the approach to choose the model with the best statistical fit after forceful fitting of kinetic parameters into the equation (KHAWAM, 2007). The result is an ambiguous interpretation because more than one reaction mechanism fits into the data and the Arrhenius parameters are drastically varied. (VYAZOVKIN and WIGHT, 1999).

The model free method does not need any assumption of specific reaction models $f(\propto)$ (VYAZOVKIN and WIGHT, 1999) and yields kinetic parameters as a function of either conversion (isoconversional analysis) or temperature (non-parametric analysis) (VYAZOVKIN, 2000). 


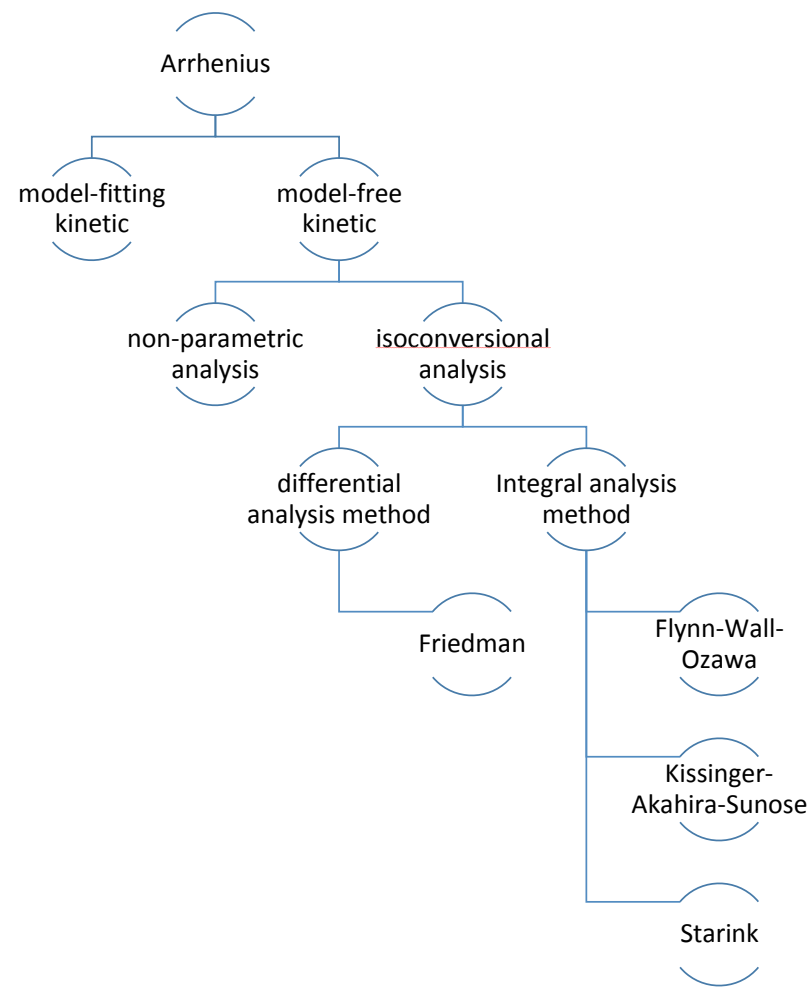

Figure 9: Various methods for kinetic analysis (VYAZOVKIN and WIGHT, 1999; VYAZOVKIN, 2000)

The advantage in choosing the model-free analysis is the simplicity and avoidance of errors. For thermochemical conversion research the isoconversion methods are reliable methods to determine the activation energy and is more frequently adopted (ABOYADE et al., 2012) and therefore applied in this research.

\subsection{Isoconversion methods}

Isoconversional analysis methods are based on the isoconversional principle which states that at a constant extent of conversion the reaction rate is a function only of the temperature. (VYAZOVKIN, S.; SBIRRAZZUOLI, 2006). This constant extent of conversion may be defined as stage at which a fixed amount is transformed (STARINK, 2003), so an equivalent stage of the reaction for different heating rates. Therefore this method needs several kinetic curves to perform the analysis because activation energy is calculated for each conversion point (KHAWAM, 2007).

These isoconversion methods can be divided into two classes based on the basic equation the use (STARINK, 2003) in either differential or integral analysis methods (MISHRA and BHASKAR, 2014). 


\subsubsection{The differential analysis methods}

The most known differential method, called after the first researcher in this field, is the Friedman method. He takes the logarithm on both sides from the equation (16)

$$
\ln \left[\beta_{i}\left(\frac{d \propto}{d T}\right)_{\propto, i}\right]=\ln \left[A_{\propto} f(\propto)\right]-\frac{E_{\propto}}{R T_{\alpha, i}}
$$

In Friedman's equation $\propto$ indicates the value related to a considered conversion and the subscript "i" refers the heating rate (MISHRA and BHASKAR, 2014).

Relevant to obtain the activation energy $E_{\propto}$ are the absolute temperature (T) and the transformation rate $(d \propto / \mathrm{dt})$ both measured at a fixed stage $(\propto)$ for each of the experiments with different heating rates $(\beta)\left(\right.$ STARINK, 2003). By plotting $\ln \left[\beta_{i}\left(\frac{d \propto}{d T}\right)_{\alpha, i}\right]$ against the inverse of pyrolysis temperature $(1 / \mathrm{T})$ the value of the slope demonstrates the value of activation energy. Friedman created a method, which can be applied to any thermal history including temperature program. (MISHRA and BHASKAR, 2014).

The Friedman method does not need mathematical approximations however creates uncertainties because the accuracy of the measurement and the calibration of the analysis equipment play an important role (STARINK, 2003). This method is very sensitive to systematic variations of the total heat released with the heating rate, therefore the results can be inaccurate (from 7 to 16\%) (SBIRRAZZUOLI, 2007). Because of its unreliability and variability in the measured values (STARINK, 2003) the Friedman method will not be applied in this study.

\subsubsection{The integral analysis methods}

The integral methods are based on the integral form of the equation (16) (MISHRA and BHASKAR, 2014) and need to determine the activation energy only data on $\mathrm{T}(\beta)$.

$$
\int_{0}^{\alpha} \frac{d \alpha}{f(\alpha)}=g(\propto)=\frac{A}{\beta} \int_{T_{0}}^{T_{f}} \exp \left(-\frac{E}{R T}\right) d T=\left(\frac{A}{\beta}\right) p(x)
$$

This method needs a range of approximations for the temperature integral (STARINK, 2003) which would be $\mathrm{p}(\mathrm{x})$ in equation (18). There does not exists an exact analytical solution for $\mathrm{p}(\mathrm{x})$ 
therefore exist different empirical interpolation formulas in terms of approximation by various researchers (GAI et al., 2013). The best-known methods are Kissinger-Akahira-Sunose (KAS) and Flynn-Wall-Ozawa method (FWO), both use different empirical approximations, and based on the KAS method exist a deviation by Starink, called the Starink method.

\subsubsection{Flynn-Wall-Ozawa method}

The FWO method uses for the temperature integral the Doyle's approximation as follows

$$
\int_{T_{0}}^{T_{f}} \exp \left(-\frac{E}{R T}\right) d T=\left(\frac{E}{R}\right)\left(0.0484 e^{-1.0516 u}\right)
$$

and then substituting it in the above equation (18) and then taking the logarithm of both sides results in following equation (STARINK, 2003)

$$
\ln \beta=\ln \frac{A E}{R g(\alpha)}-5.331-1.052 \frac{E}{R T}
$$

\subsubsection{Kissinger Akahira and Sunose method}

The best example to explain the differential methods is the Kissinger-Alkahira-Sunose (KAS) method which is also called the generalised Kissinger method (STARINK, 2003). KAS uses the temperature integral approximation according to Coats-Redfern which looks as following

$$
\int_{T_{0}}^{T_{f}} \exp \left(-\frac{E}{R T}\right) d T=\frac{E_{\beta}}{R A T}
$$

and then, same as demonstrated above, substituting it in the above equation (18) and then taking the logarithm of both sides results in following equation (MISHRA and BHASKAR, 2014)

$$
\ln \left(\frac{\beta}{T^{2}}\right)=\ln \left(\frac{A R}{E_{\propto} g(\alpha)}\right)-\frac{E_{\propto}}{R T_{\propto, i}}
$$




\subsubsection{Starink method}

$$
\ln \left(\frac{\beta}{T^{1.8}}\right)=\ln \left(\frac{A R}{E_{\propto} g(\propto)}\right)-1.0037 \frac{E_{\propto}}{R T_{\propto, i}}
$$

Based on the KAS method, Starink conducted further analysis and changed the equation which results, according to Starink, in a higher precision of activation energy (GAI et al., 2013).

The expression $g(\propto)$ is constant at a given value of conversion (SLOPIECA et al., 2011) and depending on the reaction order. The reaction order for pyrolysis of plastic is, based on results obtained by various authors, a first order reaction (ENCINAR and GONZALEZ, 2007) which results in following equation: $g(\propto)=-\ln (1-\alpha)$

All the integral analysis methods can be described as (GAI et al., 2013)

$$
\ln \left(\frac{\beta}{T^{s}}\right)=C-\frac{B E_{\propto}}{R T_{\propto, i}}
$$

$\begin{array}{llll}\text { FWO } & \mathrm{s}=0 & \mathrm{~B}=1.052 & \mathrm{C}=\ln \frac{A E}{R g(\alpha)}-5.331 \\ \text { KAS } & \mathrm{s}=2 & \mathrm{~B}=1 & \mathrm{C}=\ln \left(\frac{A R}{E_{\propto} g(\alpha)}\right) \\ \text { Starink } & \mathrm{s}=1.8 & \mathrm{~B}=1.0037 & \mathrm{C}=\ln \left(\frac{A R}{E_{\propto} g(\alpha)}\right)\end{array}$

The activation energy is obtained by plotting the left hand side of the equation (24) $\ln \left(\frac{\beta}{T^{s}}\right)$ versus $1 / \mathrm{T}$, this yields a straight line which slope gives the value $\frac{B E_{\alpha}}{R}$ and the intercept the value of $\mathrm{C}$ form equation (24) (SLOPIECA et al., 2011).

For real experiment data the accuracy of determination of transformation is limited and according to various authors, integral methods are more accurate than differential methods (STARINK, 2003). 


\section{Method}

\subsection{Technique of measurement}

There exists a variety of measurement methods and depending on which physical and chemical properties one wants to measure, one can choose between DSC (differential scanning calorimeter), TGA (thermogravimetric analysis), TMA (thermomechanical analysis) and DMA (dynamic mechanical analysis). A combination of all four techniques is also possible (HAMMER et al., 2013).

The differential scanning calorimeter measures the energy absorbed or released by the sample. Hence shows the heat flow to and from a sample compared to a reference (crucible with material or empty) as a function of temperature. The DSC signal demonstrates if the reaction is exothermic or endothermic as well as specific heat capacity and peak areas (HAMMER et al., 2013).

The thermogravimetric analysis is a technique, which measures the weight loss of a substance as a function of temperature in a controlled atmosphere and temperature program. The TGA signal shows changes in the mass of the sample, if it is a stepwise change, and can detect the temperature when the mass loss curve displays specific losses or gains (HAMMER et al., 2013).

During a thermomechanical analysis the sample is subject to a force, which can be constant, increasing or modulate, to measure the deformation and dimensional changes of a sample as a function of temperature. It is used to determine thermal effects influenced by temperature and expansion coefficients (HAMMER et al., 2013).

Dynamic mechanical analysis technique puts the sample to mechanical stress to measure force amplitude, displacement amplitude and phase shift as function of temperature or frequency. It is used to determine thermal effects influenced by change damping behaviour (HAMMER et al., 2013).

Table 8 gives an overview of the four methods and how well they measure certain parameters.

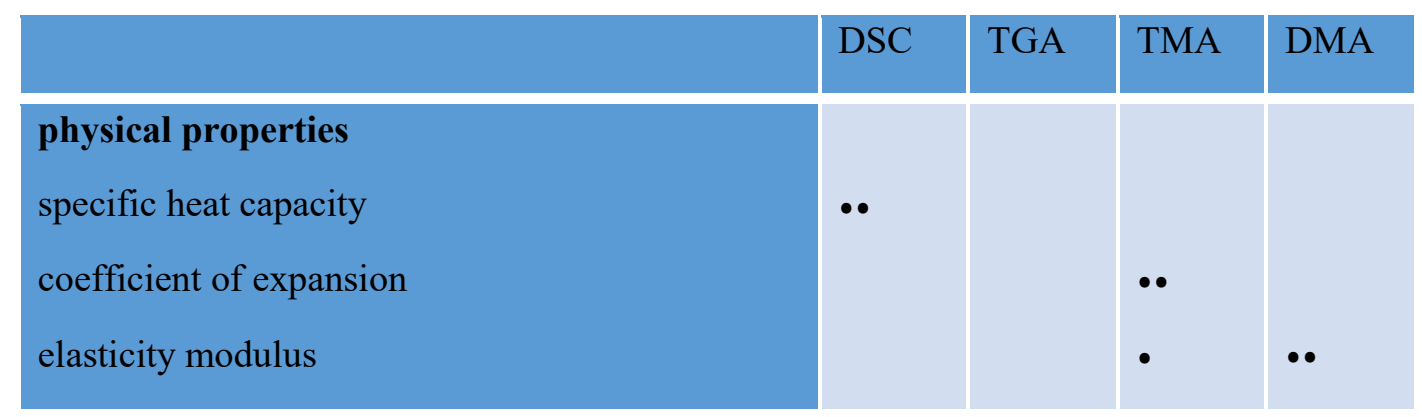




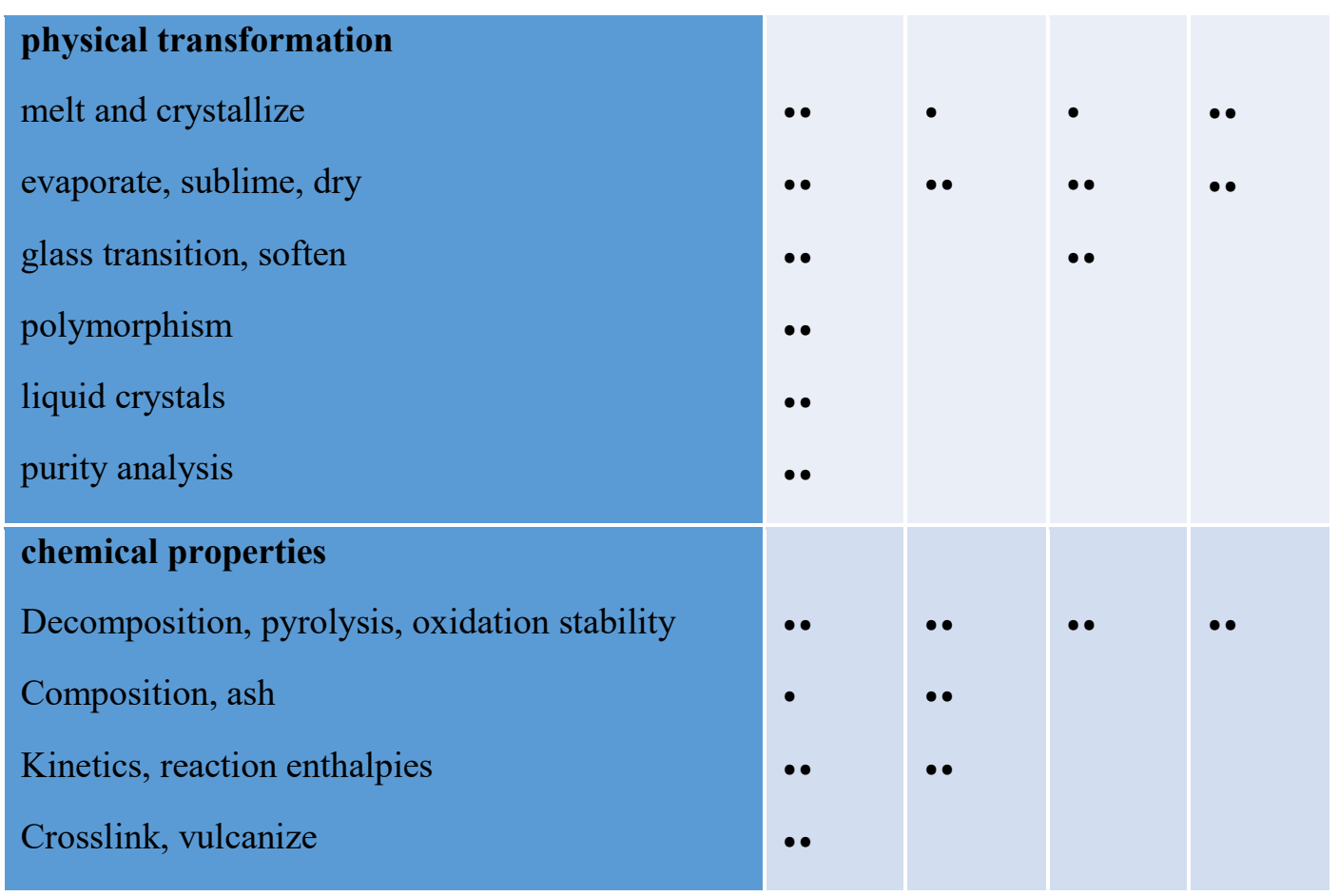

Table 8: Overview of the possible applications of the different thermoanalytical measurement techniques, ••Very suitable, -less suitable (SCHUBNELL, 2005)

The parameters produced by the DSC and TGA methods offer a good fit to detect the required measurement to examine thermochemical behaviour and conduct a kinetic study.

\subsection{Thermogravimetric analysis}

The coupling of DSC and TGA signal is advantageous because it measures physical transformation as evaporation, sublimation, drying, the physical property as heat flow, as well as the chemical properties required for the kinetics (see Table 8) (SCHUBNELL, 2005). Keeping in mind that the DSC signal from a TGA/DSC measurement is less sensitive than obtained from an individual DSC measurement (HAMMER, 2013).

Figure 10 shows the TGA and DTG curves in the upper diagram and the DSC curve in the lower diagram, respectively for Polyethylene terephalate (HAMMER, 2013).

The TGA curve of Thermoplastics shows the mass loss steps relating to the loss of volatile components, polymer decomposition, combustion and final residues. Based on this information it is even possible to conclude the individual components of the sample, to some extent. Furthermore offers the first derivative of the TGA curve, the DTG curve, the relation to time and proceeds proportional to the rate of decomposition. The combination of both methods offers 
understanding for the effects of glass transition, coly crystallization, melting and decomposition (HAMMER, 2013).

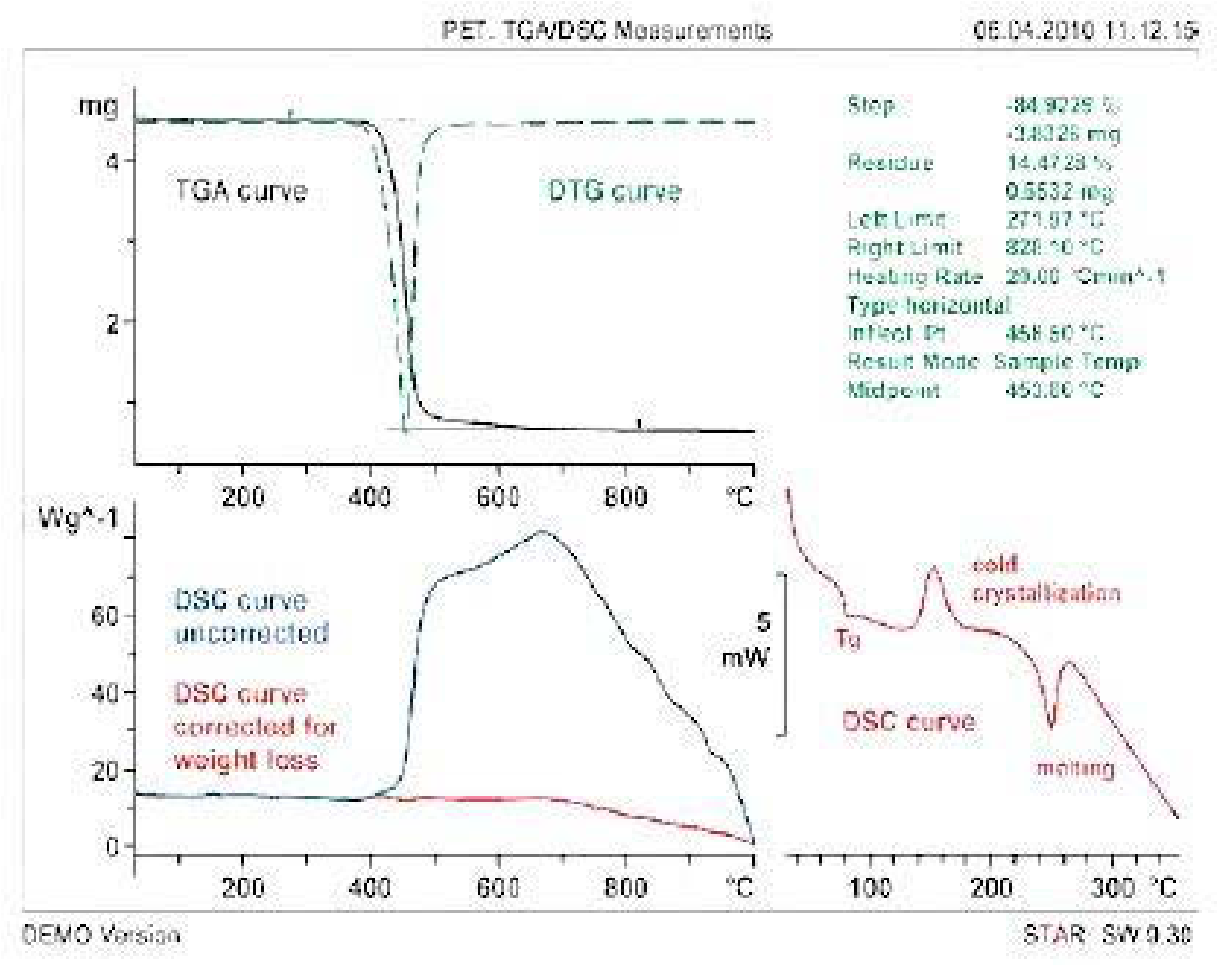

Figure 10: Measurement curves of PET recorded from 30 to $1000^{\circ} \mathrm{C}$ at a heatingnrate of 20 K/min using a TGA/DSC (HAMMER, 2013)

Furthermore, artefacts have to be taken into account those are effects on the measurement curve which were not caused by the sample. Nominal valued artefacts are the occurrence effect, which is caused by the gas density decreasing during heating, a weight increase is the consequence. This effect can be counteracted by a blank curve (WIDMANN, 2001). A blank curve, or a base line, is a measurement curve which has been created under the same conditions, but without a sample so only an empty crucible (RIESEN, 2007). Fluctuations in the flushing gas stream is another artefact since they can be seen on the measurement curve and should therefore not be changed during the measurement (WIDMANN, 2001).

\subsubsection{Sample carrier}

The TGA sample carrier cannot measure a DSC signal therefore where all measurements undertaken with a DSC sample carrier. The first step, before starting with the analysis, is to calibrate the sample carrier for sensitivity and temperature. The calibration occurred with five different metals: indium, zinc, bismuth, aluminium and gold. All of them were heated $50^{\circ} \mathrm{C}$ above the melting point and then cooled $50^{\circ} \mathrm{C}$ below it, this procedure was repeat five times. 
The observed onset of the melting point temperature and enthalpy (area underneath the curve) were then afterwards compared with the existing values of the mentioned metals.

\subsubsection{Crucible}

The selection of the crucibles is crucial since it can influence the measurement in various means. First of all the size of the crucible determines the amount of the sample. It can also reduce the amount on resolving power through the heat capacity of the crucible. The material of the crucible must not react with the sample; otherwise the measurement will be disturbed and thus unusable (SCHUBNELL, 2005).

The chosen crucible has a volume of 20 micrometre, made of aluminium oxide $\left(\mathrm{Al}_{2} \mathrm{O}_{3}\right)$ and the sample weight is therefore 16 milligram (weight in with a tolerance of $+/-0.1 \%$ ).

\subsubsection{Sampling and sample preparation}

The marine litter is globally distributed and hence are several locations to collect a litter sample. The Mediterranean Sea has densely populated coasts and 30\% of the world's maritime traffic (UNEP, 2015) and represents therefore a good sampling location. HIDALGO-RUZ et al. (2012) published a review that compared the methodologies used for the quantification of microplastic from the marine environment. The majority of the samples were sediment samples which came from sandy beaches at the high tide line. The sampling location for this study was a sandy beach on the Greek island Rhodos. A member of the institute for chemical and energy engineering at the University of Natural Resources and Life Sciences Vienna collected several kilo of marine litter in 2015.

In general can the sampling methods be disgusted into three kinds: selective sampling, bulk sampling, or volume-reduced sampling. The sample for this study was a bulk sample, which refers to samples where the entire volume is taken without reducing it during the sampling process (HIDALGO-RUZ et al., 2012).

To reduce the volume of the field sample to gain a laboratory sample a sample division method was applied. For the taper division the sample (in this case two kilo of the entire field sample) is poured on a clean surface (see Figure 11) and then divided into four equal sized parts (taper shaped) (see Figure 12). One or two parts, usually the two diagonal lying, remain (MOSTBAUER, 2016). 


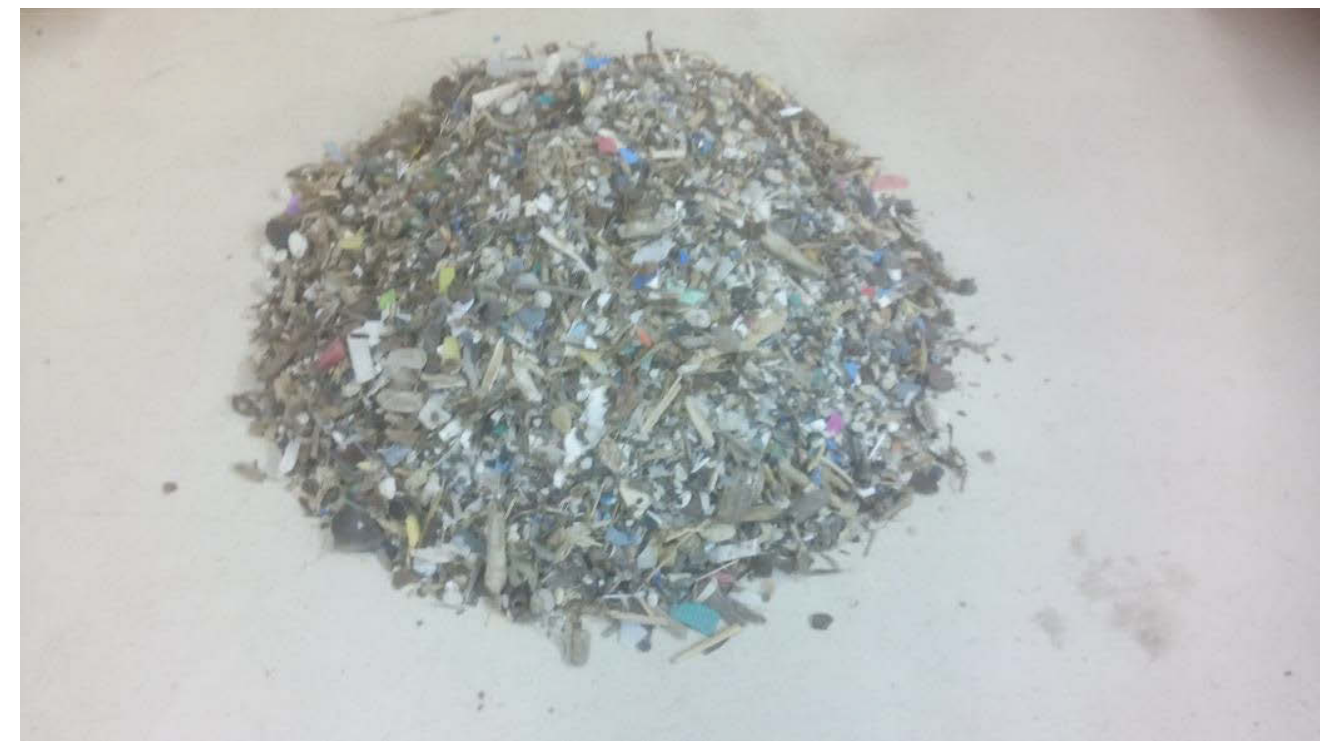

Figure 11: Field sample from Rhodos

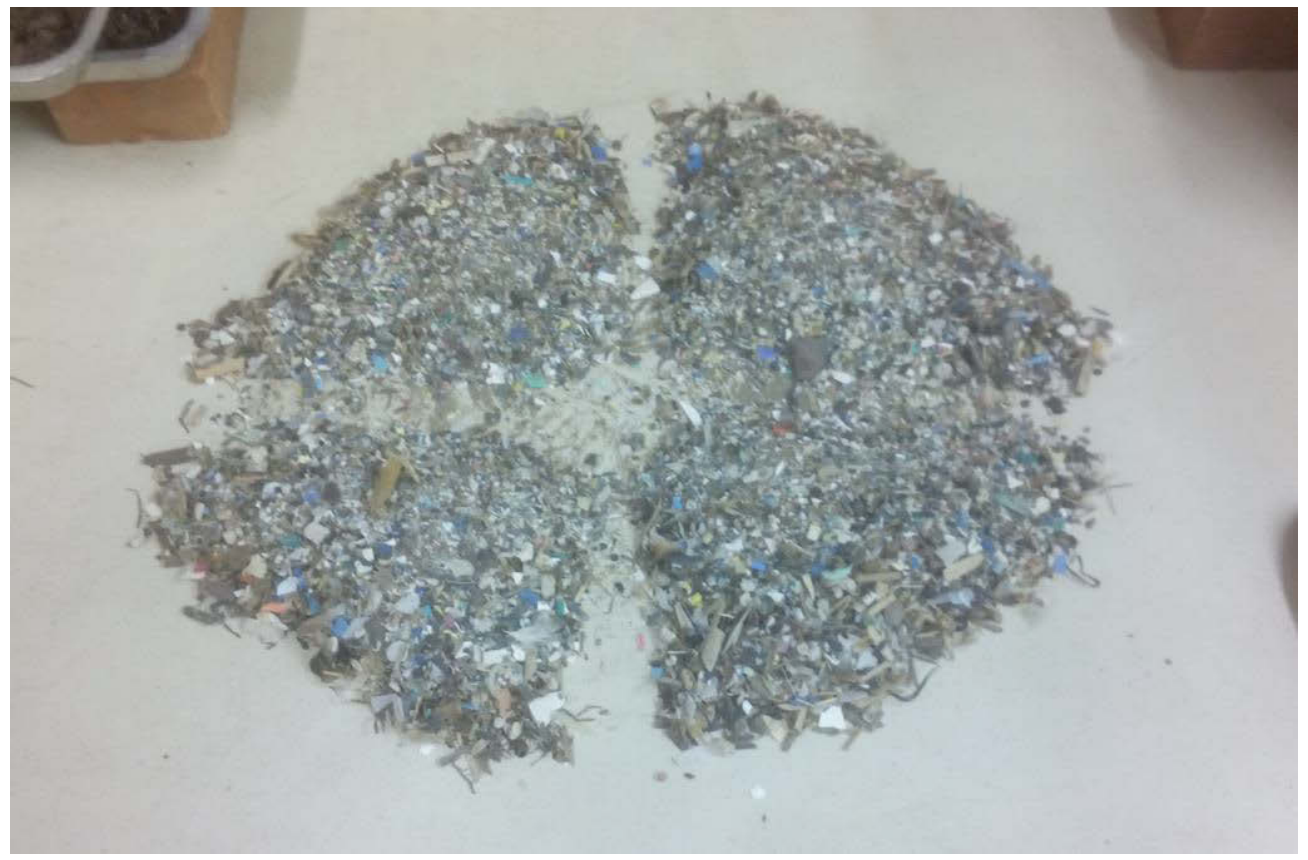

Figure 12: Taper division of the sample

The two opposite lying tapers were chosen and therefore mixed. The steps for sample processing can include density separation, filter, sieve and visual sorting (HIDALGO-RUZ et al., 2012).

As the density separation had no effective result this step was omitted and the sample was directly sieved with a vibrating plate sieve. For the sieving process it is important to decide on the mesh size of the sieves. The selection of the mesh size refers to the size fraction of European Working Group (chapter 1). In the sample was no section bigger than $25 \mathrm{~mm}$ present; therefore the class macroplastic was omitted. According to the remaining size classes the sieve with $4 \mathrm{~mm}$ 
mesh size accumulates the mesoplastic $(4-25 \mathrm{~mm}), 1 \mathrm{~mm}$ mesh size collects the large microplastic $(1-4 \mathrm{~mm})$ and the collection pan comprise the small microplastic fraction $(<1 \mathrm{~mm})$. Figure 13 shows the plastic after sieving, left the mesoplastic, in the middle the large microplastic and right the small microplastic.

Visual sorting was one of the most commonly used methods for the identification of micro plastic and hence applied also in this case. The plastic particles are separate from other materials (e.g. wood, shell fragments, metal, ect.) by direct examination by naked eye (HIDALGO-RUZ et al., 2012).

The plastic material was further on mechanically processed to have a homogenous feedstock for the thermogravimetric analysis. The three classes were separately milled with a disc vibrating mill (firm Retsch RS1, with 700 turns/min) and a centrifugal mill (firm Retsch ZM 1000 , with 10.000 turns $/ \mathrm{min}$ and a sieve with $0,5 \mathrm{~mm}$ ). To ensure that all kind of plastic is sufficiently in the feedstock this procedure, with both mills, was repeated several times because harder plastic may need more than just one crushing step.

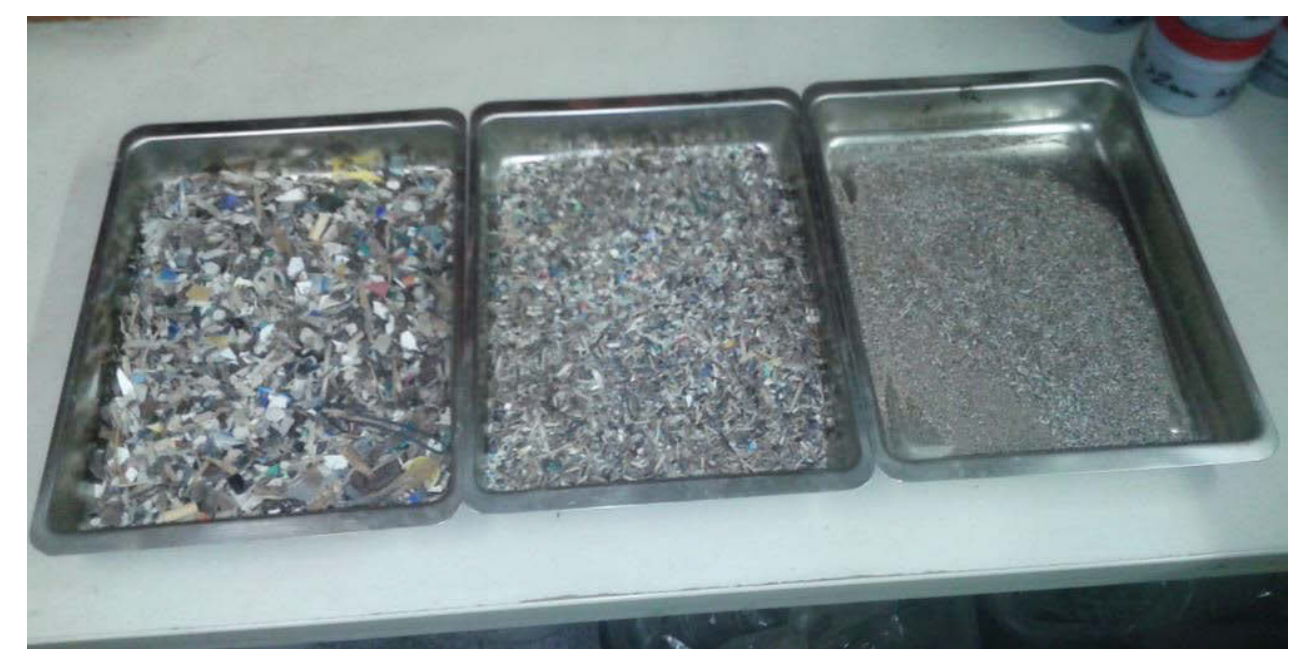

Figure 13: Microplastic in three size classes

\subsubsection{Measuring mode: temperature program, selection of atmosphere}

The pyrolysis process occurs in an oxygen free atmosphere therefore it is necessary to use inert gas, such as argon. All tests had the same temperature program starting with $34^{\circ} \mathrm{C}$ up to $1000^{\circ} \mathrm{C}$ and run through a start-standby $\left(34^{\circ} \mathrm{C}\right.$ with $1 \mathrm{~K} / \mathrm{min}$ heating rate for $\left.10 \mathrm{~min}\right)$ to observe the drying and to better compare the different runs. Isoconversional analysis methods need several 
mesh size accumulates the mesoplastic $(4-25 \mathrm{~mm}), 1 \mathrm{~mm}$ mesh size collects the large microplastic $(1-4 \mathrm{~mm})$ and the collection pan comprise the small microplastic fraction $(<1 \mathrm{~mm})$. Figure 13 shows the plastic after sieving, left the mesoplastic, in the middle the large microplastic and right the small microplastic.

Visual sorting was one of the most commonly used methods for the identification of micro plastic and hence applied also in this case. The plastic particles are separate from other materials (e.g. wood, shell fragments, metal, ect.) by direct examination by naked eye (HIDALGO-RUZ et al., 2012).

The plastic material was further on mechanically processed to have a homogenous feedstock for the thermogravimetric analysis. The three classes were separately milled with a disc vibrating mill (firm Retsch RS1, with 700 turns/min) and a centrifugal mill (firm Retsch ZM 1000 , with 10.000 turns $/ \mathrm{min}$ and a sieve with $0,5 \mathrm{~mm}$ ). To ensure that all kind of plastic is sufficiently in the feedstock this procedure, with both mills, was repeated several times because harder plastic may need more than just one crushing step.

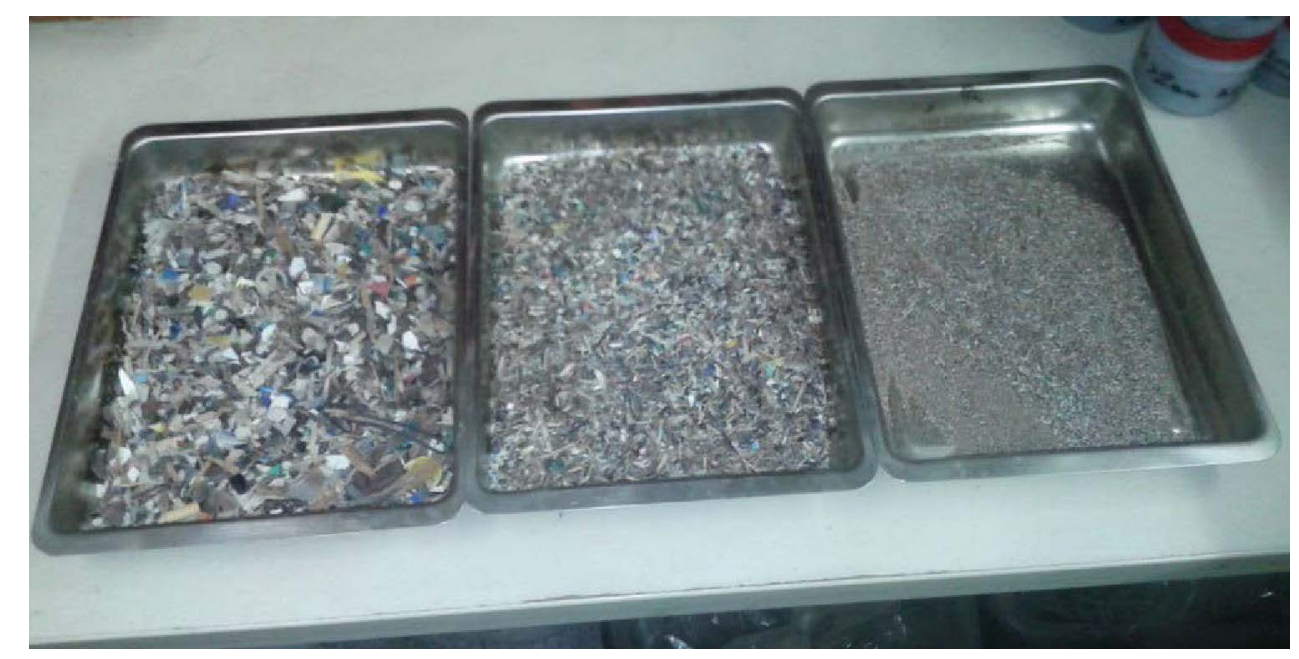

Figure 13: Microplastic in three size classes

\subsubsection{Measuring mode: temperature program, selection of atmosphere}

The pyrolysis process occurs in an oxygen free atmosphere therefore it is necessary to use inert gas, such as argon. All tests had the same temperature program starting with $34^{\circ} \mathrm{C}$ up to $1000^{\circ} \mathrm{C}$ and run through a start-standby $\left(34^{\circ} \mathrm{C}\right.$ with $1 \mathrm{~K} / \mathrm{min}$ heating rate for $\left.10 \mathrm{~min}\right)$ to observe the drying and to better compare the different runs. Isoconversional analysis methods need several 
kinetic curves to perform the analysis (KHAWAM, 2007) therefore the samples were heated at four different heating rates, namely at $5,10,15$ and $20 \mathrm{~K} / \mathrm{min}$.

Before starting with the first sample it was necessary that the empty crucible run through a whole test program, in order to correct afterwards the curves from possible deviation triggered from the crucible. This crucible correction creates the blank curve and was repeated for all heating rates always before the measurements with the samples.

Between all pyrolysis tests the furnace needed an oxidative process $\left(1000^{\circ} \mathrm{C}\right.$, Argon $40 \mathrm{ml}$, Oxygen $10 \mathrm{ml}$ ) to remove all possible remaining form the sample in the furnace. Additionally to the TGA/DSC signals the skimmer, which is a surface aspirator, collected the exhaust gases and led them to a mass spectrometer to detect the contained substances (Scan Baragraph from 1 to 100$)$.

Test-parameters:

- Program: dynamic pyrolysis, non-isothermal

- Sample weight: $16 \mathrm{mg}$

- Sample gas: Argon with $50 \mathrm{ml} / \mathrm{min}$

- Temperature: $34^{\circ} \mathrm{C}-1000^{\circ} \mathrm{C}$

- Heating rate: $5,10,15,20 \mathrm{~K} / \mathrm{min}$

- Device: Netzsch STA 409 CD

The table 9 shows the pyrolysis test, bake-out processes and the blank curve runs. 


\begin{tabular}{|c|c|c|c|c|}
\hline Date & Heating rate & Size class & Crucible & Thermal process \\
\hline \multirow[t]{3}{*}{20.06 .2016} & $5 \mathrm{~K}$ & Empty - blank curve & DSC2 & Pyrolysis \\
\hline & $5 \mathrm{~K}$ & Mesoplastic & DSC2 & Pyrolysis \\
\hline & \multicolumn{2}{|c|}{ Oxidative process } & DSC2 & Combustion \\
\hline \multirow[t]{2}{*}{23.06 .2016} & $5 \mathrm{~K}$ & Small microplastic & DSC2 & Pyrolysis \\
\hline & \multicolumn{2}{|c|}{ Oxidative process } & DSC2 & Combustion \\
\hline \multirow[t]{2}{*}{26.06 .2016} & $5 \mathrm{~K}$ & Large microplastic & DSC2 & Pyrolysis \\
\hline & \multicolumn{2}{|c|}{ Oxidative process } & DSC2 & Combustion \\
\hline \multirow[t]{3}{*}{27.06 .2016} & $20 \mathrm{~K}$ & Empty - blank curve & DSC4 & Pyrolysis \\
\hline & $20 \mathrm{~K}$ & Large microplastic & DSC4 & Pyrolysis \\
\hline & \multicolumn{2}{|c|}{ Oxidative process } & DSC4 & Combustion \\
\hline \multirow[t]{4}{*}{28.06 .2016} & $20 \mathrm{~K}$ & Mesoplastic & DSC4 & Pyrolysis \\
\hline & \multicolumn{2}{|c|}{ Oxidative process } & DSC4 & Combustion \\
\hline & $20 \mathrm{~K}$ & Small microplastic & DSC4 & Pyrolysis \\
\hline & Oxidative pr & & DSC4 & Combustion \\
\hline \multirow[t]{5}{*}{30.06 .2016} & $15 \mathrm{~K}$ & Empty - blank curve & DSC4 & Pyrolysis \\
\hline & $15 \mathrm{~K}$ & Mesoplastic & DSC4 & Pyrolysis \\
\hline & \multicolumn{2}{|c|}{ Oxidative process } & DSC4 & Combustion \\
\hline & $15 \mathrm{~K}$ & Large microplastic & DSC4 & Pyrolysis \\
\hline & Oxidative pr & & DSC4 & Combustion \\
\hline \multirow[t]{2}{*}{01.07 .2016} & $15 \mathrm{~K}$ & Small microplastic & DSC4 & Pyrolysis \\
\hline & \multicolumn{2}{|c|}{ Oxidative process } & DSC4 & Combustion \\
\hline \multirow[t]{3}{*}{06.07 .2016} & $10 \mathrm{~K}$ & Empty - blank curve & DSC4 & Pyrolysis \\
\hline & $10 \mathrm{~K}$ & Mesoplastic & DSC4 & Pyrolysis \\
\hline & \multicolumn{2}{|c|}{ Oxidative process } & DSC4 & Combustion \\
\hline \multirow[t]{4}{*}{14.07 .2016} & $10 \mathrm{~K}$ & Large microplastic & DSC4 & Pyrolysis \\
\hline & \multicolumn{2}{|c|}{ Oxidative process } & DSC4 & Combustion \\
\hline & $10 \mathrm{~K}$ & Small microplastic & DSC4 & Pyrolysis \\
\hline & \multicolumn{2}{|c|}{ Oxidative process } & DSC4 & Combustion \\
\hline
\end{tabular}

Table 9: Timeline of all pyrolysis test, oxidative processes and the blank curve runs 


\section{Results and Discussion}

\subsection{Thermogravimetric analysis}

The mass loss (TG) thermograms of thermal decomposition of marine plastic pyrolysis of three difference sizes classes (small microplastic, large microplastic and mesoplastic) at four heating rates $($ beta $=5,10,15,20 \mathrm{~K} / \mathrm{min}$ ) under argon atmosphere are shown in figure $12-14$.

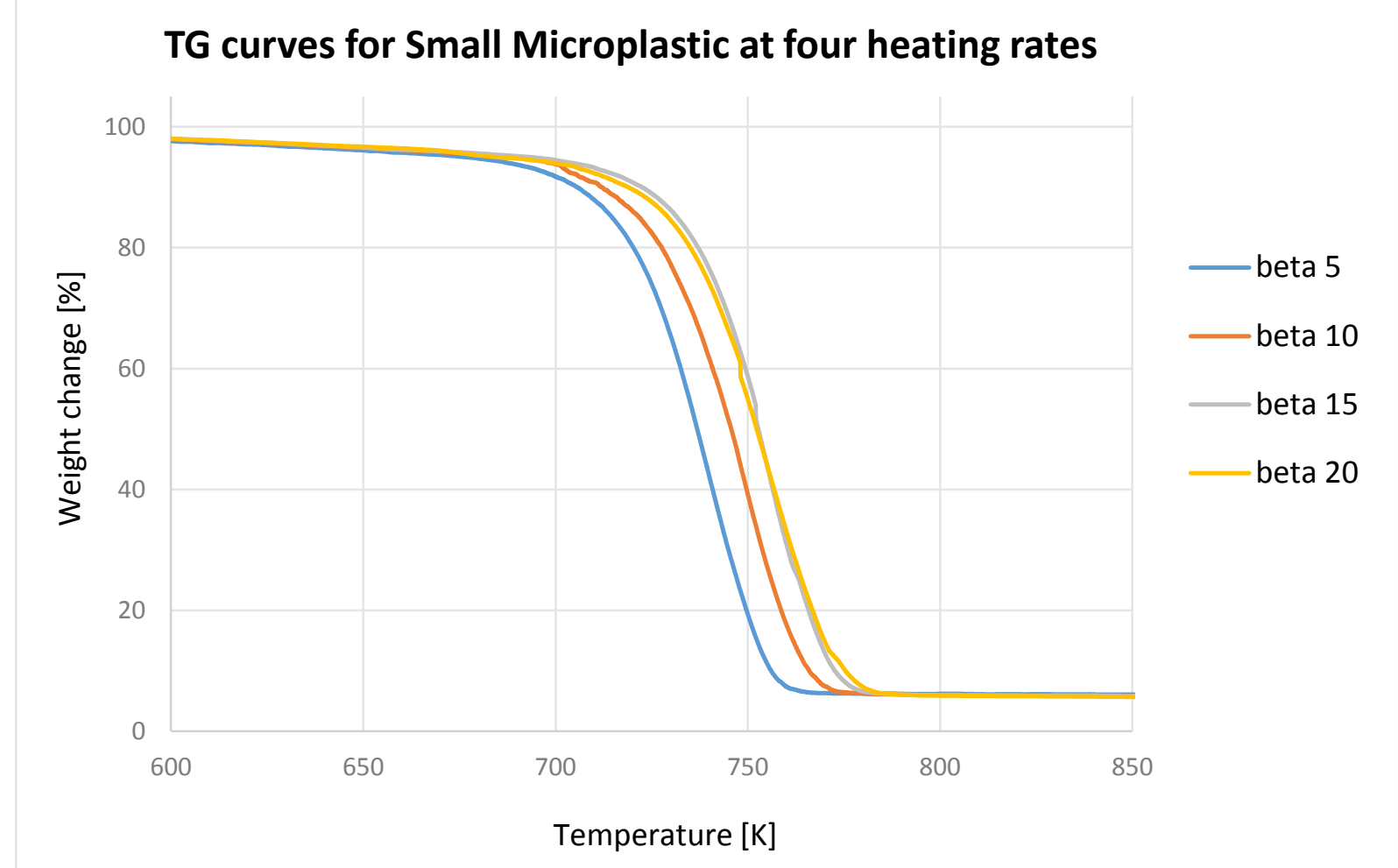

Figure 14: TG curves for small microplastic at four heating rates

The weight loss curve (TG) shows the loss of mass with temperature at different heating rates and all three size classes have a similar temperature behaviour and shape of the decomposition curves. As can be seen from the plot, there is no great variation in the first 600 Kelvin, because there is a lack of inherent water. The degradation process begins at about 700 Kelvin and proceeds rapidly until 780 Kelvin. After $790 \mathrm{~K}$ there is no variation to observe. It is single stage degradation with a single peak and most of the total weight loss (95\%).

If compared with the degradation of a biomass sample, the samples run through the three stages of pyrolysis: dehydration (moisture evaporation), active stage (main devolatilization) and passive pyrolysis (continuous slight devolatilization) and have usually a higher percentage of solid residue (MISHRA and BHASKAR, 2014). 


\section{TG curves for Large Microplastic at four heating rates}

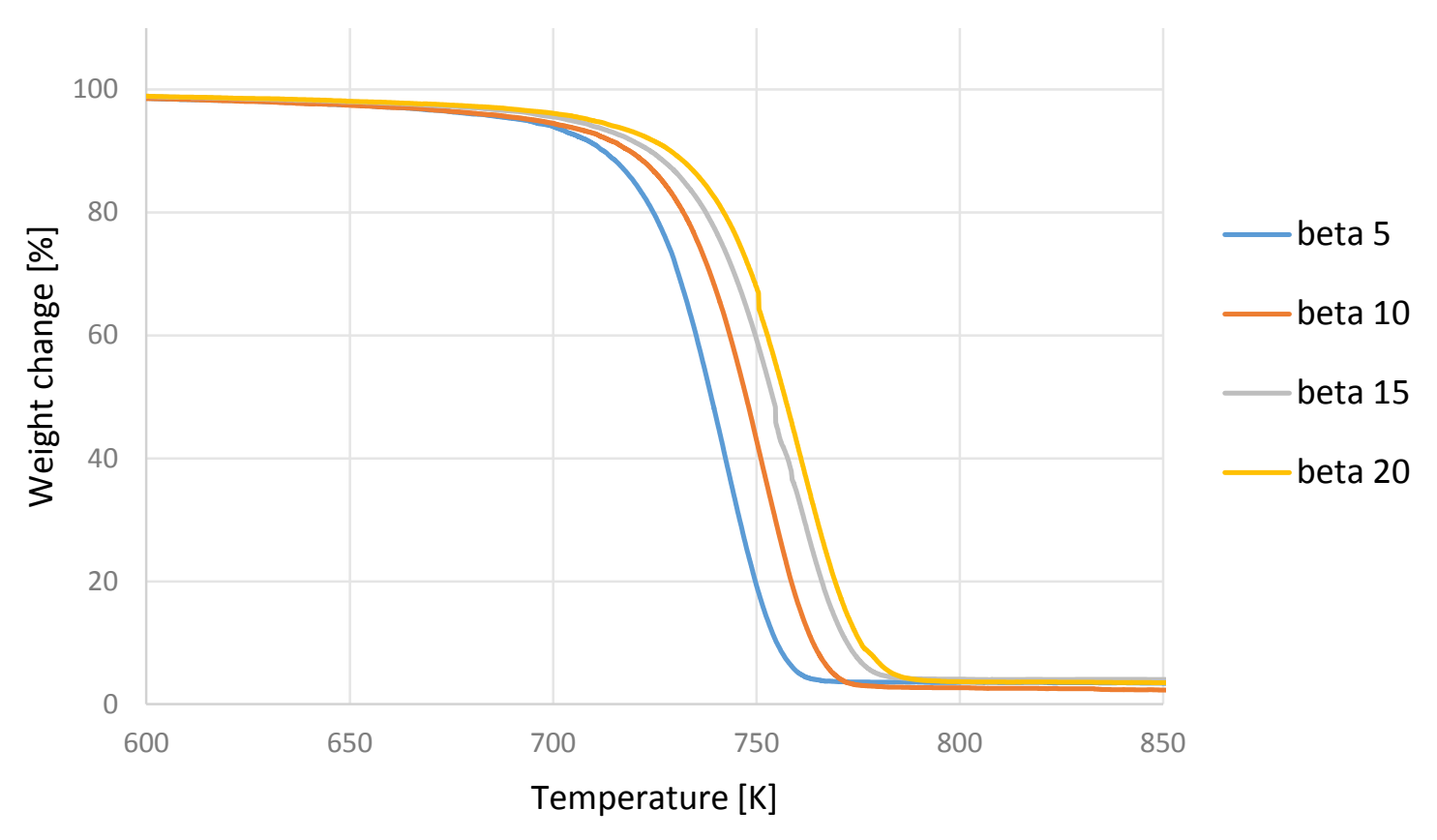

Figure 15: TG curves for large microplastic at four heating rates

TG curves for Mesoplastic at four heating rates

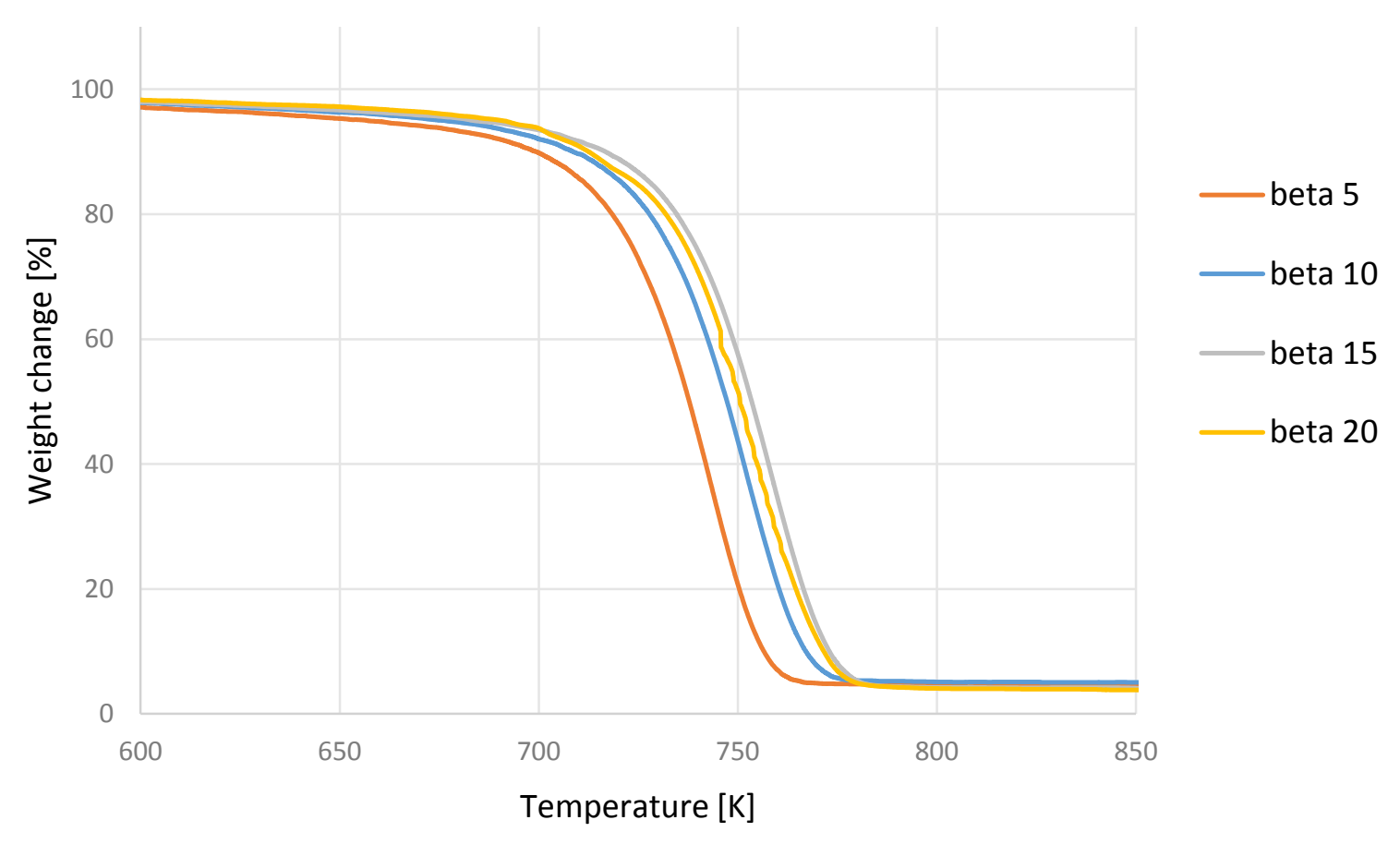

Figure 16: TG curves for mesoplastic at four heating rates 
There is, after the entire structural breakdown, nearly none solid reside (around 2-5\%). The different size classes demonstrated no great variation, although the large microplastic had even less solid residue.

The different heating rates have a different behaviour depending on the size class. Heating rates affects the TG curve position mainly the temperature peaks at maximum weight loss.

The heating rate $5 \mathrm{~K} / \mathrm{min}$ and $10 \mathrm{~K} / \mathrm{min}$ are always lower than the other two, but the $15 \mathrm{~K} / \mathrm{min}$ and $20 \mathrm{~K} / \mathrm{min}$ overlap each other in the category small microplastic, in large microplastic $20 \mathrm{~K} / \mathrm{min}$ is higher than $15 \mathrm{~K} / \mathrm{min}$ and in the last class mesoplastic the highest heating rate lies lower than $15 \mathrm{~K} / \mathrm{min}$. This is an unexpected behaviour. The noise of the signal can be related to various sources.

As two of the three selected class-sized showed the same problem it could be that the heat transfer from the furnace to the sample was not optimal provided.

As mentioned in the chapter above (5.2. Thermogravimetric Analysis) artefacts could occur during measurement. Caused by change of the heat transfer from the sample to the crucible or from the crucible to the sensor. An example could be a slight deviations of the crucible triggered through different expansion coefficient or change of the room temperature (SCHAWE et al., 2000).

The increase of temperature did not influence the weight loss rate significantly.

The differential mass loss (DTG) thermograms of thermal decomposition of marine plastic pyrolysis of three difference sizes classes (small microplastic, large microplastic and mesoplastic) at four heating rates $(5,10,15,20 \mathrm{~K} / \mathrm{min})$ under argon atmosphere are shown in Figure $15-17$. 


\section{DTG of Small Microplastic at different heating rates}

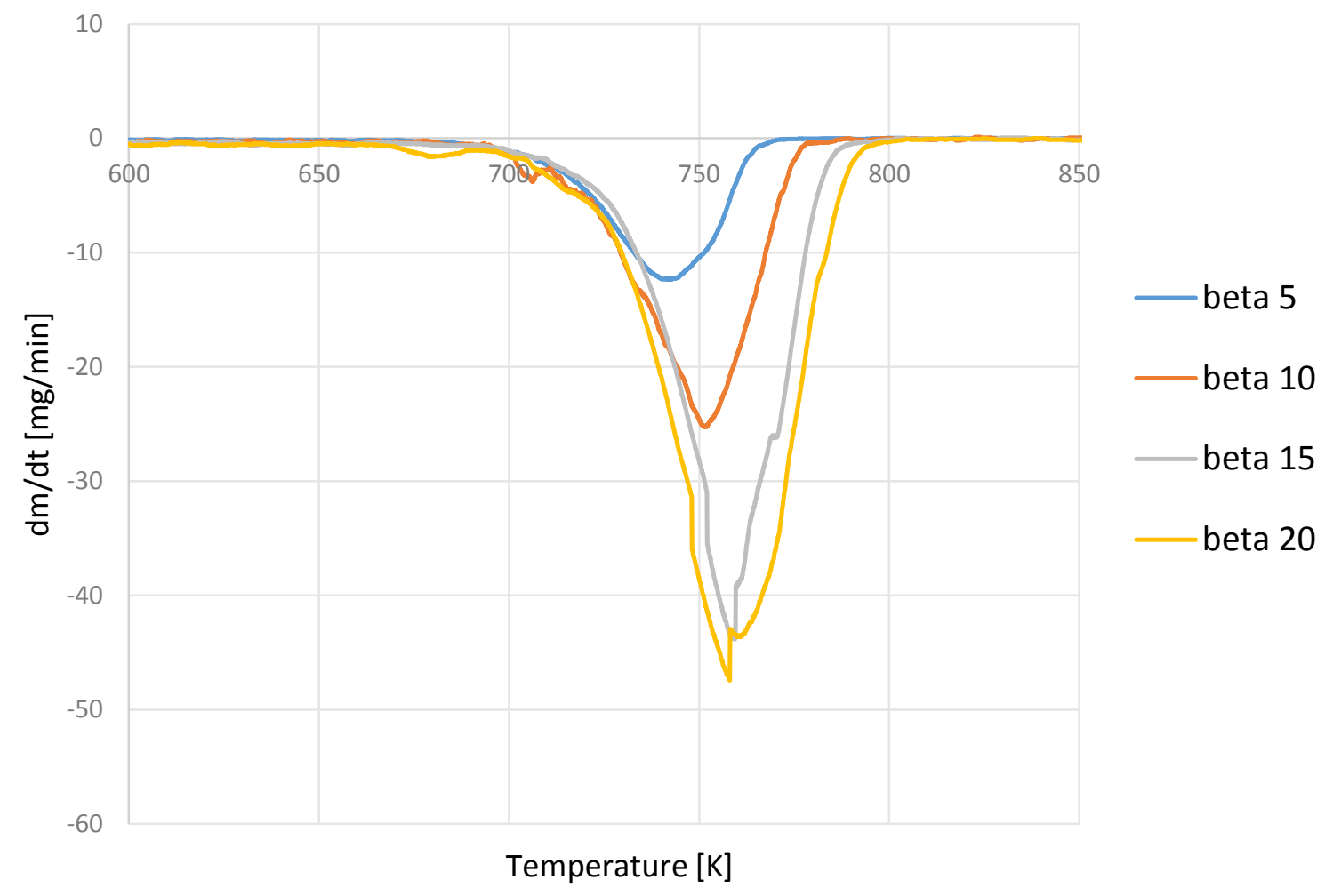

Figure 17: DTG curves of small microplastic at four heating rates

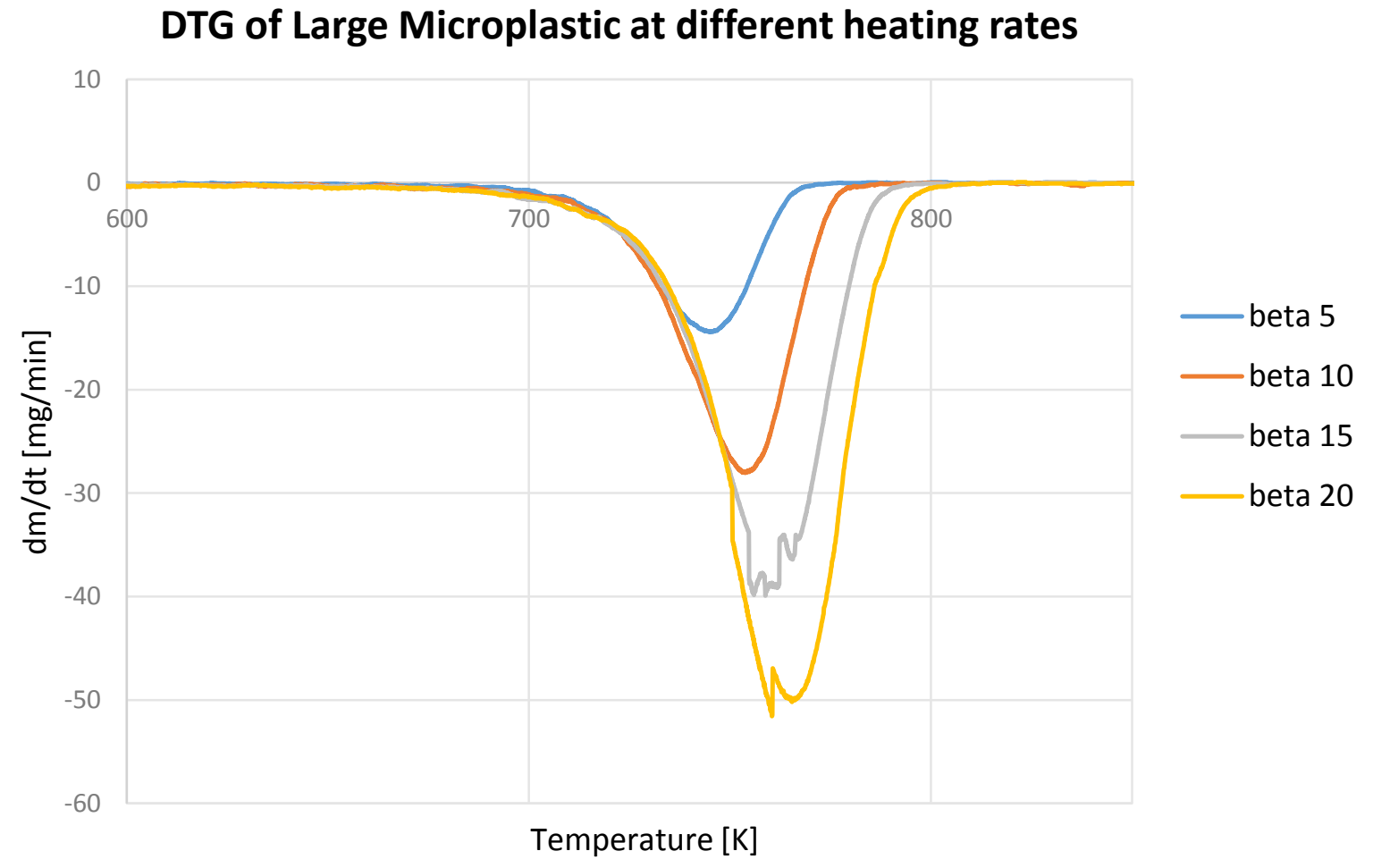

Figure 18: DTG curves of large microplastic at four heating rates

IVET-BOKU 
The DTG curve is the first derivation of the TG curve and thus demonstrates the mass change per time along the temperature program. When heating rate increases, starting and final temperature of pyrolysis region slightly also increase. Hence a higher heating rate permits a shorter time for the entire decomposition process but it starts and ends at a higher temperature level.

This phenomenon can be explained by means of the heat transition limit. At a low heating rate, it takes more time for the purge gas to heat up and to reach the equilibrium with the furnace or the sample, since a larger quantity of immediate thermal energy is provided. In this temperature range, one is faster with a higher heating rate, therefore has a shorter reaction time, but the temperature to be decomposed for the sample is also higher. This shifts the maximum rate curve to the right (QUAN et al.; 2009).

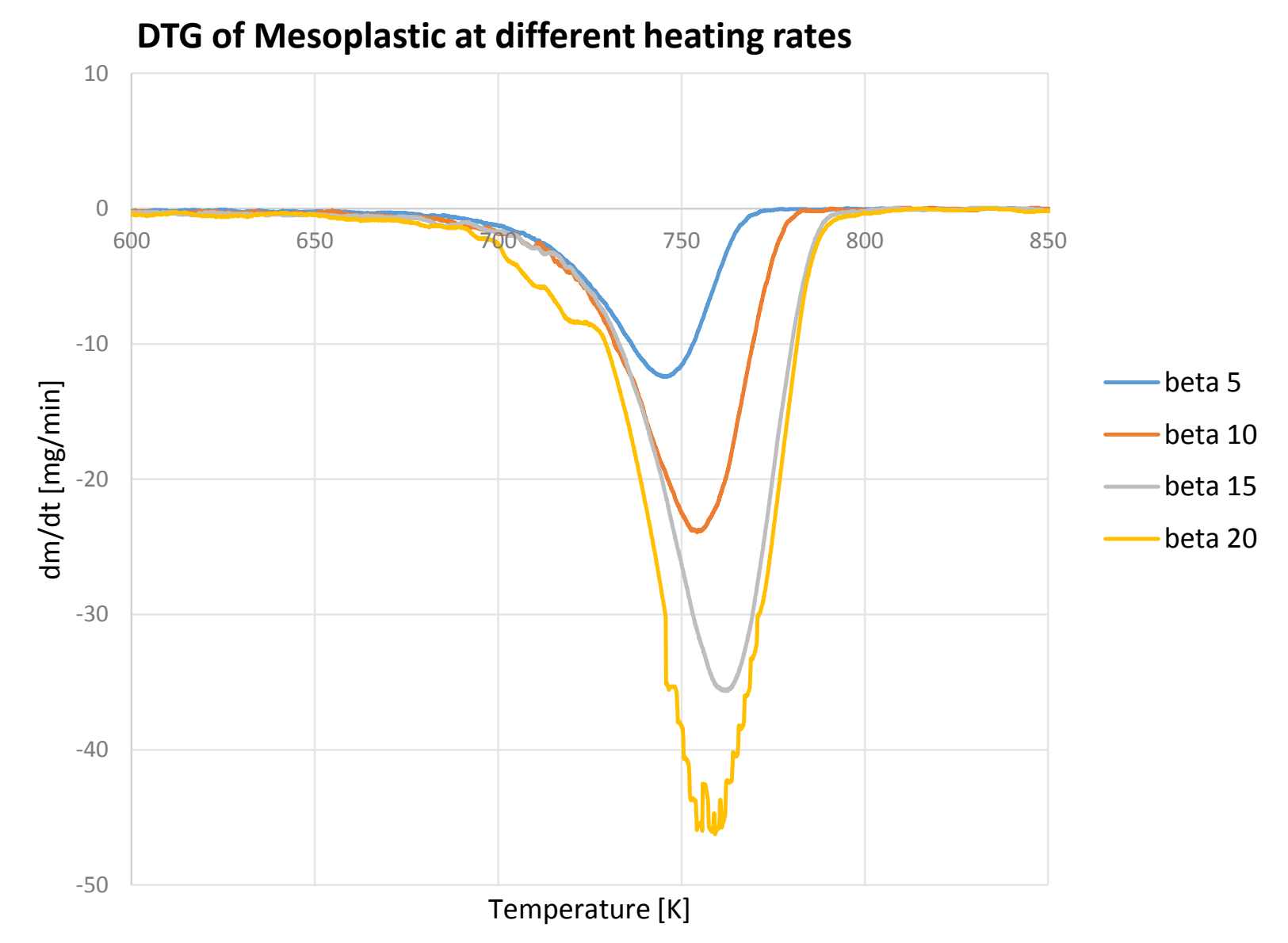

Figure 19: DTG curves of mesoplastic at four heating rates 
Compared with the pyrolysis of biomass, an increase of the heating rate, would lead also to an increase of the start and final temperature of active and passive pyrolysis region. The dehydration zone would demonstrate a great variation with change of heating rate (MISHRA and BHASKAR, 2014).

\subsection{Kinetic analysis}

The activation energy and pre-exponential factor (A) were obtained using isoconversional analysis methods based on the integral approach, namely the Kissinger-Akahira-Sunose method (KAS), Starink method and Flynn-Wall-Ozawa method (FWO).

First it is important to define the value of conversion, so an equivalent stage of the reaction for different heating rates as the activation energy is calculated for each conversion point (KHAWAM, 2007). This value of conversion, or the term "alpha" $(\propto)$, is calculated through the total weight loss (VYAZOVKIN et al., 2011) according equation 12 (chapter 4.1). The extent of conversion occurred in a wide spread from alpha 0.05 until 0.95 for all samples, as example shows Figure 18 the curve for mesoplastic. Therefore the selected values for alpha are: $0.05,0.15,0.25,0.35,0.45,0.55,0.65,0.75,0.85$ and 0.95 .

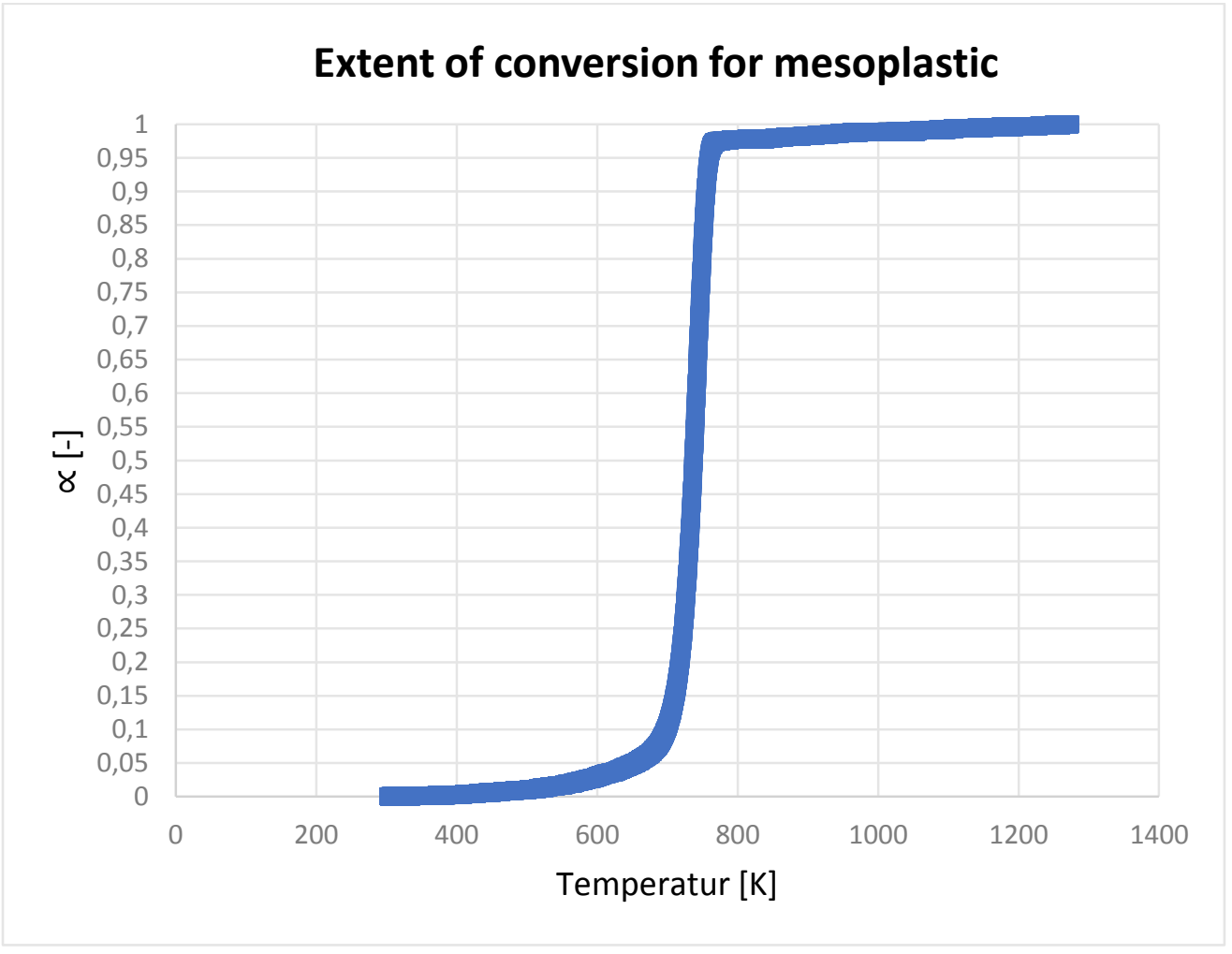

Figure 20: Extent of conversion for the degradation process for mesoplastic at heating rate $5 \mathrm{~K} / \mathrm{min}$ 
The apparent activation energies were obtained from the slope and pre-exponential factors from the intercept of regression line, as described in chapter 4 with the equation 24.

The regression lines for the KAS methods, thus the plot of $\ln \left(\beta / \mathrm{T}^{2}\right)$ versus $1000 / \mathrm{T}$ at different values of conversion for the class size small microplastic are shown in Figure 19. The similar regression lines of the two other methods, hence Starink method which plots $\ln \left(\beta / \mathrm{T}^{1.8}\right)$ versus $1000 /$ T and FWO methods of $\ln (\beta)$ versus $1000 / \mathrm{T}$ at different values of conversion are shown in Figure 20 and 21, respectively.

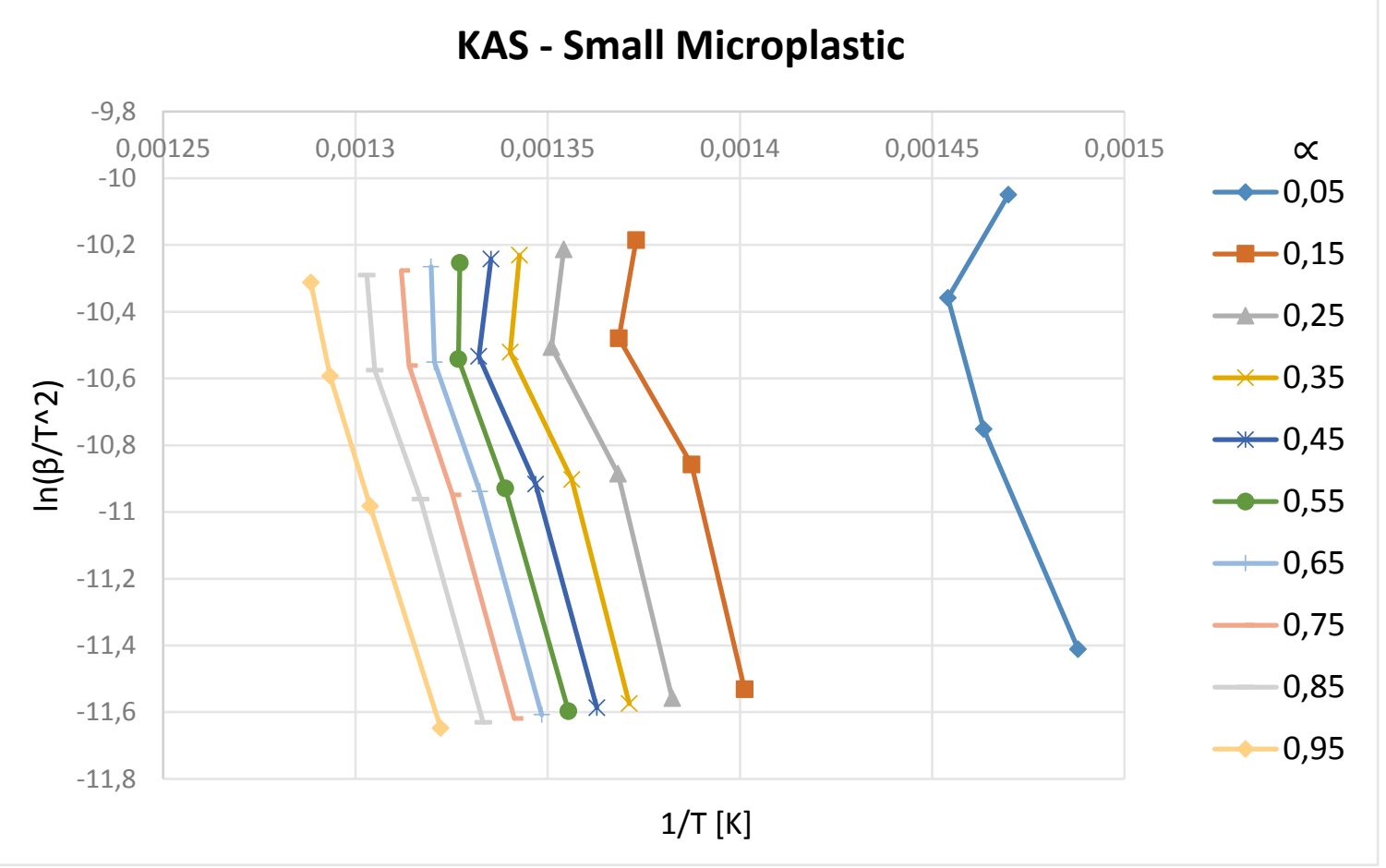

Figure 21: Regressionlines for KAS method for small microplastic

To obtain the required values, activation energy and pre-exceptional factors, slope and intercept were further calculated. For the activation energy the slope value was firstly multiplied with the gas constant and then divided through thousand to result in the unit kilojoule per mol. The Starink and the FWO method had to further divide the result through 1.0037 and 1.052 . 


\section{FWO - Small Microplastic}

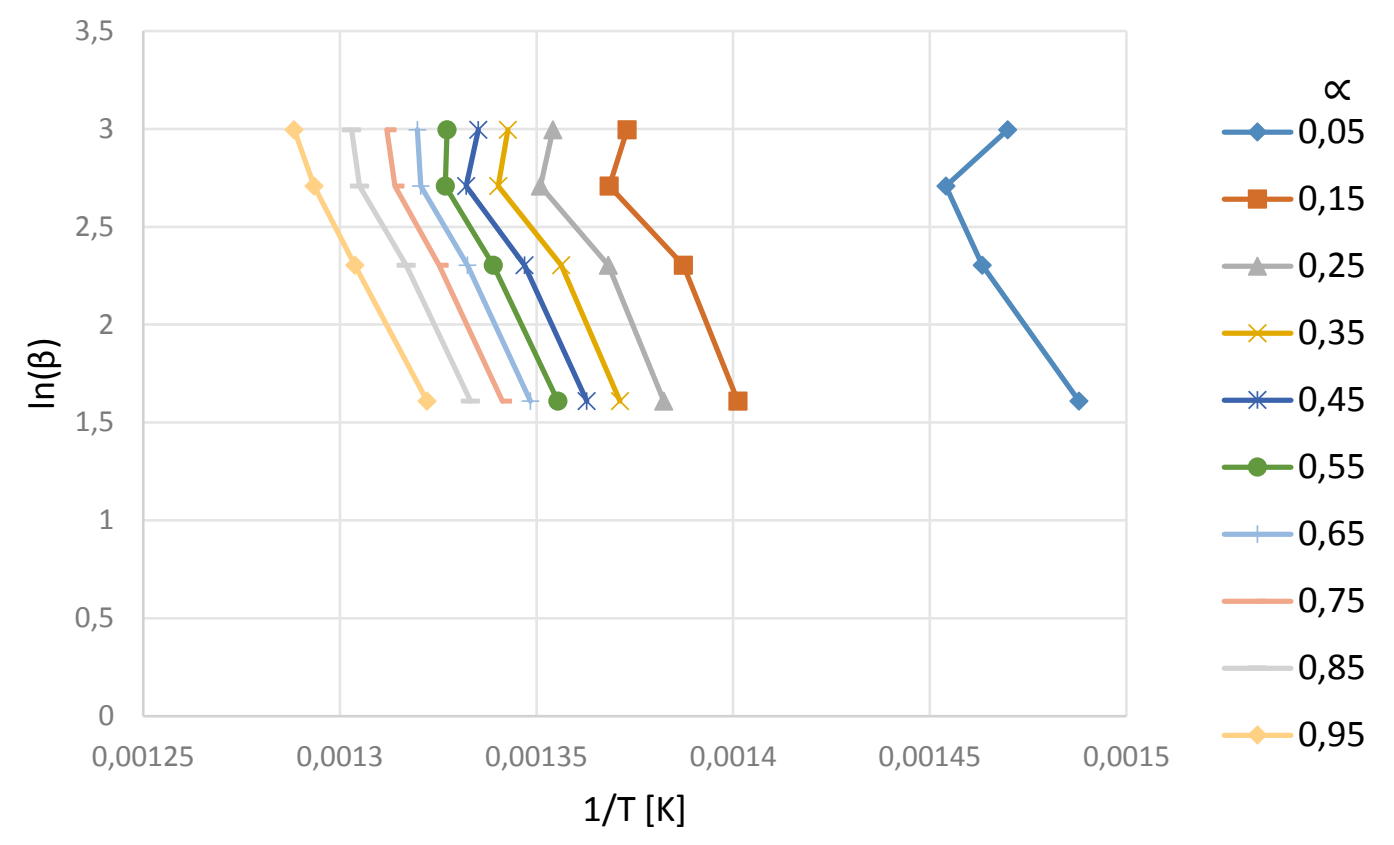

Figure 22: Regressionline for FWO method for small microplast

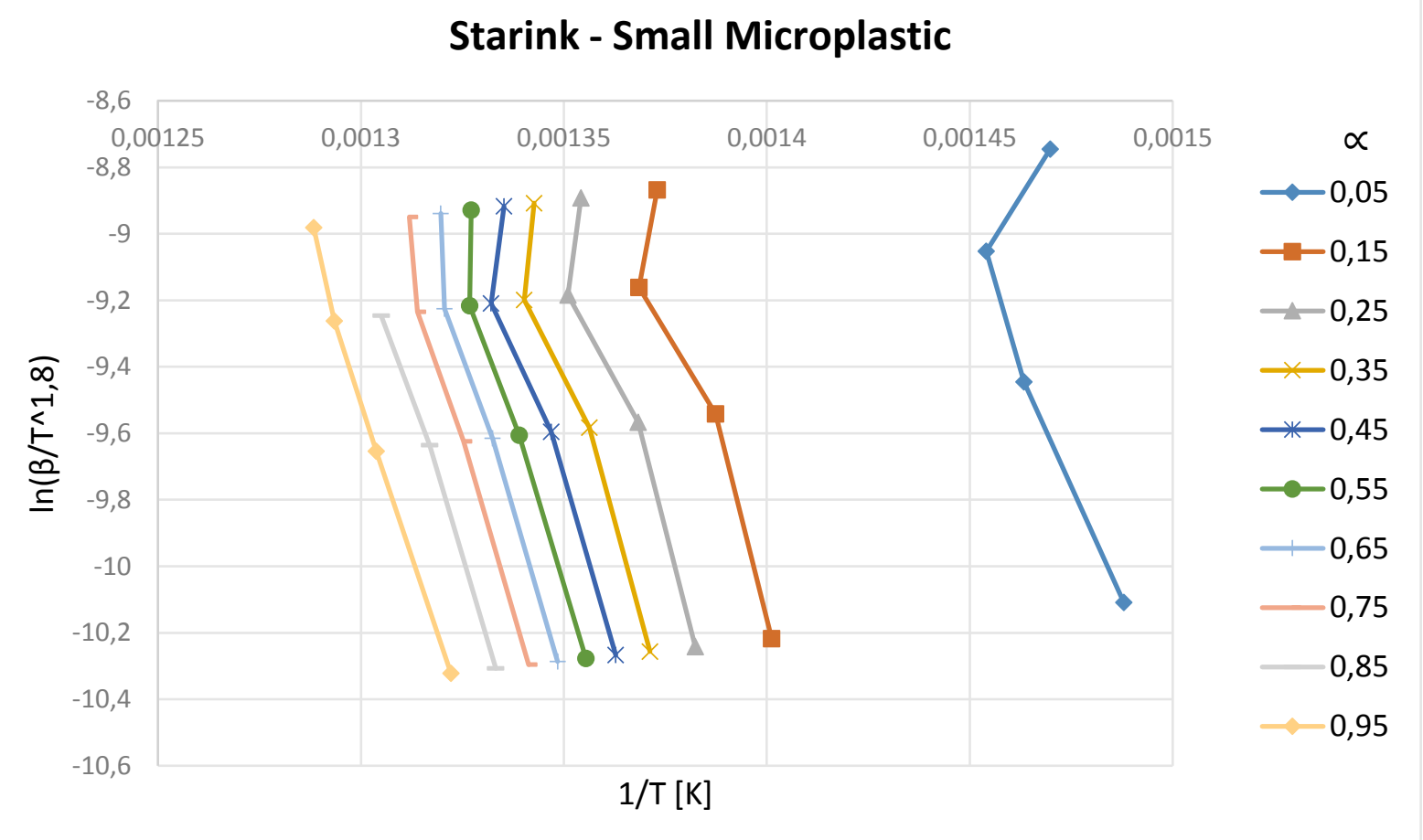

Figure 23: Regressionline for Starink method for small microplastic 
The intercept represented the variable $\mathrm{C}$ (chapter 3.) and was obtained by activating the equation towards $\mathrm{A}$. The function $\mathrm{g}(\alpha)$ was, according to other authors a first order reaction and therefore, solved with $g(\alpha)=-\ln (1-\alpha)$ (ENCINAR and GONZALEZ, 2007).

$\mathrm{R}^{2}$ represents the correlation coefficient and varies between 0 and 1. Zero means no correlation and one perfect correlation between the components $\mathrm{x}$ and $\mathrm{y}$. In other words the dependent variable $\mathrm{x}$, in this case the temperature at a certain conversion point, has a weak or strong influence on the independent variable $y$, in this case the logarithm of beta (or the left hand side of the above mentioned equations 24 chapter 4 ).

The values for the small microplastic can be observed in table 10 for the three different analysis methods. The value for alpha 0.05 showed a weak correlation, and a low value for the frequency factor (A) for all three analysis methods.

\begin{tabular}{|l|l|l|c|c|c|c|c|c|c|}
\hline $\begin{array}{c}\text { Small } \\
\text { Microplastic }\end{array}$ & \multicolumn{3}{|c|}{ KAS } & \multicolumn{3}{c|}{ Starink } & \multicolumn{3}{c|}{ FWO } \\
\hline Alpha & $\begin{array}{c}\mathrm{E} \\
(\mathrm{kJ} / \mathrm{mol})\end{array}$ & $\mathrm{A}\left(\mathrm{min}^{-1}\right)$ & $\mathrm{R}^{2}$ & $\begin{array}{c}\mathrm{E} \\
(\mathrm{kJ} / \mathrm{mol})\end{array}$ & $\mathrm{A}\left(\mathrm{min}^{-1}\right)$ & $\mathrm{R}^{2}$ & $\begin{array}{c}\mathrm{E} \\
(\mathrm{kJ} / \mathrm{mol})\end{array}$ & $\mathrm{A}\left(\mathrm{min}^{-1}\right)$ & $\mathrm{R}^{2}$ \\
\hline 0,05 & 239,96 & $9,08 \times 10^{16}$ & 0,494 & 240,20 & $4,09 \times 10^{17}$ & 0,496 & 238,84 & $3,74 \times 10^{14}$ & 0,517 \\
\hline 0,15 & 306,27 & $1,66 \times 10^{21}$ & 0,882 & 306,34 & $7,56 \times 10^{21}$ & 0,883 & 302,55 & $4,77 \times 10^{18}$ & 0,890 \\
\hline 0,25 & 319,73 & $1,37 \times 10^{22}$ & 0,906 & 319,76 & $6,26 \times 10^{22}$ & 0,906 & 315,49 & $3,72 \times 10^{19}$ & 0,912 \\
\hline 0,35 & 325,24 & $3,25 \times 10^{22}$ & 0,922 & 325,26 & $1,49 \times 10^{23}$ & 0,923 & 320,82 & $8,65 \times 10^{19}$ & 0,928 \\
\hline 0,45 & 332,24 & $1,02 \times 10^{23}$ & 0,913 & 332,24 & $4,66 \times 10^{23}$ & 0,914 & 327,54 & $2,63 \times 10^{20}$ & 0,919 \\
\hline 0,55 & 350,71 & $2,08 \times 10^{24}$ & 0,954 & 350,65 & $9,54 \times 10^{24}$ & 0,954 & 345,17 & $4,88 \times 10^{21}$ & 0,957 \\
\hline 0,65 & 354,53 & $3,78 \times 10^{24}$ & 0,969 & 354,46 & $1,73 \times 10^{25}$ & 0,970 & 348,85 & $8,78 \times 10^{21}$ & 0,971 \\
\hline 0,75 & 354,89 & $3,86 \times 10^{24}$ & 0,980 & 354,83 & $1,7710^{25}$ & 0,981 & 349,26 & $9,03 \times 10^{21}$ & 0,982 \\
\hline 0,85 & 343,65 & $5,91 \times 10^{23}$ & 0,980 & 343,64 & $2,72 \times 10^{24}$ & 0,980 & 338,65 & $1,49 \times 10^{21}$ & 0,981 \\
\hline 0,95 & 321,38 & $1,56 \times 10^{22}$ & 0,995 & 321,46 & $7,18 \times 10^{22}$ & 0,995 & 317,60 & $4,57 \times 10^{19}$ & 0,996 \\
\hline Average & 324,86 & $1,0510^{24}$ & 0,900 & 324,88 & $4,81 \times 10^{24}$ & 0,900 & 320,48 & $2,46 \times 10^{21}$ & 0,900 \\
\hline
\end{tabular}

Table 10: Result table for small microplastic for the analysis methods: KAS, Starink and FWO

The same approach was made made for the two other class size large microplastic as well as mesoplastic. The regression lines can be observed Figures $22-24$ for large microplastic and in Figures 25 - 27 for mesoplastic. The obtained values for the activation energy, pre-exponential factor and correlation coefficient are then in the tables below (see 11 and 12). Detailed values can be looked up in the Appendix. 


\section{KAS - Large Microplastic}

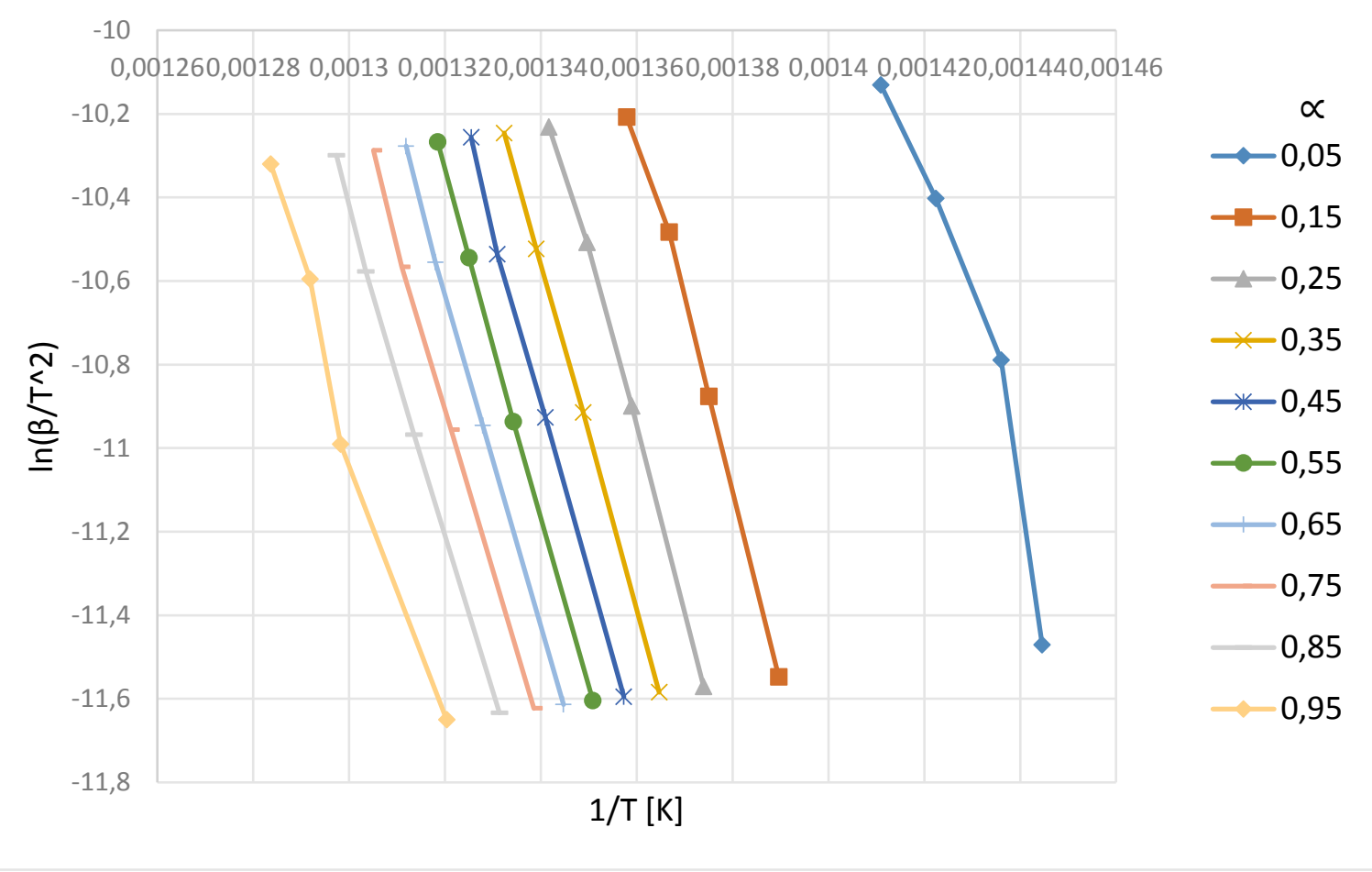

Figure 24: Regressionline for KAS method for large microplastic

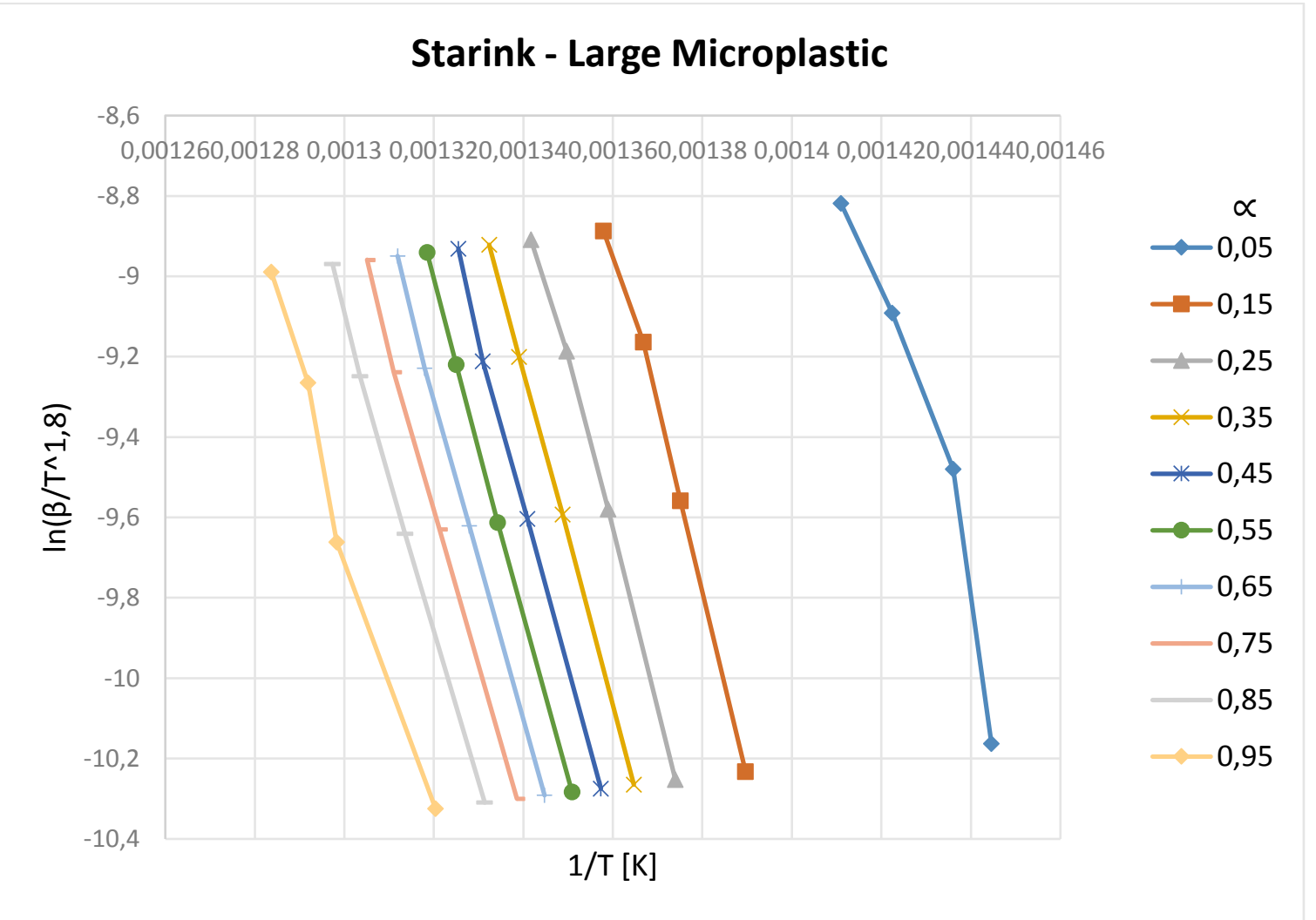

Figure 25: Regressionline for Starink method for large microplastic 


\section{FWO - Large Microplastic}

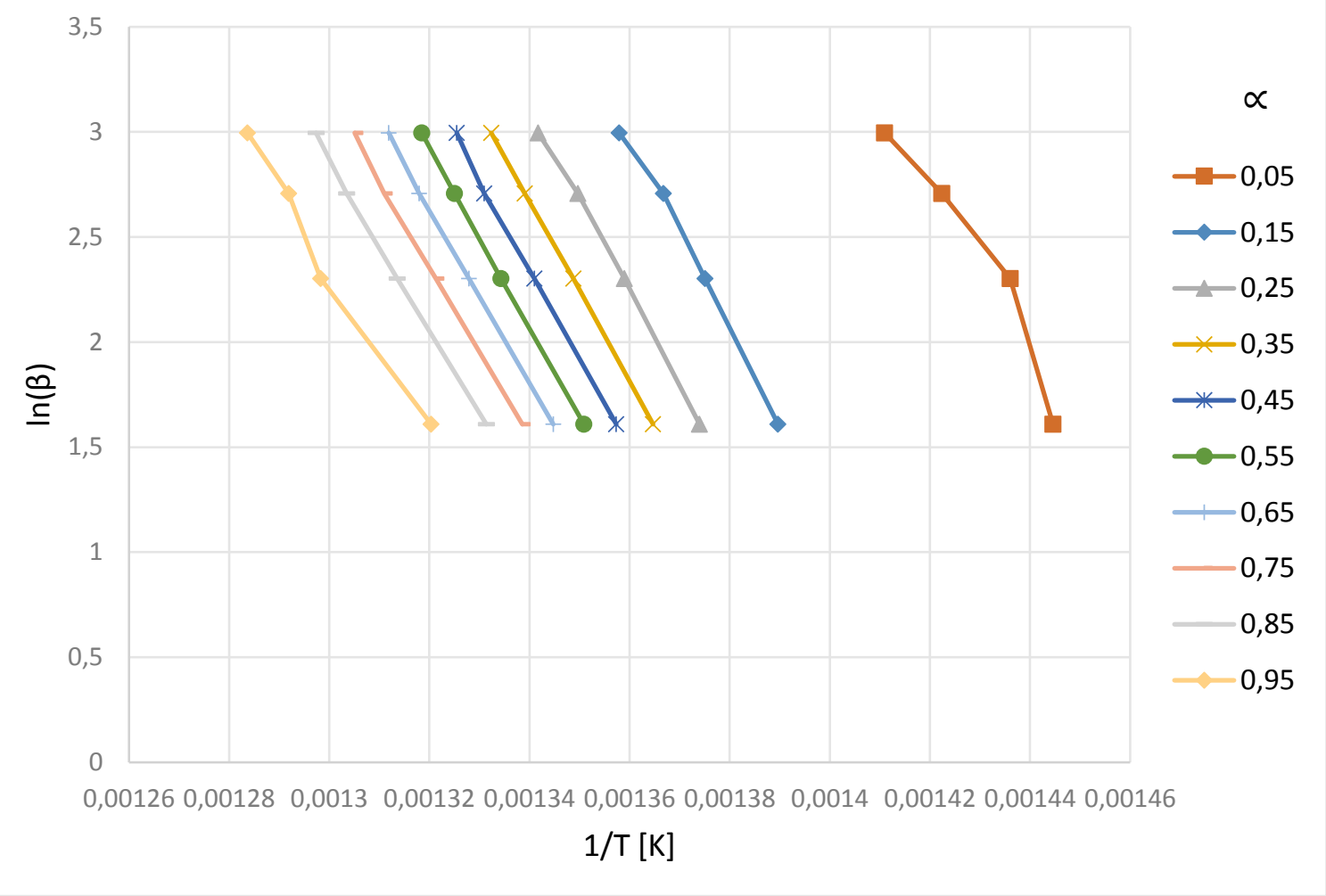

Figure 26: Regressionline for FWO method for large microplastic

\begin{tabular}{|l|c|c|c|c|c|c|c|c|c|}
\hline $\begin{array}{c}\text { Large } \\
\text { Micropl. }\end{array}$ & \multicolumn{3}{|c|}{ KAS } & \multicolumn{3}{c|}{ Starink } & \multicolumn{3}{c|}{ FWO } \\
\hline Alpha & $\begin{array}{c}\mathrm{E} \\
(\mathrm{kJ} / \mathrm{mol})\end{array}$ & $\mathrm{A}\left(\mathrm{min}^{-1}\right)$ & $\mathrm{R}^{2}$ & $\begin{array}{c}\mathrm{E} \\
(\mathrm{kJ} / \mathrm{mol})\end{array}$ & $\mathrm{A}\left(\mathrm{min}^{-1}\right)$ & $\mathrm{R}^{2}$ & $\begin{array}{c}\mathrm{E} \\
(\mathrm{kJ} / \mathrm{mol})\end{array}$ & $\mathrm{A}\left(\mathrm{min}^{-1}\right)$ & $\mathrm{R}^{2}$ \\
\hline 0,05 & 312,97 & $9,82 \times 10^{21}$ & 0,923 & 312,98 & $4,45 \times 10^{22}$ & 0,924 & 308,58 & $2,55 \times 10^{19}$ & 0,928 \\
\hline 0,15 & 357,06 & $5,73 \times 10^{24}$ & 0,993 & 356,95 & $2,61 \times 10^{25}$ & 0,993 & 350,91 & $1,24 \times 10^{22}$ & 0,994 \\
\hline 0,25 & 347,98 & $1,09 \times 10^{24}$ & 0,997 & 347,92 & $4,99 \times 10^{24}$ & 0,997 & 342,42 & $2,53 \times 10^{21}$ & 0,998 \\
\hline 0,35 & 343,89 & $5,43 \times 10^{24}$ & 1,000 & 343,84 & $2,49 \times 10^{24}$ & 1,000 & 338,60 & $1,31 \times 10^{21}$ & 1,000 \\
\hline 0,45 & 344,59 & $6,12 \times 10^{23}$ & 0,999 & 344,56 & $2,81 \times 10^{24}$ & 0,999 & 339,34 & $1,49 \times 10^{21}$ & 0,999 \\
\hline 0,55 & 343,09 & $4,84 \times 10^{23}$ & 1,000 & 343,07 & $2,22 \times 10^{24}$ & 1,000 & 337,97 & $1,20 \times 10^{21}$ & 1,000 \\
\hline 0,65 & 335,87 & $1,49 \times 10^{23}$ & 0,999 & 335,88 & $6,84 \times 10^{23}$ & 0,999 & 331,16 & $3,88 \times 10^{20}$ & 0,999 \\
\hline 0,75 & 328,07 & $4,22 \times 10^{22}$ & 0,999 & 328,11 & $1,94 \times 10^{23}$ & 0,999 & 323,81 & $1,16 \times 10^{20}$ & 0,999 \\
\hline 0,85 & 323,37 & $1,99 \times 10^{22}$ & 0,999 & 323,44 & $9,17 \times 10^{22}$ & 0,999 & 319,41 & $5,70 \times 10^{19}$ & 0,999 \\
\hline 0,95 & 302,54 & $6,75 \times 10^{20}$ & 0,983 & 302,70 & $3,11 \times 10^{21}$ & 0,983 & 299,72 & $2,24 \times 10^{18}$ & 0,984 \\
\hline Average & 333,94 & $8,68 \times 10^{23}$ & 0,989 & 333,95 & $3,97 \times 10^{24}$ & 0,989 & 329,19 & $1,95 \times 10^{21}$ & 0,990 \\
\hline
\end{tabular}

Table 11: Result table for large microplastic for the analysis methods: KAS, Starink and FWO 


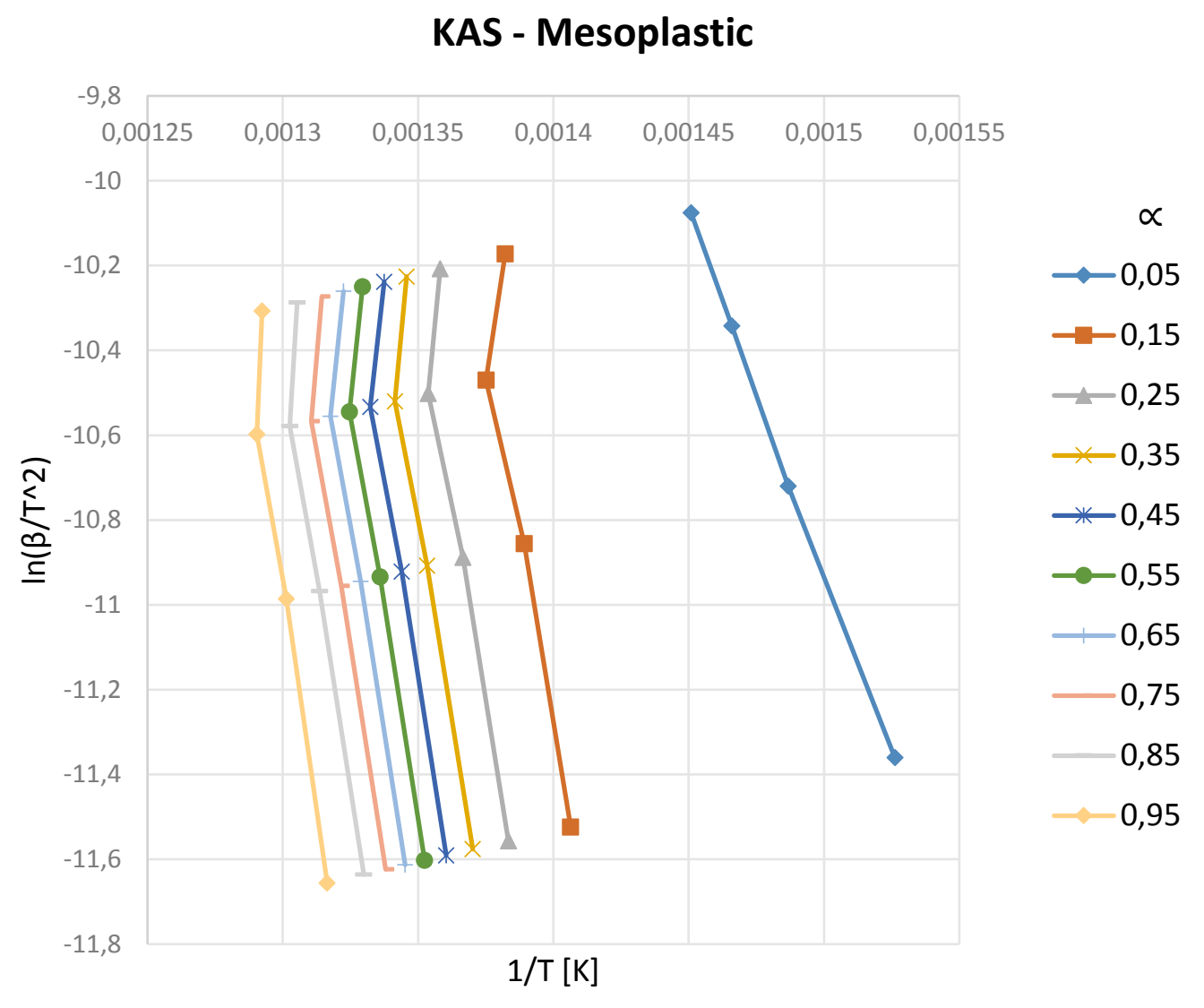

Figure 27: Regressionline for KAS method for mesoplastic

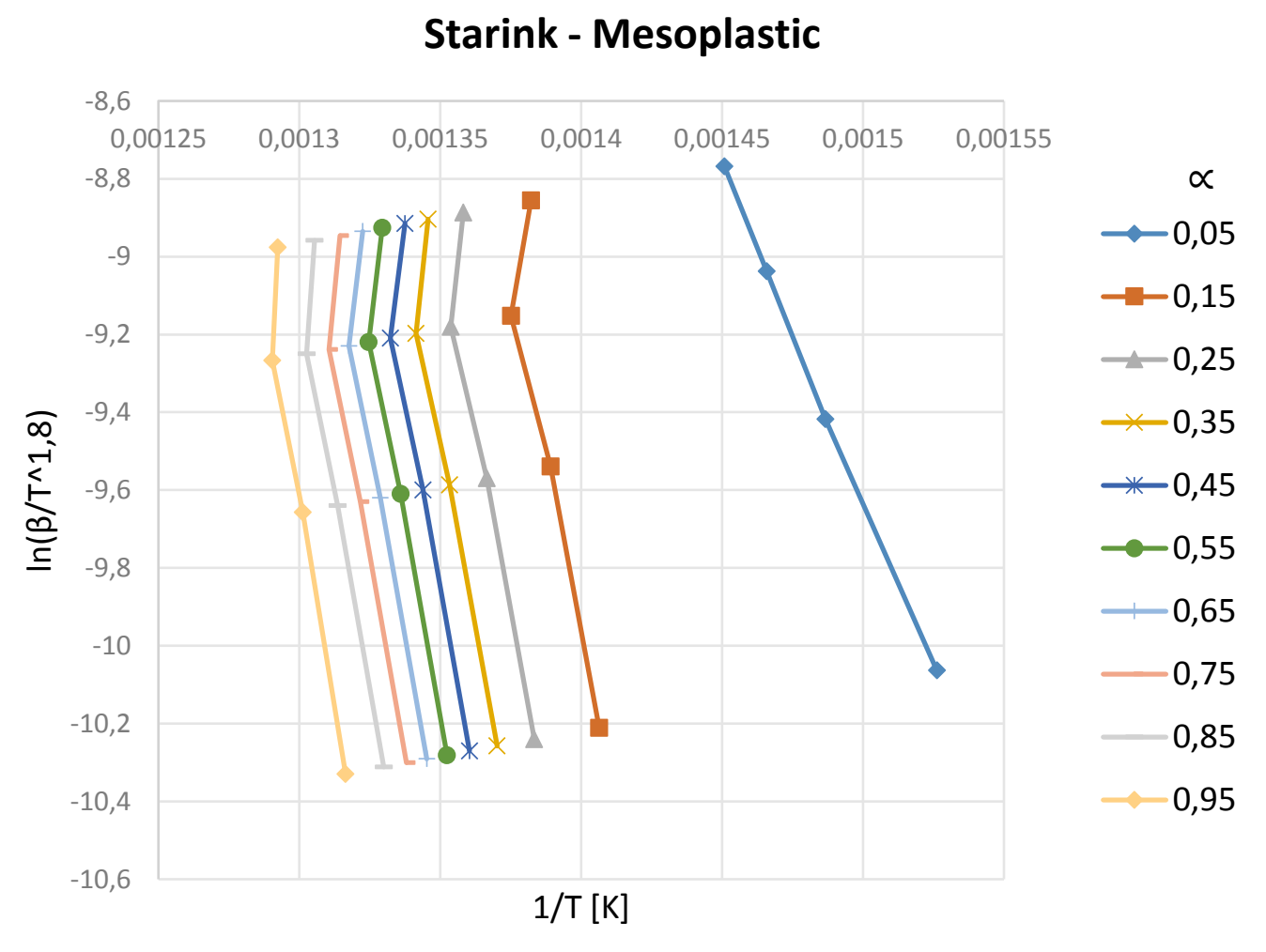

Figure 28: Regressionline for Starink method for mesoplastic 


\section{FWO - Mesoplastic}

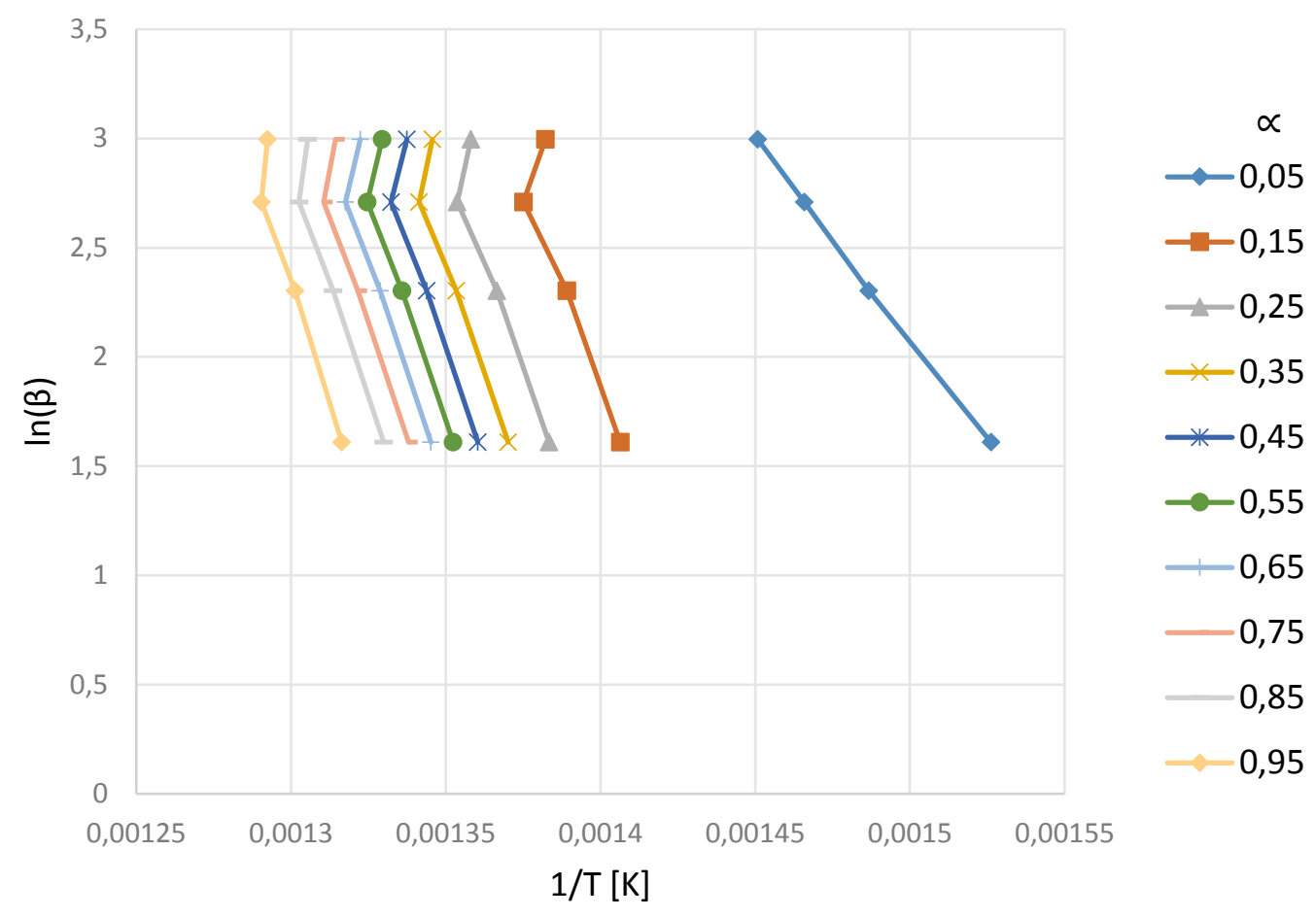

Figure 29: Regressionline for FWO method for mesoplastic

\begin{tabular}{|l|c|c|c|c|c|c|c|c|c|}
\hline $\begin{array}{c}\text { Meso- } \\
\text { plastic }\end{array}$ & \multicolumn{3}{|c|}{ KAS } & \multicolumn{3}{c|}{ Starink } & \multicolumn{3}{c|}{ FWO } \\
\hline Alpha & $\begin{array}{c}\mathrm{E} \\
(\mathrm{kJ} / \mathrm{mol})\end{array}$ & $\mathrm{A}\left(\mathrm{min}^{-1}\right)$ & $\mathrm{R}^{2}$ & $\begin{array}{c}\mathrm{E} \\
(\mathrm{kJ} / \mathrm{mol})\end{array}$ & $\mathrm{A}\left(\mathrm{min}^{-1}\right)$ & $\mathrm{R}^{2}$ & $\begin{array}{c}\mathrm{E} \\
(\mathrm{kJ} / \mathrm{mol})\end{array}$ & $\mathrm{A}\left(\mathrm{min}^{-1}\right)$ & $\mathrm{R}^{2}$ \\
\hline 0,05 & 141,73 & $2,00 \times 10^{10}$ & 0,999 & 142,32 & $9,04 \times 10^{9}$ & 0,999 & 145,33 & $2,24 \times 10^{7}$ & 0,999 \\
\hline 0,15 & 328,36 & $8,83 \times 10^{22}$ & 0,825 & 328,35 & $4,02 \times 10^{23}$ & 0,826 & 323,49 & $2,19 \times 10^{20}$ & 0,835 \\
\hline 0,25 & 348,36 & $1,74 \times 10^{24}$ & 0,881 & 348,87 & $7,96 \times 10^{24}$ & 0,882 & 342,68 & $3,98 \times 10^{21}$ & 0,888 \\
\hline 0,35 & 358,59 & $8,16 \times 10^{24}$ & 0,879 & 358,49 & $3,73 \times 10^{25}$ & 0,879 & 352,52 & $1,79 \times 10^{22}$ & 0,886 \\
\hline 0,45 & 367,73 & $3,38 \times 10^{25}$ & 0,854 & 367,60 & $1,55 \times 10^{26}$ & 0,855 & 361,28 & $7,15 \times 10^{22}$ & 0,862 \\
\hline 0,55 & 371,67 & $5,98 \times 10^{25}$ & 0,861 & 371,55 & $2,74 \times 10^{26}$ & 0,861 & 365,11 & $1,26 \times 10^{23}$ & 0,868 \\
\hline 0,65 & 373,74 & $7,94 \times 10^{25}$ & 0,858 & 373,61 & $3,65 \times 10^{26}$ & 0,859 & 367,14 & $1,66 \times 10^{23}$ & 0,866 \\
\hline 0,75 & 375,63 & $1,01 \times 10^{26}$ & 0,883 & 375,49 & $4,64 \times 10^{26}$ & 0,884 & 369,0 & $2,02 \times 10^{23}$ & 0,890 \\
\hline 0,85 & 375,42 & $9,08 \times 10^{25}$ & 0,909 & 375,29 & $4,18 \times 10^{26}$ & 0,909 & 368,87 & $1,93 \times 10^{23}$ & 0,914 \\
\hline 0,95 & 393,99 & $1,89 \times 10^{26}$ & 0,925 & 393,73 & $6,97 \times 10^{27}$ & 0,926 & 386,64 & $2,99 \times 10^{24}$ & 0,930 \\
\hline Average & 343,52 & $1,89 \times 10^{26}$ & 0,887 & 343,48 & $8,73 \times 10^{26}$ & 0,888 & 338,21 & $3,78 \times 10^{23}$ & 0,894 \\
\hline
\end{tabular}

Table 12: Result table for mesoplastic for the analysis methods: KAS, Starink and FWO

The apparent activation energy could be also described as the minimum of energy required to break chemical bonds between atoms. If the apparent activation energy has a high value, the reaction will be slow. Hence is a parameter for the reactivity and sensitivity of a reaction (GAI et al., 2013). The activation energy visualized in graphic can be seen in Figure 28 - 30 for the three different sizes classes calculated according the three different analysis methods. 


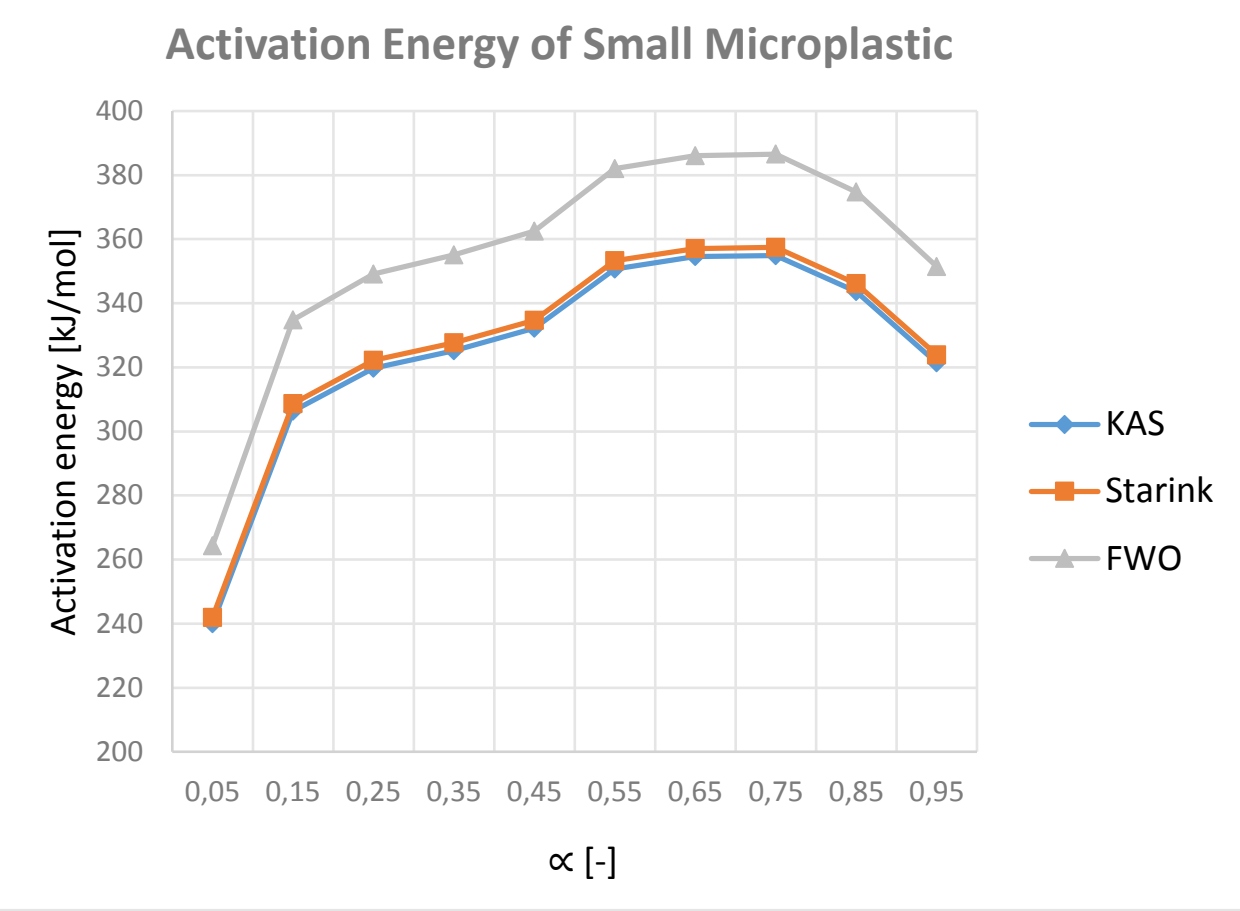

Figure 30: Activation energy of small microplastic according the KAS, Starink and FWO methods

All three size-classes showed in the average a similar trend. The value generated from the FWO method had the lowest activation energy value, the KAS method a higher value and Starink the slightly higher one than KAS. The small microplastic had averaged activation energy values between 320 - $325 \mathrm{~kJ} / \mathrm{mol}$, large microplastic between 329 - $334 \mathrm{~kJ} / \mathrm{mol}$ and mesoplastic 338 $-344 \mathrm{~kJ} / \mathrm{mol}$. Hence the values generated form the three different methods for each category differed only slightly. Small microplastic had the lowest average activation energy and mesoplastic the highest.

With increase of conversion from 0.05 to 0.95 the activation energy varied a lot. Different energy levels for different points of conversion means that pyrolysis proceeds with varied reaction mechanisms. It is therefore a complex multistep mechanism and the whole decomposition process and the activation energy is dependent on conversion (GAI et al., 2013).

All three selected categories had their lowest value for the activation energy for alpha 0.05 and the highest each at different conversion points. The values for the category small microplastic increased until alpha 0.75 , there they reached the highest value. On the contrary was the behaviour for large microplastic, because it had the highest activation energy at alpha 0.15 and the then dropped slowly. The size-class mesoplastic raised rapidly from 0.05 to 0.15 and grew slowly to the peak at alpha 0.95 . 
The correlation coefficient showed good values, means a strong relation between the components $\mathrm{x}$ and $\mathrm{y}$. The correlation coefficient lied between for small microplastic lied between 0,88 - 0,99 (besides for alpha 0,05 there the value was 0.5). The category large microplastic had values between $0,92-1$ and mesoplastic between $0,82-0,99$.

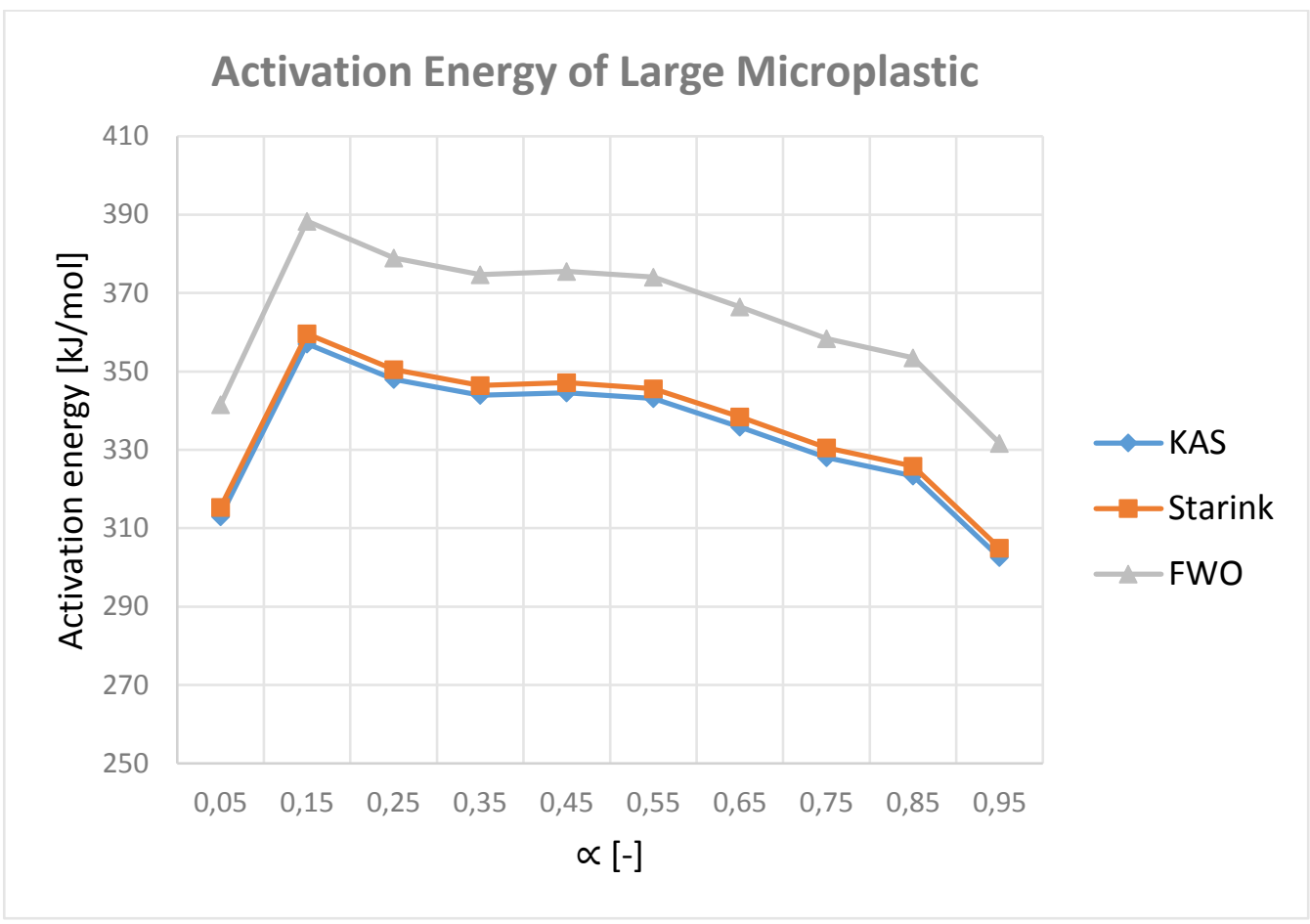

Figure 31: Activation energy of large microplastic according the KAS, Starink and FWO methods

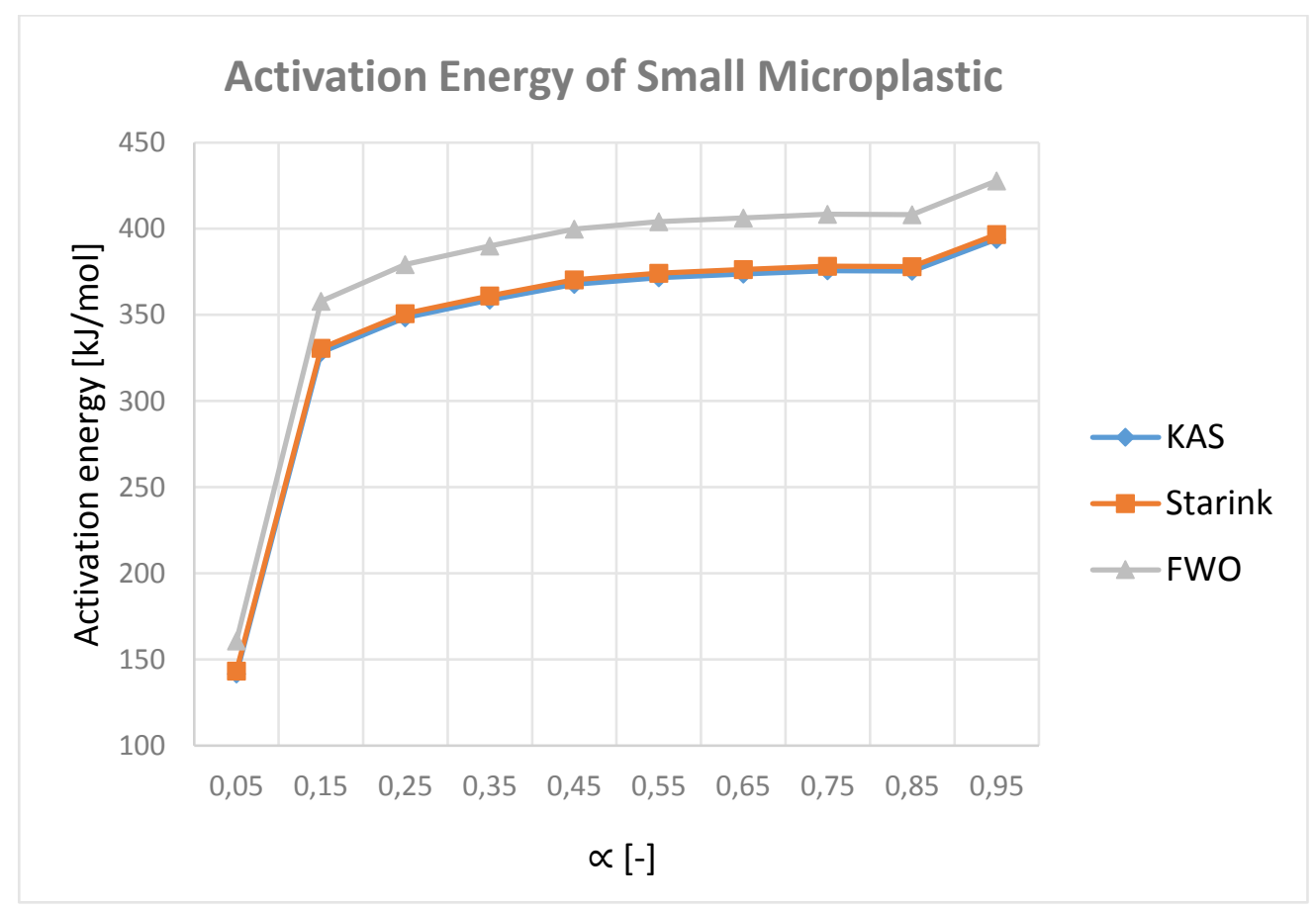

Figure 32: Activation energy of mesoplastic according the KAS, Starink and FWO methods 
The Arrhenius parameters for plastic, single and mixed, found in the literature were calculated from different methods and at different conditions. For marine plastic litter no paper could be found which made a thermogravemic analysis or calculated kinetic parameters.

ABOULKASA et al. (2010) exanimated individual plastic and calculated the activation energy after a pyrolysis process with the model-free kinetic methods according to KAS and FWO. They affirmed for LDPE (low density polyethylene) $215 \mathrm{~kJ} / \mathrm{mol}$ for KAS and $218 \mathrm{~kJ} / \mathrm{mol}$ for FWO, for HDPE (high density polyethylene) $238 \mathrm{~kJ} / \mathrm{mol}$ and $243 \mathrm{~kJ} / \mathrm{mol}$ and for PP, $179 \mathrm{~kJ} / \mathrm{mol}$ and $183 \mathrm{~kJ} / \mathrm{mol}$.

SAHA and GHOSHAL (2005) calculated the activation energy from waste soft drink bottles (PET) using n-th order model technique. The samples had a weight loss of $70-80 \%$ in the temperature range 653-788 $\mathrm{K}$ and the Coca Cola samples reached 322,3 kJ/mole and Pepsi bottles samples $338,98 \mathrm{~kJ} /$ mole for the activation energy.

CAI et al. (2007) had for HDPE an activation energy of $457.2 \mathrm{~kJ} / \mathrm{mol}$ and pre-exponential factor $3.5 \times 10^{30} \mathrm{~min}^{-1}$, LDPE $300.4 \mathrm{~kJ} / \mathrm{mol}, 2.2 \times 10^{20} \mathrm{~min}^{-1}$ and for PP $319.7 \mathrm{~kJ} / \mathrm{mol}, 5.9 \times 10^{21} \mathrm{~min}^{-1}$. ENCINAR and GONZALEZ (2007) pyrolized individual and recycled plastic at different heating rates and for heating rate $20 \mathrm{~K} / \mathrm{min}$ they observed for Polystyrene $175.2 \mathrm{~kJ} / \mathrm{mol}$ for the activation energy and $4,61 \times 10^{13}$ as pre-exponential factor, PET $223.7 \mathrm{~kJ} / \mathrm{mol}$ and $2.34 \times 10^{17}$, PP 218.5 , and $3.09 \times 10^{16}$ and recycled plastic 234.1 and $1.38 \times 10^{17}$.

The values vary strongly therefore it is not possible to say what kind of plastic dominated.

But generally the obtained values fit to the literature. But the marine litter consist not alone of plastic, but also of other material, mainly biomass.

When mixing biomass to the plastic it can be seen also as a co-pyrolysis, although the percentage is very flexible and not fixed. The synergetic effect between those two input materials is not yet clear. But their structural differences influences directly their structural breakdown (ÇEPELIOĞULLARA and PÜTÜN, 2013).

The degradation of the observed plastic is characterized through a radical initiation and a radical termination and the biomass component has a lower temperature decomposition compared with plastic (ZHOU et al., 2006). The required activation energy for plastic was higher also then for the biomass (ÇEPELIOĞULLARA and PÜTÜN, 2013).

Significant changes can be also observed in kinetic behaviour when mixing biomass and plastic feedstock. A study SURIAPPARAO et al. (2014) focuses on co-pyrolysis of cellulose and 
polypropylene (PP), former major component of biomass and later abundantly present in plastic waste. The activation energy, calculated according to Kissinger and Kissinger-Akahira-Sunose techniques, showed that the mixture indicated the presence of interaction between the two input materials. The presence of cellulose in the mixture decreased the apparent activation energy of PP decomposition (from 210 to $120 \mathrm{~kJ}$ mol-1). The presence of PP in the mixture did not affect the apparent activation energy of cellulose but shifted the char formation to higher temperatures and reduced the final char content (SURIAPPARAO et al., 2014).

Adjusting the parameters can control the desired product yield by pyrolysis. Those parameters are temperature, residence time, pressure and type of reactor as well as type of reaction gas with its flow rate. The temperature is the most critical parameter, as it has the strongest influence on the yield and depending on the chemical structure of the plastic type they decomposition temperature can differ (SHARUDDIN et al., 2016). 


\section{Conclusion}

Marine litter is a global problem that causes damage from Arctic to Antarctic, from plankton to whales, ultimately reaches people's attention. Already decades ago scientists reported this phenomenon and are predicting an ever-increasing amount of plastic debris in our marine environment. Many scientists, companies and other organizations are trying to find a solution to manage the existing as well as the future plastic debris in a sustainable way. The concept proposed in this thesis, to design a pyrolysis reactor, would be an interesting approach but still needs many further researches to realize this project.

The first step to approach such a project is to investigate the thermal behaviour and kinetic parameters, to know the required temperature as well as the residence time of the feedstock. The marine litter in the oceans contains more than $80 \%$ plastic and the most found types of plastic were PE, PP, PS, PET and PVC. The collected sample comprised certainly also those components but cannot be compared with individual, original plastic because it was set under different conditions like wave action or UV-light exposure. Papers published in the last decade divided the marine plastic litter into different size classes as the majority of marine litter contains of microplastic $(<5 \mathrm{~mm})$. Therefore the sample was sieved and separated into three different size classes, whereby two size classes represented the microplastic fraction (Small and large microplastic) and one the mesoplastic fraction.

The results obtained from the thermogravimetric analysis showed for all samples the same shape for the curve: single stage degradation in the temperature region $427-507^{\circ} \mathrm{C}(700-$ $780 \mathrm{~K})$ with most of the total weight loss (95\%). The DTG curve revealed a single peak, which shifted with heating rate. Therefore the starting and final temperature of pyrolysis region increased slightly with higher heating rates.

The Arrhenius parameters, the activation energy and pre-exponential factor, were obtained by model-free methods offered by KAS, Starink and FWO. The generated values by those three methods for a size class differed slightly. The FWO method had the lowest activation energy values and Starink method the slightly higher ones than KAS method. All three size-classes of plastic showed in the average value a same trend: small microplastic had an average activation energy between 320 - $325 \mathrm{~kJ} / \mathrm{mol}$, large microplastic between $329-334 \mathrm{~kJ} / \mathrm{mol}$ and mesoplastic $338-344 \mathrm{~kJ} / \mathrm{mol}$. 
Based on these results, thus high temperatures and short residence time, a flash pyrolysis reactor would be suitable. A flash pyrolysis process of mixed contaminated plastic produces a high amount of liquid oil, which can be directly used in several applications like furnaces, boilers and turbines. The gaseous and solid products can also be used, e.g. to compensate the overall energy requirement of the pyrolysis plant. By adjusting the parameters the product yield can be controlled, however the majority will be oil and to a less extent gas. If biomass is added to the feedstock the char formation will probably rise and the activation energy could decrease.

\section{Outlook}

Further research could contain the DSC signal, that measures the absorbed or released energy (HAMMER et al., 2013), which was also measured during the experiment and was not yet evaluated. Although the signal measured from a TGA/DSC coupling is not so sensitive, the combination has advantages. Furthermore was connected to the furnace a mass spectrometer and the off gas was analysed there. This data would offer a possible interpretation of the contained substances and how they overlap with those from the literature. Interesting would also be a pyrolysis test with other marine litter, like biomass. Also there would be significant to study the thermal behaviour and kinetic parameters. 


\section{References}

ABOULKASA, A.; EL HARFIA, K.; EL BOUADILIB, A. (2010): Thermal degradation behaviors of polyethylene and polypropylene. Part I: Pyrolysis kinetics and mechanisms. Energy Conversion and Management Volume 51, Issue 7: pp 1363-1369.

ABOYADE, A.O.; GORGENS, J.; MEER, E. KNOETZE, J. (2012): Thermogravimetic study of the pyrolysis characteristics and kinetics of coal blends with corn and sugarcane residue. Fuel Process. Technol. 106: pp 310-320.

ANDRADY, A. L. (2015): Persistence of plastic litter in the oceans. Marine anthropogenic litter, Springer, Berlin: pp. 57-72.

ALLSOPP, M.; WALTERS, A.; SANTILLO, D.; JOHNSTON, P. (2006): Plastic Debris in the World's Oceans, Greenpeace International.

BARNES, D. K. A., GALGANI, F., THOMPSON, R. C., \& BARLAZ, M. (2009): Accumulation and fragmentation of plastic debris in global environments. Philosophical Transactions of the Royal Society Series B, 364: pp 1985-1998.

BRIDGWATER, A.V., MEIER, D., RADLEIN, D. (1999): An overview of fast pyrolysis of biomass. Organic Geochemistry 30: pp 1479-1493

CAI, J.; WANG, Y.; ZHOU, L.; HUANG, Q. (2007): Thermogravimetric analysis and kinetics of coal/plastic blends during co-pyrolysis in nitrogen atmosphere. Fuel Processing Technology 89: pp 2127.

CARPENTER, E.J.; SMITH, K. L. (1972): Plastics on the Sargasso Sea Surface. Science Vol.175, Issue 4027: pp 1240-1241.

ÇEPELIOĞULLARA, Ö.; PÜTÜN, A.E. (2013): Thermal and kinetic behaviors of biomass and plastic wastes in co-pyrolysis. Energy Conversion and Management Volume 75: pp 263-270.

COLANTONI, S.; DELLA GATTA, S.; DE PROSPERIS R.; RUSSO A.; FANTOZZI F.; DESIDERI U. (2010): Gas turbines fired with biomass pyrolysis syngas, analysis of the overheating of hot gas path components. Journal of Engineering Gas Turbnes Power, Vol. 1132, No. 6.

DEMIRBAS, A. (2004): Pyrolysis of municipal plastic wastes for recovery of gasoline-range hydrocarbons. Journal of Analytical and Applied Pyrolysis 72: pp 97-102.

DI BLASI, C. (1996): Kintetic and Heat Transfer Contorol in the Slow and Flash Pyrolysis of Solids. Ind. Eng. Chem. Res. 35: pp 37-46.

DIE WELT (2016): Lübecker Schiff soll Ozeane von Plastikmüll säubern. Online:

https://www.welt.de/wissenschaft/article150548030/Luebecker-Schiff-soll-Ozeane-von-Plastikmuellsaeubern.html (06.12.2016).

DÜMICHEN, E.; BARTHEL, A.; BRAUN, U.; BANNICK, C.G.; BRAND, K. et al. (2015): Analysis of polyethylene microplastics in environmental samples, using a thermal decomposition method.

Water Research 85: pp $451-457$.

ENCINAR, J.M.; GONZALEZ, J.F. (2007): Pyrolysis of synthetic polymers and plastic waste. Kinetic study, Fuel Processing Technology 89: pp 678-686.

ENGLER, R. E. (2012): The complex Interaction between marine debris and toxic chemicals in the Ocean. Environmental Science and Technology 46: pp 12302-12315. 
ERIKSSEN, M.; LEBRETON, L. C. M.; CARSON, H. S.; THIEL, M.; MOORE, C. J. et al. (2014): Plastic pollution in the world's oceans: More than 5 trillion plastic pieces weighing over 250,000 tons afloat at sea. PLOS ONE 9 (12).

GAI, C.; DONG, Y.; ZHANG, T. (2013): The kinetic analysis of the pyrolysis of agricultural residue under non-isothermal conditions. Bioresource Technology 127: pp 298-305.

GALGANI, F.; HANKE, G.; MAES, T. (2015): Global Distriubution, Composition and Abudance of Marine Litter. Marine Anthropogenic Litter, Chapter 2: pp 29-56.

GALGANI, F. et al. (2010): Marine Strategy Framework Directive Task Group10. Report Marine litter. JCR Scientific and Technical Reports.

GALGANI, F.; HANKE, G.; WERNER, S.; OOSTERBAAN, L.; NILSSON, P.; FLEET, D.(2013): Monitoring guidance for marine litter in European Seas, JRC Scientific and Policy Reports: 120.

GOYAL, H.; SEAL, D.; SAXENA, R.; (2008): Bio-fuels from thermochemical conversion of renewable resources: A review. Renewable and sustainable Energy Reviews Vol 12, No 2: pp. $504-$ 517.

HAMMER, A. et al (2013): Thermal Analysis of Polymers - selceted applications, Handbook Mettler-Toledo AG, Switzerland.

HELLERICH, W.; HARSCH, G.; BAUR, E. (2010): Werkstoff-Führer Kunststoffe - Eigenschaften, Prüfungen, Kennwerte. Carl Hanser Verlag GmbH \& Co. KG, 10. Auflage

HIDALGO-RUZ, V.; GUTOW, L.; THOMPSON, R. C.; THIEL, M. (2012): Microplastics in the Marine Environment: A Review of the Methods Used for Identification and Quantification. Environmental Science \&Technology No. 46: pp. 3060-3075.

HOORNWEG, D.; BHADA-TATA, P. (2012): What a waste - a global review of solid waste management. The World Bank.

JAMBECK, J.R.; GEYER, R.; WILCOX, C.; SIEGLER, T.R.; PERRYMAN, M.; ANDRADY, A.; NARAYAN, R.; LAW, K. L. (2015): Plastic waste inputs from land into the ocean. Science Vol 347, Issue 6223: pp. 768-770.

KALTSCHMITT, M.; HARTMANN, H.; HOFBAUER, H. (2009): Energie aus Biomasse Grundlagen, Technken und Verfahren. 2. Auflage, Springer, Berlin.

KHAWAM, A. (2007): Application of solid state-kinetics to desolvation reactions. Iowa University Doctorial Thesis.

KOOI, M.; REISSER, J.; SLAT, B.; FERRARI, F.F.; SCHMID, M.S.; CUNSOLO, S. et al. (2016): The effect of particle properties on the depth profile of buoyant plastics in the ocean. Scientific Reports 6.

KUHN, S.; BRAVO REBOLLEDO E.L., VAN FRANEKER J.A. (2015): Deleterious effects of litter on marine life. Marine anthropogenic litter, Springer, Berli: pp 75-116.

LIDLER, K. (1970): Reaktionskinetik 1 - Homogene Gasreaktionen. Bibliographisches Institut AG, Mannheim.

LEBRETON, L.; GREER, S.; BORRERO, J. C. (2012): Numerical modelling of floating debris in the world's oceans. Marine Pollution Bulletin 64: pp 653-661. 
MACGRANAHAN, G.; BALK, D.; ANDERSON, B. (2007): The rising tide: Assessing the risks of climate change and human settlements in low elevation coastal zones. Environment and Urbanization, 19: pp 17-37.

MARTENS, H. (2011): Recyclingtechnik - Fachbuch für Lehre und Praxis. Spektrum Akademsicher Verlag Heidelberg: pp. 42-43, 192-196.

MARTENS, H.; GOLDMANN, D. (2016): Recyclingtechnik - Fachbuch für Lehre und Praxis. 2. Auflage, Springer Verlag, Berlin.

MEWES, D.; TOKARZ, A. (2000): Nutzung von Abfällen durch Stoff- und Energieumwandlung. Wiesbanden, 1. Auflage.

MISHRA, G.; BHASKAR, T. (2014): Non isothermal model free kinetics for pyrolysis of rice straw. Bioresource Technology 169: pp 614-621.

MORÉT-FERGUSON, S.; LAW, K.L.; PROSKUROWSKI, G.; MURPHY, E.K.; PEACOCK, E.E.; REDDY, C.M. (2010): The size, mass, and composition of plastic debris in the western North Atlantic Ocean. Marine Pollution Bulletin 60.

MOSTBAUER, P. (2016): Chemie und Untersuchung von Abfällen - Probenahme und Probenaufbereitung. Universität für Bodenkultur Wien, Department für Wasser, Atmosphäre und Umwelt, Institut für Abfallwirtschaft.

OCEAN CONSERVANCY (2016): Ocean Convervancy. Online: http://www.oceanconservancy.org (25.11.2016).

PHAM, C. K.; RAMIREZ-LLODRA, E.; ALT, C. H. S.; AMARO, T.; BERGMANN, M.; CANALS, M., et al. (2014): Marine litter distribution and density in European Seas, from the shelves to deep basins. PLOS ONE 9.

RAIN, N. (2012): Flotsam-spotting: Elie Ahovi's Marine Drone, Like a Roomba for Ocean Garbage. Core77. Online: http://www.core77.com/posts/22902/flotsam-spotting-elie-ahovis-marine-drone-likea-roomba-for-ocean-garbage-22902 (06.12.2016).

RIESEN, R. (2007): Wahl der Basislinien, UserCom 1, Mettler Toledo: pp 1-6.

RYAN, P. G., MOORE, C. J., VANFRANEKER, J. A., \& MOLONEY, C. L. (2009): Monitoring the abundance of plastic debris in the marine environment, Philosophical Transactions of the Royal Society B, 364 (1526): pp 1999-2012.

SAHA, B.; GHOSHAL, A.K. (2005): Thermal degradation kinetics of poly(ethylene terephthalate) from waste soft drinks bottles. Chemical Engineering Journal 111: pp 39-43.

SAHA, B.; GHOSHAL, A.K. (2006): Model-free kinetics analysis of waste PE sample. Thermochimica Acta 451: pp 27-33.

SBIRRAZZUOLI, N. (2007): Is the Friedman Method applicable to transformations with temperature dependent reaction heat? Macromol. Chem. Phys. 208: pp1592-1597.

SCHAWE, J., RIESEN, R., WIDMANN, J., SCHUBNELL, M., JÖRIMANN, U. (2000): DSCKurven interpretieren - Teil 1: Dynamische Messungen. UserCom 1, Mettler Toledo: pp 1-7.

SCHUBNELL, M. (2005): Methodenentwicklung in der thermischen Analyse: Teil 1, UserCom1, Mettler Toledo: pp 1-4.

SHARUDDIN, S.D.A.; ABNISA, F.; DAUD, W. M. A. W.; AROUA, M. K. (2016): A review on pyrolysis of plastic wastes. Energy Conversion and Management 115: pp 308-326. 
SHEAVLY, S.B.; REGISTER, K.M. (2007): Marine Debris \& Plastics: Environmental Concerns, Sources, Impacts and Solutions. Journal of Polymers and the Environment 15: 301-305.

SINGH, N.; HUI, D.; SINGH, R.; AHUJA, I.P.S.; FEO, L.; FRATERNALI, F. (2016): Recycling of plastic solid waste: A state of art review and future Applications, Elsevier Composites Part B.

SLOPIECA, K.; BARTOCCI, P.; FANTOZZI, F. (2011): Thermogravimetric analysis and kinetic study of poplar wood pyrolysis. University of Perugia, CRB-Biomass Research Centre, Third international conference on applied Energy, pp.1688-1698.

SMITH, S. D. A.; MARKIC, A. (2013): Estimates of marine debris accumulation on beaches are strongly affected by the temporal scale of sampling. PLOS One, 8(12).

SURIAPPARAO, D.V.; KUMAR,D.; TANUMOY, O.; VINU, R. (2014): Kinetic analysis of copyrolysis of cellulose and polypropylene. Journal of Thermal analysis and Calorimetry Volume 117, Issue 3: pp 1441.

STARINK, M.J. (2003): The determination of activation energy from linear heating rate experiments: a comparison of the accuracy of isoconversion methods. Thermochimica Acta 404: pp. 163-176.

THE OCEAN CLEAN UP (2016): The Ocean Clean up. Online: https://www.theoceancleanup.com (25.11.2016).

THOMPSON, R. C. (2015): Microplastics in the marine environment: Sources, consequences and solutions. Marine anthropogenic litter: pp. 185-200.

TIMROTT, J. (2015): Strandgut aus Plastik und anderer Meeresmüll. Kiel, Hamburg: Wachholz Verlag, ISBN: 9783529054563, p 8.

QUAN, C.; Li, A.; Gao, N. (2009): Thermogravimetric analysis and kinetic study on large particles of printed circuit board wastes. Waste Management, Vol.29, No 8: pp 1041-1048.

QUATRA, K. (2014): Dyson will mit einem riesigen Staubsauger Flüsse und Küsten von Müll befreien. Motherboard Online: http://motherboard.vice.com/de/read/dyson-will-mit-einem-riesigenstaubsauger-fluesse-und-kuesten-von-muell-befreien (06.12.2016)

UNEP (2016): Marine plastic debris and microplastics - Global lessons and research to inspire action and guide policy change. United Nations Environment Programme, Nairobi.

UNEP (2015): Marine Litter Assessment in the Mediterranean. United Nations Environment Programme, Nairobi. https://wedocs.unep.org/rest/bitstreams/9739/retrieve

VENRICK, E. L.; BACKMAN, T. W.; BARTRAM, W. C.; PLATT, C. J.; THORNHILL, M. S.,; YATES, R. E. (1972): Man-made objects on the surface of the Central North Pacific Ocean. Nature, $241,271$.

VYAZOVKIN, S. (2000): Computational aspects of kinetic analysis. Part C. The ICTAC kinetic project - light at the end of the tunnel?. Thermovhim. Acta 355: pp 155-163

VYAZOVKIN, S.; BURNHAM, A.; CRIADO, J.; MAQUEDA, L.; POPESCU, C.; SBIRRAZZUOLI, N. (2011): ICTAC Kinetics Committee recommendations for performing kinetic computations on thermal analysis data. Thermochim. Acta 520: pp1-19.

VYAZOVKIN, S.; SBIRRAZZUOLI, N. (2006): Isoconversional kinetic analysis of thermally stimulated processes in polymers. Macromol. Papid Commun. 27: pp 1515-1532.

VYAZOVKIN, S.; WIGHT, C. (1999): Model-free and model-fitting approaches to kinetic analysis of isothermal and nonisothermal data. Thermochim. Acta: pp $340-341,53-68$. 
WEARDEN, G. (2016): More plastic than fish in the sea by 2050, says Ellen MacArthur. The guardian, Online: https://www.theguardian.com/business/2016/jan/19/more-plastic-than-fish-in-thesea-by-2050-warns-ellen-macarthur (07.12.2016).

WIDMANN, G (2001): Interpretation von TGA-Kurven. UserCom 1, Mettler Toledo:pp 1-4

WOJCIECHOWSKI, B.W.; RICE, N.M. (2003): Experimental Methods in Kinetic Studies, Elsevier Science B.V.

ZHOU, L.; WANG, Y.; HUANG, Q.; CAI, J. (2006): Thermogravimetric characteristics and kinetic of plastic and biomass blends co-pyrolysis. Fuel Processing Technology 87: 963-969. 


\section{Annex}

\section{Calculations for Small Microplastic}

Values for beta and the corresponding value for alpha.

\begin{tabular}{|c|c|c|c|c|c|c|c|c|c|c|c|}
\hline beta/alpha & 0,05 & 0,15 & 0,25 & 0,35 & 0,45 & 0,55 & 0,65 & 0,75 & 0,85 & 0,95 & Average \\
\hline 5 & 0,0015 & 0,0014 & 0,0014 & 0,0014 & 0,0014 & 0,0014 & 0,0013 & 0,0013 & 0,0013 & 0,0013 & \\
\hline 10 & 0,0015 & 0,0014 & 0,0014 & 0,0014 & 0,0013 & 0,0013 & 0,0013 & 0,0013 & 0,0013 & 0,0013 & \\
\hline 15 & 0,0015 & 0,0014 & 0,0014 & 0,0013 & 0,0013 & 0,0013 & 0,0013 & 0,0013 & 0,0013 & 0,0013 & \\
\hline 20 & 0,0015 & 0,0014 & 0,0014 & 0,0013 & 0,0013 & 0,0013 & 0,0013 & 0,0013 & 0,0013 & 0,0013 & \\
\hline 8,31447 & & & & & & & & & & & \\
\hline$g(\alpha)=-\ln (1-\alpha)$ & 0,05 & 0,16 & 0,29 & 0,43 & 0,60 & 0,80 & 1,05 & 1,39 & 1,90 & 3,00 & \\
\hline
\end{tabular}

Kissinger Akahira and Sunose method

\begin{tabular}{|c|c|c|c|c|c|c|c|c|c|c|c|}
\hline \multirow[b]{2}{*}{$\ln \left(\beta / T^{\wedge} 2\right)$} & \multicolumn{10}{|c|}{ KAS } & \\
\hline & & & & & & & & & & & \\
\hline 5 & $-11,41$ & $-11,53$ & $-11,56$ & $-11,57$ & $-11,59$ & $-11,60$ & $-11,61$ & $-11,62$ & $-11,63$ & $-11,65$ & \\
\hline 10 & $-10,75$ & $-10,86$ & $-10,89$ & $-10,90$ & $-10,92$ & $-10,93$ & $-10,94$ & $-10,95$ & $-10,96$ & $-10,98$ & \\
\hline 15 & $-10,36$ & $-10,48$ & $-10,51$ & $-10,52$ & $-10,53$ & $-10,54$ & $-10,55$ & $-10,56$ & $-10,58$ & $-10,59$ & \\
\hline 20 & $-10,05$ & $-10,19$ & $-10,21$ & $-10,23$ & $-10,24$ & $-10,25$ & $-10,26$ & $-10,28$ & $-10,29$ & $-10,31$ & \\
\hline$E / R(J)$ & $-28860,00$ & $-36836,00$ & $-38455,00$ & $-39117,00$ & $-39959,00$ & $-42181,00$ & $-42640,00$ & $-42683,00$ & $-41331,00$ & $-38653,00$ & \\
\hline$E(J)$ & 239955,60 & 306271,82 & 319732,94 & 325237,12 & 332237,91 & 350712,66 & 354529,00 & 354886,52 & 343645,36 & 321379,21 & \\
\hline $\mathrm{E}(\mathrm{KJ} / \mathrm{mol})$ & 239,96 & 306,27 & 319,73 & 325,24 & 332,24 & 350,71 & 354,53 & 354,89 & 343,65 & 321,38 & 324,86 \\
\hline intercept & 31,75 & 40,16 & 41,66 & 42,10 & 42,90 & 45,57 & 45,88 & 45,62 & 43,47 & 39,44 & \\
\hline$A(\min -1)$ & $9,1 \mathrm{E}+16$ & $1,7 E+21$ & $1,4 \mathrm{E}+22$ & $3,2 E+22$ & $1,0 E+23$ & $2,1 E+24$ & $3,8 E+24$ & $3,9 E+24$ & $5,9 E+23$ & $1,6 \mathrm{E}+22$ & $1,0 E+24$ \\
\hline$r^{\wedge} 2$ & $4,9 \mathrm{E}-01$ & $8,8 \mathrm{E}-01$ & $9,1 \mathrm{E}-01$ & $9,2 \mathrm{E}-01$ & $9,1 \mathrm{E}-01$ & $9,5 \mathrm{E}-01$ & $9,7 \mathrm{E}-01$ & $9,8 \mathrm{E}-01$ & $9,8 \mathrm{E}-01$ & $1,0 E+00$ & 0,90 \\
\hline
\end{tabular}

Starink method

\begin{tabular}{|c|c|c|c|c|c|c|c|c|c|c|c|}
\hline \multirow[b]{2}{*}{$\ln \left(\beta / T^{\wedge} 1,8\right)$} & \multicolumn{10}{|c|}{ Starink } & \\
\hline & & & & & & & & & & & \\
\hline 5 & $-10,11$ & $-10,22$ & $-10,24$ & $-10,26$ & $-10,27$ & $-10,28$ & $-10,29$ & $-10,30$ & $-10,31$ & $-10,32$ & \\
\hline 10 & $-9,45$ & $-9,54$ & $-9,57$ & $-9,58$ & $-9,60$ & $-9,61$ & $-9,61$ & $-9,62$ & $-9,64$ & $-9,65$ & \\
\hline 15 & $-9,05$ & $-9,16$ & $-9,18$ & $-9,20$ & $-9,21$ & $-9,22$ & $-9,23$ & $-9,23$ & $-9,25$ & $-9,26$ & \\
\hline 20 & $-8,74$ & $-8,87$ & $-8,89$ & $-8,91$ & $-8,92$ & $-8,93$ & $-8,94$ & $-8,95$ & $-8,96$ & $-8,98$ & \\
\hline$E / R(J)$ & -28996 & -36980 & -38601 & -39264 & -40107 & -42330 & -42790 & -42834 & -41483 & -38806 & \\
\hline$E(J)$ & 241086,37 & 307469,10 & 320946,86 & 326459,35 & 333468,45 & 351951,52 & 355776,17 & 356142,01 & 344909,16 & 322651,32 & \\
\hline 1,0037 & 240197,64 & 306335,66 & 319763,73 & 325255,90 & 332239,16 & 350654,09 & 354464,65 & 354829,14 & 343637,70 & 321461,91 & \\
\hline $\mathrm{E}(\mathrm{KJ} / \mathrm{mol})$ & 240,20 & 306,34 & 319,76 & 325,26 & 332,24 & 350,65 & 354,46 & 354,83 & 343,64 & 321,46 & 324,88 \\
\hline intercept & 33,25 & 41,68 & 43,18 & 43,62 & 44,42 & 47,09 & 47,41 & 47,15 & 44,99 & 40,97 & \\
\hline$A(\min -1)$ & $4,1 E+17$ & $7,6 E+21$ & $6,3 E+22$ & $1,5 E+23$ & $4,7 E+23$ & $9,5 E+24$ & $1,7 \mathrm{E}+25$ & $1,8 \mathrm{E}+25$ & $2,7 E+24$ & $7,2 E+22$ & $4,81 E+24$ \\
\hline$r^{\wedge} 2$ & $5,0 E-01$ & $8,8 \mathrm{E}-01$ & $9,1 \mathrm{E}-01$ & $9,2 \mathrm{E}-01$ & $9,1 \mathrm{E}-01$ & $9,5 E-01$ & 9,7E-01 & $9,8 \mathrm{E}-01$ & $9,8 \mathrm{E}-01$ & $1,0 \mathrm{E}+00$ & 0,90 \\
\hline
\end{tabular}

Flynn-Wall-Ozawa method

\begin{tabular}{|c|c|c|c|c|c|c|c|c|c|c|c|}
\hline \multicolumn{12}{|c|}{ FWO } \\
\hline $\ln (\beta)$ & & & & & & & & & & & \\
\hline 5 & 1,61 & 1,61 & 1,61 & 1,61 & 1,61 & 1,61 & 1,61 & 1,61 & 1,61 & 1,61 & \\
\hline 10 & 2,30 & 2,30 & 2,30 & 2,30 & 2,30 & 2,30 & 2,30 & 2,30 & 2,30 & 2,30 & \\
\hline 15 & 2,71 & 2,71 & 2,71 & 2,71 & 2,71 & 2,71 & 2,71 & 2,71 & 2,71 & 2,71 & \\
\hline 20 & 3,00 & 3,00 & 3,00 & 3,00 & 3,00 & 3,00 & 3,00 & 3,00 & 3,00 & 3,00 & \\
\hline$E / R(J)$ & -30219 & -38280 & -39918 & -40592 & -41443 & -43673 & -44139 & -44191 & -42848 & -40185 & \\
\hline$E(J)$ & 251254,97 & 318277,91 & 331897,01 & 337500,97 & 344576,58 & 363117,85 & 366992,39 & 367424,74 & 356258,41 & 334116,98 & \\
\hline 1,052 & 238835,52 & 302545,54 & 315491,46 & 320818,41 & 327544,28 & 345169,06 & 348852,08 & 349263,06 & 338648,68 & 317601,69 & \\
\hline $\mathrm{E}(\mathrm{KJ} / \mathrm{mol})$ & 238,84 & 302,55 & 315,49 & 320,82 & 327,54 & 345,17 & 348,85 & 349,26 & 338,65 & 317,60 & 320,48 \\
\hline intercept & 46,79 & 55,328 & 56,852 & 57,309 & 58,114 & 60,799 & 61,122 & 60,874 & 58,73 & 54,723 & \\
\hline$A(\min -1)$ & $3,7 \mathrm{E}+14$ & $4,8 E+18$ & $3,7 E+19$ & $8,6 E+19$ & $2,6 \mathrm{E}+20$ & $4,9 E+21$ & $8,8 \mathrm{E}+21$ & $9,0 E+21$ & $1,5 E+21$ & $4,6 E+19$ & $2,5 E+21$ \\
\hline$r^{\wedge} 2$ & 0,52 & 0,89 & 0,91 & 0,93 & 0,92 & 0,96 & 0,97 & 0,98 & 0,98 & 1,00 & 0,91 \\
\hline
\end{tabular}




\section{Calculations for Large Microplastic}

Values for beta and the corresponding value for alpha.

\begin{tabular}{|c|c|c|c|c|c|c|c|c|c|c|c|}
\hline beta/alpha & 0,05 & 0,15 & 0,25 & 0,35 & 0,45 & 0,55 & 0,65 & 0,75 & 0,85 & 0,95 & Average \\
\hline 5 & 0,0014 & 0,0014 & 0,0014 & 0,0014 & 0,0014 & 0,0014 & 0,0013 & 0,0013 & 0,0013 & 0,0013 & \\
\hline 10 & 0,0014 & 0,0014 & 0,0014 & 0,0013 & 0,0013 & 0,0013 & 0,0013 & 0,0013 & 0,0013 & 0,0013 & \\
\hline 15 & 0,0014 & 0,0014 & 0,0013 & 0,0013 & 0,0013 & 0,0013 & 0,0013 & 0,0013 & 0,0013 & 0,0013 & \\
\hline 20 & 0,0014 & 0,0014 & 0,0013 & 0,0013 & 0,0013 & 0,0013 & 0,0013 & 0,0013 & 0,0013 & 0,0013 & \\
\hline 8,31447 & & & & & & & & & & & \\
\hline$g(\alpha)=-\ln (1-\alpha)$ & 0,05 & 0,16 & 0,29 & 0,43 & 0,60 & 0,80 & 1,05 & 1,39 & 1,90 & 3,00 & \\
\hline
\end{tabular}

Kissinger Akahira and Sunose method

\begin{tabular}{|c|c|c|c|c|c|c|c|c|c|c|c|}
\hline \multirow[b]{2}{*}{$\ln \left(\beta / T^{\wedge} 2\right)$} & \multicolumn{10}{|c|}{ KAS } & \\
\hline & & & & & & & & & & & \\
\hline \multirow{10}{*}{$\begin{array}{l}10 \\
\\
\\
\quad 15 \\
E / R(J) \\
E(J) \\
E(K J / m o l) \\
\text { intercept } \\
A \text { (min-1) } \\
r^{\wedge 2}\end{array}$} & $-11,47$ & $-11,55$ & $-11,57$ & $-11,58$ & $-11,60$ & $-11,60$ & $-11,61$ & $-11,62$ & $-11,63$ & $-11,65$ & \\
\hline & $-10,79$ & $-10,88$ & $-10,90$ & $-10,91$ & $-10,93$ & $-10,94$ & $-10,95$ & $-10,96$ & $-10,97$ & $-10,99$ & \\
\hline & $-10,40$ & $-10,48$ & $-10,51$ & $-10,52$ & $-10,54$ & $-10,54$ & $-10,56$ & $-10,57$ & $-10,58$ & $-10,60$ & \\
\hline & $-10,13$ & $-10,21$ & $-10,23$ & $-10,25$ & $-10,26$ & $-10,27$ & $-10,28$ & $-10,29$ & $-10,30$ & $-10,32$ & \\
\hline & -37642 & -42945 & -41852 & -41360 & -41445 & -41264 & -40396 & -39458 & -38893 & -36387 & \\
\hline & 312973,28 & 357064,91 & 347977,20 & 343886,48 & 344593,21 & 343088,29 & 335871,33 & 328072,36 & 323374,68 & 302538,62 & \\
\hline & 312,97 & 357,06 & 347,98 & 343,89 & 344,59 & 343,09 & 335,87 & 328,07 & 323,37 & 302,54 & 333,94 \\
\hline & 43,07 & 48,16 & 45,95 & 44,86 & 44,65 & 44,13 & 42,70 & 41,19 & 40,14 & 36,36 & \\
\hline & $9,8 E+21$ & $5,7 E+24$ & $1,1 \mathrm{E}+24$ & $5,4 E+23$ & $6,1 E+23$ & $4,8 \mathrm{E}+23$ & $1,5 \mathrm{E}+23$ & $4,2 \mathrm{E}+22$ & $2,0 \mathrm{E}+22$ & $6,7 \mathrm{E}+20$ & $8,7 E+23$ \\
\hline & $9,2 \mathrm{E}-01$ & $9,9 E-01$ & $1,0 \mathrm{E}+00$ & $1,0 \mathrm{E}+00$ & $1,0 \mathrm{E}+00$ & $1,0 \mathrm{E}+00$ & $1,0 \mathrm{E}+00$ & $1,0 \mathrm{E}+00$ & $1,0 \mathrm{E}+00$ & $9,8 \mathrm{E}-01$ & 0,99 \\
\hline
\end{tabular}

Starink method

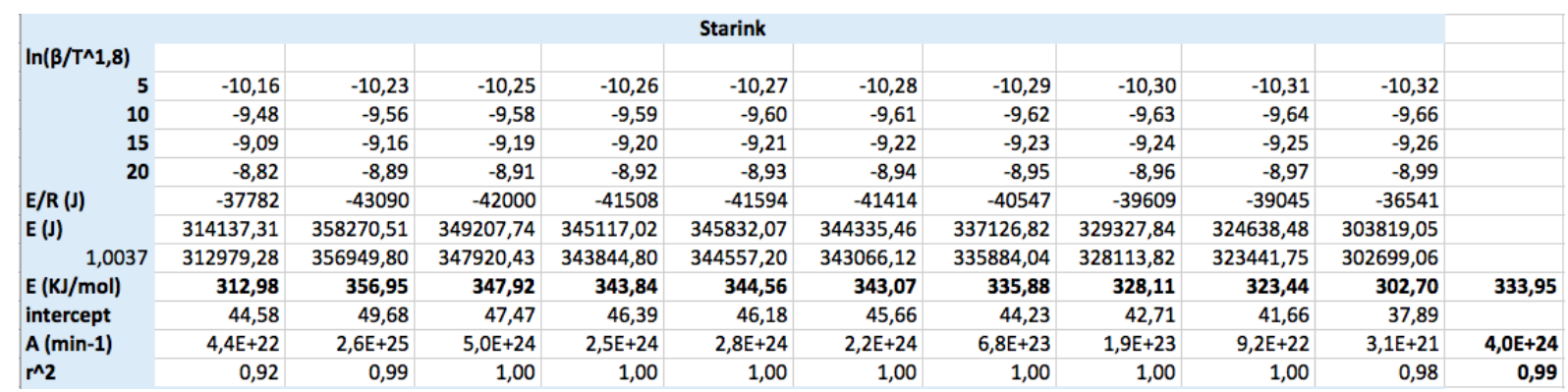

Flynn-Wall-Ozawa method

\begin{tabular}{|c|c|c|c|c|c|c|c|c|c|c|c|}
\hline \multirow[b]{2}{*}{$\ln (\beta)$} & \multicolumn{10}{|c|}{ FWO } & \\
\hline & & & & & & & & & & & \\
\hline 5 & 1,61 & 1,61 & 1,61 & 1,61 & 1,61 & 1,61 & 1,61 & 1,61 & 1,61 & 1,61 & \\
\hline 10 & 2,30 & 2,30 & 2,30 & 2,30 & 2,30 & 2,30 & 2,30 & 2,30 & 2,30 & 2,30 & \\
\hline 15 & 2,71 & 2,71 & 2,71 & 2,71 & 2,71 & 2,71 & 2,71 & 2,71 & 2,71 & 2,71 & \\
\hline 20 & 3,00 & 3,00 & 3,00 & 3,00 & 3,00 & 3,00 & 3,00 & 3,00 & 3,00 & 3,00 & \\
\hline$E / R(J)$ & -39043 & -44400 & -43325 & -42842 & -42935 & -42762 & -41901 & -40970 & -40414 & -37922 & \\
\hline & 324621,85 & 369162,47 & 360224,41 & 356208,52 & 356981,77 & 355543,37 & 348384,61 & 340643,84 & 336020,99 & 315301,33 & \\
\hline 1,052 & 308575,91 & 350914,89 & 342418,64 & 338601,26 & 339336,28 & 337968,98 & 331164,08 & 323805,93 & 319411,59 & 299716,09 & \\
\hline $\mathrm{E}(\mathrm{KJ} / \mathrm{mol})$ & 308,58 & 350,91 & 342,42 & 338,60 & 339,34 & 337,97 & 331,16 & 323,81 & 319,41 & 299,72 & 329,19 \\
\hline intercept & 58,18 & 63,34 & 61,16 & 60,08 & 59,88 & 59,37 & 57,95 & 56,44 & 55,41 & 51,65 & \\
\hline$A(\min -1)$ & $2,5 \mathrm{E}+19$ & $1,2 \mathrm{E}+22$ & $2,5 E+21$ & $1,3 E+21$ & $1,5 E+21$ & $1,2 \mathrm{E}+21$ & $3,9 E+20$ & $1,2 \mathrm{E}+20$ & $5,7 E+19$ & $2,2 \mathrm{E}+18$ & $1,9 E+21$ \\
\hline $\mathrm{r}^{\wedge} 2$ & 0,93 & 0,99 & 1,00 & 1,00 & 1,00 & 1,00 & 1,00 & 1,00 & 1,00 & 0,98 & 0,99 \\
\hline
\end{tabular}




\section{Calculations for Mesoplastic}

Values for beta and the corresponding value for alpha.

\begin{tabular}{|c|c|c|c|c|c|c|c|c|c|c|c|}
\hline beta/alpha & 0,05 & 0,15 & 0,25 & 0,35 & 0,45 & 0,55 & 0,65 & 0,75 & 0,85 & 0,95 & Average \\
\hline 5 & 0,0015 & 0,0014 & 0,0014 & 0,0014 & 0,0014 & 0,0014 & 0,0013 & 0,0013 & 0,0013 & 0,0013 & \\
\hline 10 & 0,0015 & 0,0014 & 0,0014 & 0,0014 & 0,0013 & 0,0013 & 0,0013 & 0,0013 & 0,0013 & 0,0013 & \\
\hline 15 & 0,0015 & 0,0014 & 0,0014 & 0,0013 & 0,0013 & 0,0013 & 0,0013 & 0,0013 & 0,0013 & 0,0013 & \\
\hline 20 & 0,0015 & 0,0014 & 0,0014 & 0,0013 & 0,0013 & 0,0013 & 0,0013 & 0,0013 & 0,0013 & 0,0013 & \\
\hline 8,31447 & & & & & & & & & & & \\
\hline$g(\alpha)=-\ln (1-\alpha)$ & 0,05 & 0,16 & 0,29 & 0,43 & 0,60 & 0,80 & 1,05 & 1,39 & 1,90 & 3,00 & \\
\hline
\end{tabular}

Kissinger Akahira and Sunose method

\begin{tabular}{|c|c|c|c|c|c|c|c|c|c|c|c|}
\hline \multirow[b]{2}{*}{$\ln \left(\beta / T^{\wedge} 2\right)$} & \multicolumn{10}{|c|}{ KAS } & \\
\hline & & & & & & & & & & & \\
\hline 5 & $-11,36$ & $-11,52$ & $-11,56$ & $-11,58$ & $-11,59$ & $-11,60$ & $-11,61$ & $-11,62$ & $-11,64$ & $-11,66$ & \\
\hline 10 & $-10,72$ & $-10,86$ & $-10,89$ & $-10,91$ & $-10,92$ & $-10,93$ & $-10,94$ & $-10,96$ & $-10,97$ & $-10,99$ & \\
\hline 15 & $-10,34$ & $-10,47$ & $-10,50$ & $-10,52$ & $-10,53$ & $-10,55$ & $-10,56$ & $-10,57$ & $-10,58$ & $-10,60$ & \\
\hline 20 & $-10,08$ & $-10,17$ & $-10,21$ & $-10,23$ & $-10,24$ & $-10,25$ & $-10,26$ & $-10,27$ & $-10,29$ & $-10,31$ & \\
\hline$E / R(J)$ & -17046 & -39493 & -41898 & -43129 & -44228 & -44702 & -44951 & -45178 & -45153 & -47386 & \\
\hline$E(J)$ & 141728,46 & 328363,36 & 348359,66 & 358594,78 & 367732,38 & 371673,44 & 373743,74 & 375631,13 & 375423,26 & 393989,48 & \\
\hline$E(\mathrm{KJ} / \mathrm{mol})$ & 141,73 & 328,36 & 348,36 & 358,59 & 367,73 & 371,67 & 373,74 & 375,63 & 375,42 & 393,99 & 343,52 \\
\hline intercept & 14,65 & 44,07 & 46,42 & 47,53 & 48,60 & 48,87 & 48,87 & 48,83 & 48,41 & 50,72 & \\
\hline$A(\min -1)$ & $2,004 E+09$ & $8,8 \mathrm{E}+22$ & $1,7 E+24$ & $8,2 E+24$ & $3,4 E+25$ & $6,0 E+25$ & $7,9 \mathrm{E}+25$ & $1,0 E+26$ & $9,1 E+25$ & $1,5 E+27$ & $1,9 \mathrm{E}+26$ \\
\hline $\mathrm{r}^{\wedge 2}$ & 1,00 & 0,82 & 0,88 & 0,88 & 0,85 & 0,86 & 0,86 & 0,88 & 0,91 & 0,93 & 0,89 \\
\hline
\end{tabular}

Starink method

\begin{tabular}{|c|c|c|c|c|c|c|c|c|c|c|c|}
\hline \multirow{2}{*}{\multicolumn{12}{|c|}{$\ln \left(\beta / T^{\wedge} 1,8\right)$}} \\
\hline & & & & & & & & & & & \\
\hline 5 & $-10,06$ & $-10,21$ & $-10,24$ & $-10,26$ & $-10,27$ & $-10,28$ & $-10,29$ & $-10,30$ & $-10,31$ & $-10,33$ & \\
\hline 10 & $-9,42$ & $-9,54$ & $-9,57$ & $-9,59$ & $-9,60$ & $-9,61$ & $-9,62$ & $-9,63$ & $-9,64$ & $-9,66$ & \\
\hline 15 & $-9,04$ & $-9,15$ & $-9,18$ & $-9,20$ & $-9,21$ & $-9,22$ & $-9,23$ & $-9,24$ & $-9,25$ & $-9,27$ & \\
\hline \multirow{3}{*}{$\begin{array}{l}E / R(J) \\
E(J)\end{array}$} & $-8,77$ & $-8,86$ & $-8,89$ & $-8,90$ & $-8,91$ & $-8,93$ & $-8,94$ & $-8,95$ & $-8,96$ & $-8,98$ & \\
\hline & -17180 & -39637 & -42044 & -43276 & -44376 & -44852 & -45101 & -45329 & -45305 & -47540 & \\
\hline & 142842,59 & 329560,65 & 349573,58 & 359817,00 & 368962,92 & 372920,61 & 374990,91 & 376886,61 & 376687,06 & 395269,90 & \\
\hline 1,0037 & 142316,03 & 328345,77 & 348284,92 & 358490,59 & 367602,79 & 371545,89 & 373608,56 & 375497,27 & 375298,46 & 393812,80 & \\
\hline \multirow{2}{*}{$\begin{array}{l}\mathrm{E}(\mathrm{KJ} / \mathrm{mol}) \\
\text { intercept }\end{array}$} & 142,32 & 328,35 & 348,28 & 358,49 & 367,60 & 371,55 & 373,61 & 375,50 & 375,30 & 393,81 & 343,48 \\
\hline & 16,15 & 45,58 & 47,94 & 49,05 & 50,12 & 50,39 & 50,40 & 50,36 & 49,94 & 52,25 & \\
\hline \multirow{2}{*}{$\begin{array}{l}A(\min -1) \\
r^{\wedge} 2\end{array}$} & $9,037 E+09$ & $4,0 E+23$ & $8,0 E+24$ & $3,7 E+25$ & $1,5 E+26$ & $2,7 E+26$ & $3,6 E+26$ & $4,6 E+26$ & $4,2 E+26$ & $7,0 E+27$ & $8,7 E+26$ \\
\hline & 1,00 & 0,83 & 0,88 & 0,88 & 0,85 & 0,86 & 0,86 & 0,88 & 0,91 & 0,93 & 0,89 \\
\hline
\end{tabular}

Flynn-Wall-Ozawa method

\begin{tabular}{|c|c|c|c|c|c|c|c|c|c|c|c|}
\hline \multirow[b]{2}{*}{$\ln (\beta)$} & \multicolumn{10}{|c|}{ FWO } & \\
\hline & & & & & & & & & & & \\
\hline 5 & 1,61 & 1,61 & 1,61 & 1,61 & 1,61 & 1,61 & 1,61 & 1,61 & 1,61 & 1,61 & \\
\hline 10 & 2,30 & 2,30 & 2,30 & 2,30 & 2,30 & 2,30 & 2,30 & 2,30 & 2,30 & 2,30 & \\
\hline 15 & 2,71 & 2,71 & 2,71 & 2,71 & 2,71 & 2,71 & 2,71 & 2,71 & 2,71 & 2,71 & \\
\hline 20 & 3,00 & 3,00 & 3,00 & 3,00 & 3,00 & 3,00 & 3,00 & 3,00 & 3,00 & 3,00 & \\
\hline$E / R(J)$ & -18388 & -40930 & -43359 & -44604 & -45712 & -46196 & -46453 & -46688 & -46672 & -48920 & \\
\hline & 152886,47 & 340311,26 & 360507,10 & 370858,62 & 380071,05 & 384095,26 & 386232,07 & 388185,98 & 388052,94 & 406743,87 & \\
\hline 1,052 & 145329,35 & 323489,79 & 342687,36 & 352527,21 & 361284,27 & 365109,56 & 367140,76 & 368998,08 & 368871,62 & 386638,66 & \\
\hline $\mathrm{E}(\mathrm{KJ} / \mathrm{mol})$ & 145,33 & 323,49 & 342,69 & 352,53 & 361,28 & 365,11 & 367,14 & 369,00 & 368,87 & 386,64 & 338,21 \\
\hline intercept & 29,66 & 59,22 & 61,61 & 62,74 & 63,82 & 64,10 & 64,12 & 64,09 & 63,68 & 66,01 & \\
\hline$A(\min -1)$ & 22410593 & $2,2 \mathrm{E}+20$ & $4,0 E+21$ & $1,8 \mathrm{E}+22$ & $7,2 E+22$ & $1,3 E+23$ & $1,7 \mathrm{E}+23$ & $2,1 E+23$ & $1,9 E+23$ & $3,0 E+24$ & $3,78 \mathrm{E}+23$ \\
\hline $\mathrm{r}^{\wedge}$ & 1,00 & 0,83 & 0,89 & 0,89 & 0,86 & 0,87 & 0,87 & 0,89 & 0,91 & 0,93 & 0,89 \\
\hline
\end{tabular}

